\title{
Avaliação do papel de galectina-3 no recrutamento de macrófagos e sua participação na angiogênese em modelo de fibrossarcoma
}

\author{
Tese apresentada à Faculdade de \\ Medicina da Universidade de São \\ Paulo para obtenção do título de \\ Doutor em Ciências
}

Programa de Oncologia

Orientador: Prof. Dr. Roger Chammas

(Versão corrigida resolução CoPGr6018/11, de 01 de Nov 2011 a versão original está disponível na biblioteca da FMUSP)

São Paulo 


\title{
Avaliação do papel de galectina-3 no recrutamento de macrófagos e sua participação na angiogênese em modelo de fibrossarcoma
}

\author{
Tese apresentada à Faculdade de \\ Medicina da Universidade de São \\ Paulo para obtenção do título de \\ Doutor em Ciências
}

Programa de Oncologia

Orientador: Prof. Dr. Roger Chammas

(Versão corrigida resolução CoPGr6018/11, de 01 de Nov 2011 a versão original está disponível na biblioteca da FMUSP)

São Paulo 
Dados Internacionais de Catalogação na Publicação (CIP)

Preparada pela Biblioteca da

Faculdade de Medicina da Universidade de São Paulo

Creprodução autorizada pelo autor

Furuzawa, Karina Mie

Avaliação do papel de galectina-3 no recrutamento de macrófagos e sua

participação na angiogênese em modelo de fibrossarcoma / Karina Mie Furuzawa . -São Paulo, 2016.

Tese(doutorado)--Faculdade de Medicina da Universidade de São Paulo. Programa de Oncologia.

Orientador: Roger Chammas.

Descritores: 1.Galectina 3 2.Fibrossarcoma 3.Microambiente tumoral 4.Angiogênese 5.Macrófagos 6.Carcinógenos

USP/FM/DBD-299/16 
Aos meus pais. 
O presente trabalho foi desenvolvido no Centro de Investigação Translacional em Oncologia do Instituto do Câncer do Estado de São Paulo Octavio Frias de Oliveira e Faculdade de Medicina da Universidade de São Paulo, em colaboração com o Instituto de Ciências Biomédicas da Academia Sinica, Taiwan. 


\section{AGRADECIMENTOS}

Ao meu orientador, Prof. Dr. Roger Chammas, por todos os inestimáveis ensinamentos, pelo exemplo de profissional e ser humano e por sempre acreditar em mim, desde o primeiro instante.

À Dra. Camila Machado, por compartilhar tantos conhecimentos comigo durante todos os anos do mestrado e doutorado, por sua amizade especial, por sempre me apoiar e incentivar nos momentos mais difíceis. Por sempre estar presente, mesmo fisicamente distante.

Ao Dr. Fu-Tong Liu por ter me recebido de maneira tão acolhedora em seu laboratório e pela experiência inigualável que tive em Taipei. Ao Dr. Huan-Yuan Chen por todo o auxílio e cuidado. À Annie, pela preciosa ajuda na rotina do laboratório.

Ao saudoso Prof. Dr. Francesco Langone, pelo exemplo de vida e por ter me guiado para este caminho.

Aos queridos amigos de laboratório Adalberto, Alexandre, Ana Carol, Andréia, Giovani, Jânio, Lizeth, Luciana Andrade, Luciana Kovacs, Mariana, Mauro, Mayara Jacomassi, Mayara Klimuk, Priscila, Rafael, Renata, Sílvia, Silvina, Tati e Tharcísio, pela amizade, disposição em ajudar, por todas as discussões científicas e por tornarem a rotina muito mais leve.

À Tati, minha amiga-irmã, por seu coração enorme e por Deus ter cruzado nossos caminhos mais uma vez. Por estar sempre, sempre presente, mesmo quando fui para o outro lado do mundo, pela ajuda nos experimentos, estatísticas e na correção da tese.

À Angélica, por sempre estar disposta a me ajudar e ensinar, pelos experimentos em parceria e por ser uma amiga tão presente.

À Carol Rosal, pela ajuda na correção da tese, por tantos momentos de alegria e pela amizade que levarei para a vida toda. 
À Camila MM, pela ajuda nos experimentos de ELISA, pelas incansáveis tentativas de imunofluorescência, pelo apoio e amizade durante todos esses anos.

Ao Mauro, pelos preciosos ensinamentos sobre o ImageJ.

À Cida e André, pelos cuidados na manutenção dos camundongos no biotério de experimentação animal.

À Sueli Nonogaki, pela realização de algumas das reações imunoistoquímicas.

Ao setor de Patologia-ICESP pelo processamento em parafina e confecção de lâminas.

Ao Grupo de Apoio do CTO, pelo importante suporte na rotina do laboratório.

À CAPES, CNPq e FAPESP pela disponibilização dos recursos financeiros para a realização deste trabalho.

À minha mãe, Clara, pela paciência, por cada dia de trabalho árduo, por sempre me colocar à frente de tudo, não importa quão dolorido tenha sido para ela. Por sempre me incentivar a alcançar os meus sonhos, por me entender tão bem e me respeitar como ninguém.

Ao meu pai, Adolfo, pela confiança que me passa, por acreditar tanto em mim, quando eu mesma já não tinha forças, por nunca deixar eu desistir, por cada oração. Por cada dia sofrido em silêncio e por tantos e tantos momentos de felicidade que compartilhamos.

À minha obatian, Teruko, e ao meu saudoso oditian, Kingo, pelo exemplo de vida e por todo o Amor.

Aos meus avós Sono e Isamu, a quem pouco pude conhecer, mas são parte importante de mim.

Ao Ryu, por simplesmente ser quem ele é e por me tornar quem eu sou. 


\section{SUMÁRIO}

Lista de abreviaturas

Lista de figuras

Resumo

Abstract

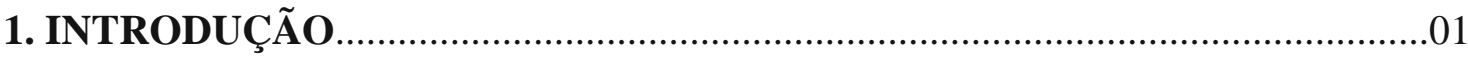

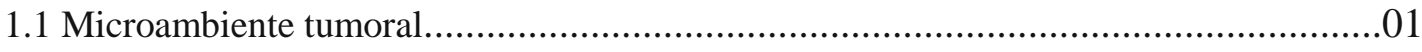

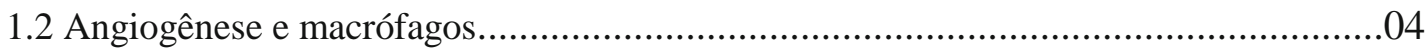

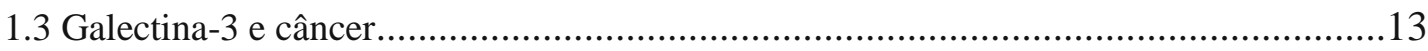

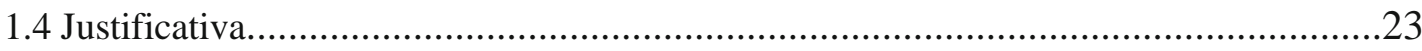

2. OBJETIVOS

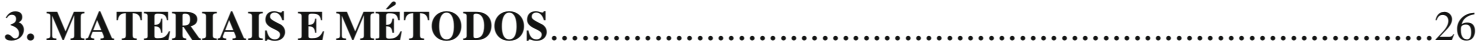

3.1 Animais e indução tumoral com carcinógeno...........................................................26

3.2 Análise da velocidade de fluxo sanguíneo intratumoral por ultrassonografia com color

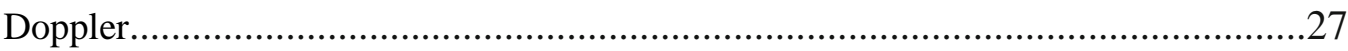

3.3 Tomografia por Emissão de Pósitrons/Tomografia Computadorizada (PET/CT)...........28

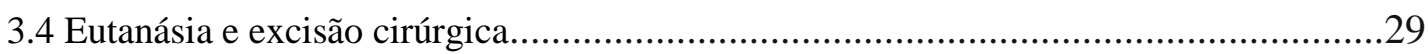

3.5 Processamento em parafina e análises histológicas.....................................................30

3.6 Análises imunoistoquímicas (gal-3, PCNA e CD34)..................................................31

3.7 Análises imunoistoquímicas (CD68, CD206 e Foxp3) - Academia Sinica, Taiwan........33

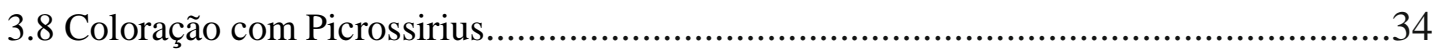

3.9 ELISA (Enzyme-Linked Immunosorbent Assay) para VEGF.....................................35

3.10 Análises de expressão gênica por PCR quantitativo em tempo real............................36

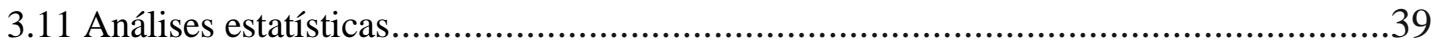

4. RESULTADOS 


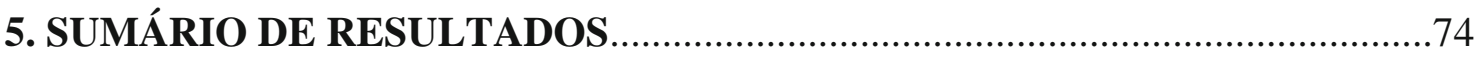

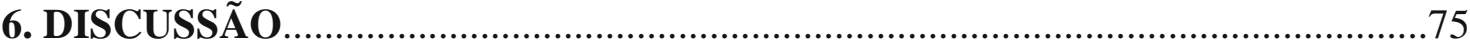

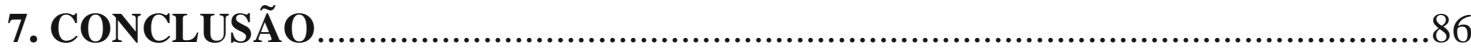

8. ANEXO

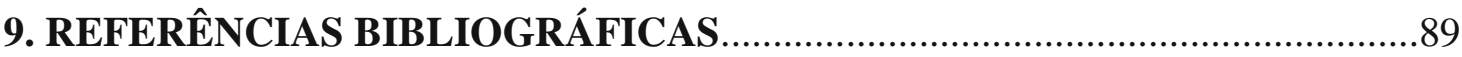

APÊNDICE 


\section{LISTA DE ABREVIATURAS}

AhR: receptor de aril hidrocarboneto

ARNT: translocador nuclear de AhR

BCA: ácido bicinconínico

Bcl: linfoma de células B

bFGF: fator de crescimento de fibroblastos básico

BMDM: macrófago derivado da medula óssea

CCL: C-C motif chemokine ligand

cDNA: DNA complementar

CGA: campos de grande aumento

CRD: domínio de reconhecimento de carboidratos

CT: tomografia computadorizada

CXCL: $C-X$-C motif chemokine ligand

DEPC: dietilpirocarbonato

DES: dietilestilbestrol

ECM: matriz extracelular

EGFR: receptor do fator de crescimento epidérmico

ELISA: Enzyme-Linked Immunosorbent Assay

et al.: e outros

FAK: quinase de adesão focal

FDG: fluodeoxiglicose

Gal-3: galectina-3

H\&E: hematoxilina e eosina

HIF: fator induzido por hipóxia

HRP: horseradish peroxidase

HUVEC: célula endotelial humana de cordão umbilical

IFN: interferon

IHC: imunoistoquímica

IL: interleucina

iNOS/NOS2: óxido nítrico sintase induzível

LPS: lipopolissacarídeo

MCA: 3-metilcolantreno 
MCP: proteína quimiotática de monócitos

M-CSF: fator estimulador de colônias de macrófagos

MHC: complexo principal de histocompatibilidade

MMP: metaloproteinase de matriz

mRNA: ácido ribonucleico mensageiro

$\mathrm{NF} \kappa \mathrm{B}$ : fator nuclear $\kappa \mathrm{B}$

NIH: National Institutes of Health

NK: natural killer

OPD: o-fenilenodiamina diidrocloreto

PBS: tampão fosfato salino

PCNA: antígeno nuclear de proliferação celular

PCR: Reação em Cadeia da Polimerase

PDGF: fator de crescimento derivado de plaquetas

PET: tomografia por emissão de pósitrons

PLGF: fator de crescimento placentário

ROI: região de interesse

ROS: espécies reativas de oxigênio

SUV: standardized uptake value

TAM: macrófago associado a tumores

TCR: receptor de célula $\mathrm{T}$

TGF: fator transformador de crescimento

$\mathrm{T}_{\mathrm{H}}$ : T helper

TLR: receptor do tipo Toll

TLS: estruturas linfoides terciárias

TNF: fator de necrose tumoral

$\mathrm{T}_{\text {reg: }} \mathrm{T}$ regulatórias

US: ultrassonografia

VEGF: fator de crescimento endotelial vascular

VEGFR: receptor do fator de crescimento endotelial vascular

WT: selvagem

XRE: elemento responsivo a xenobióticos 


\section{LISTA DE FIGURAS}

FIGURA 01. Representação esquemática da polarização M1/M2 de macrófagos. .08

FIGURA 02. Representação esquemática do metabolismo da L-arginina em macrófagos M1 e M2 .09

FIGURA 03. Representação esquemática da estrutura dos diferentes membros da família de galectinas. .14

FIGURA 04. Funções extracelulares mediadas por gal-3. .19

FIGURA 05. Curvas de Kaplan-Meier de camundongos WT e Gal-3 KO após segunda injeção de MCA ou veículo.

FIGURA 06. Curvas individuais de crescimento tumoral de camundongos WT ou Gal3 KO que receberam injeção subcutânea de MCA. .42

FIGURA 07. Secções histológicas de sarcomas induzidos por MCA em camundongos WT (WT MCA) e Gal-3 KO (KO MCA).

FIGURA 08. Expressão de gal-3 nos sarcomas induzidos por MCA em animais WT (WT MCA) e Gal-3 KO (KO MCA).

FIGURA 09. Quantificação de fibras de colágeno em sarcomas induzidos por MCA em camundongos WT (WT MCA) e Gal-3 KO (KO MCA).

FIGURA 10. Expressão do marcador de proliferação celular PCNA em sarcomas induzidos por MCA em camundongos WT (WT MCA) e Gal-3 KO (KO MCA) .49

FIGURA 11. Quantificação de figuras mitóticas em sarcomas induzidos por MCA em camundongos WT (WT MCA) e Gal-3 KO (KO MCA). .50

FIGURA 12. Quantificação de áreas necróticas em sarcomas induzidos por MCA em camundongos WT (WT MCA) e Gal-3 KO (KO MCA). .51

FIGURA 13. Marcação para CD34 em sarcomas induzidos por MCA em camundongos WT (WT MCA) e Gal-3 KO (KO MCA). .52

FIGURA 14. Expressão relativa de VEGF em sarcomas induzidos por MCA em camundongos WT (WT MCA) e Gal-3 KO (KO MCA). .53

FIGURA 15. Velocidades médias de fluxo sanguíneo em vasos tumorais obtidas por ultrassonografia com color Doppler em sarcomas induzidos por MCA em camundongos WT (WT MCA) ou Gal-3 KO (KO MCA). .55

FIGURA 16. Imagens obtidas por ultrassonografia (US) com color Doppler de sarcomas induzidos por MCA em camundongos WT ou Gal-3 KO. .56 
FIGURA 17. Imagens de PET/CT com fluodeoxiglicose $\left({ }^{18} \mathrm{~F}-\mathrm{FDG}\right)$ de camundongo WT com sarcoma induzido por MCA .58

FIGURA 18. Imagens de PET/CT com fluodeoxiglicose $\left({ }^{18} \mathrm{~F}-\mathrm{FDG}\right)$ de camundongo Gal-3 KO com sarcoma induzido por MCA 59

FIGURA 19. Quantificações da incorporação de fluodeoxiglicose $\left({ }^{18}\right.$ F-FDG) em PET/CT pelo tecido tumoral de camundongos WT e Gal-3 KO. .60

FIGURA 20. Expressão de células positivas para CD68 (macrófagos) na periferia ou interior de sarcomas induzidos por MCA em camundongos WT e Gal-3 KO.

FIGURA 21. Expressão de células positivas para CD68 (macrófagos) na periferia ou interior de sarcomas induzidos por MCA em camundongos WT e Gal-3 KO.

FIGURA 22. Expressão de células positivas para CD206 (macrófagos M2) na periferia ou interior de tumores de camundongos WT e Gal-3 KO. .64

FIGURA 23. Expressão gênica relativa de marcadores relacionados à polarização de macrófagos em sarcomas de camundongos WT e Gal-3 KO. .65

FIGURA 24. Expressão de Foxp3 (células $T_{\text {reg}}$ ) em sarcomas induzidos por MCA em camundongos WT e Gal-3 KO. .66

FIGURA 25. Expressão de gal-3 na região de inóculo de MCA ou veículo em camundongo WT uma semana após a segunda injeção

FIGURA 26. Expressão de gal-3 na região de inóculo de MCA ou veículo em camundongo Gal-3 KO uma semana após a segunda injeção.

FIGURA 27. Quantificação de células CD68-positivas (macrófagos) em camundongos WT e Gal-3 KO, no local de injeção subcutânea de MCA ou veículo. .70

FIGURA 28. Expressão de CD68 (macrófagos) em camundongos WT e Gal-3 KO no local de injeção subcutânea de MCA ou veículo. .71

FIGURA 29. Quantificação de células CD206-positivas (macrófagos M2) em camundongos WT e Gal-3 KO, no local de injeção subcutânea de MCA ou veículo....72 FIGURA 30. Expressão de CD206 (macrófagos M2) em camundongos WT e Gal-3 KO, no local de injeção subcutânea de MCA ou veículo. .73 


\section{RESUMO}

Furuzawa KM. Avaliação do papel de galectina-3 no recrutamento de macrófagos e sua participação na angiogênese em modelo de fibrossarcoma [Tese]. São Paulo: Faculdade de Medicina, Universidade de São Paulo; 2016.

Assim como tecidos normais, tumores possuem uma demanda de nutrientes e oxigênio, suprida através da vasculatura a eles associada que resulta do processo de angiogênese. Fatores pró-angiogênicos são capazes de atrair monócitos, os quais se diferenciam em macrófagos associados a tumores (TAMs). TAMs comumente apresentam fenótipo M2, cujas características são consideradas pró-tumorais, como a promoção da angiogênese e a degradação de matriz extracelular. Estudos indicam que galectina-3 (gal-3), uma proteína pleiotrópica que se liga a $\beta$-galactosídeos, participa do controle da angiogênese e da infiltração de macrófagos M2 na massa tumoral, mas pouco se sabe sobre os mecanismos envolvidos. No presente estudo, utilizamos um modelo de sarcoma induzido por carcinógeno em camundongos selvagens (WT) e knockout para gal-3 (Gal$3 \mathrm{KO}$ ). Comparando os tumores de animais WT e Gal-3 KO, não observamos diferenças no padrão de crescimento tumoral, na área necrótica relativa, na proliferação celular e na quantificação de fibras de colágeno. Demonstramos que, embora ambos os grupos desenvolvam tumores, a angiogênese foi inibida em um microambiente desprovido de gal-3. Entretanto, não houve diferença na produção do fator de crescimento endotelial vascular (VEGF). As imagens obtidas in vivo indicaram que gal3 também influencia na formação estrutural de vasos adjacentes ao tumor. Além de mediar aspectos morfológicos relacionados à angiogênese, demonstramos que gal-3 também contribuiu para a funcionalidade vascular, pois houve uma redução na velocidade de fluxo sanguíneo nos vasos intratumorais de animais Gal-3 KO. Nossos dados sugeriram que há menos macrófagos no tumor que não expressa gal-3 e, dentre os TAMs, há mais M2 em comparação ao tumor gal-3-positivo. A análise do tecido onde o tumor se desenvolve, na fase inicial da tumorigênese, indicou que a ausência de gal-3 está relacionada a uma maior densidade de macrófagos M2. Considerando que a presença maior de macrófagos M2 nos sarcomas gal-3-negativos não resultou em maior produção de VEGF, mas sim na inibição da angiogênese, nossos resultados apontam para uma participação significativa de gal-3 na mediação da angiogênese pelos macrófagos. 
Descritores: galectina 3, fibrossarcoma, microambiente tumoral, angiogênese, macrófagos, carcinógenos. 


\begin{abstract}
Furuzawa KM. Evaluation of the role of galectin-3 in macrophage recruitment and its participation in angiogenesis in a fibrosarcoma model [Thesis]. São Paulo: "Faculdade de Medicina, Universidade de São Paulo"; 2016.

As well as normal tissues, tumors require nutrients and oxygen, which are supplied by the associated vasculature that results from the process of angiogenesis. Pro-angiogenic factors are able to attract monocytes and they differentiate into tumor-associated macrophages (TAMs). TAMs commonly exhibit M2 phenotype, which has characteristics considered pro-tumoral, such as angiogenesis promotion and degradation of extracellular matrix. Studies show that galectin-3 (gal-3), a pleiotropic $\beta$-galactosidebinding protein, participates in angiogenesis control and M2 macrophage infiltration into the tumor mass, but little is known about the mechanisms involved. In this work, we established a model of carcinogen-induced sarcoma in wild-type (WT) and gal-3 knockout (Gal-3 KO) mice. Comparing tumors from WT and Gal-3 KO animals, there were no differences in the pattern of tumor growth, relative necrotic area, cell proliferation and collagenous fibers. We demonstrated that, although both groups develop tumors, angiogenesis was inhibited in a microenvironment devoid of gal-3. However, there was no difference in the production of vascular endothelial growth factor (VEGF). The images obtained in vivo indicated that gal-3 also influenced the structural formation of vessels adjacent to the tumor. In addition to mediating morphological aspects related to angiogenesis, we demonstrated that gal-3 also contributes to vascular functionality, since there was a reduction in blood flow velocity in intratumoral vessels from Gal-3 KO animals. Our data suggested that there are fewer macrophages in tumors without gal-3 and, among TAMs, there are more M2 compared to gal-3-positive tumors. Analysis of the tissue where the tumor develops, in early stages of tumorigenesis, indicated that the lack of gal-3 is related to an increased density of M2 macrophages. Since the greater number of M2 macrophages in gal-3-negative fibrosarcomas did not result in increased VEGF production, but inhibited angiogenesis, our results suggest a significant role of gal-3 in regulation of angiogenesis by macrophages.
\end{abstract}

Descriptors: galectin 3, fibrosarcoma, tumor microenvironment, angiogenesis, macrophages, carcinogens. 


\section{INTRODUÇÃO}

\subsection{Microambiente tumoral}

Tumores desenvolvem-se num ambiente altamente complexo contendo células parenquimatosas (por exemplo, células epiteliais nos carcinomas), células estromais, sistemas vasculares sanguíneo e linfático e células do sistema imune (Coussens e Werb, 2002). As células neoplásicas interagem com o microambiente beneficiando-se com os nutrientes oriundos de vasos sanguíneos e fatores de crescimento produzidos por células inflamatórias e estromais, além de apresentarem mecanismos de escape da vigilância imunológica (Hanahan e Weinberg, 2011).

A hipóxia, que acompanha o crescimento tumoral, resulta na produção do fator de crescimento endotelial vascular (VEGF) pelas células neoplásicas, induzindo a angiogênese necessária para a chegada de oxigênio, ao mesmo tempo facilitando a infiltração de células do sistema imune na massa tumoral (Noman et al., 2011). Apesar de seu importante papel no reconhecimento e eliminação de células neoplásicas, evidências indicam que o sistema imune pode ser manipulado para favorecer a progressão tumoral (de Visser et al., 2005). Respostas imunes persistentes estimulam a ativação de células do sistema imune no microambiente tumoral, onde podem contribuir para a seleção de células tumorais não-imunogênicas e para o suprimento de elementos favoráveis à expansão tumoral (Coussens e Werb, 2002).

Respostas inflamatórias podem ter efeitos de promoção tumoral através da liberação de moléculas bioativas no microambiente, como fatores de crescimento que estimulam a proliferação, fatores de sobrevivência que inibem a morte celular, fatores 
pró-angiogênicos, enzimas que atuam sobre a matriz extracelular (ECM) facilitando a angiogênese, invasão e metástase, e sinais indutores da via de transição epitéliomesênquima (DeNardo et al., 2010; Grivennikov et al., 2010; Qian e Pollard, 2010).

A observação de que pacientes submetidos a tratamento imunossupressor póstransplante apresentam maior incidência de câncer e de que camundongos deficientes em componentes da imunidade inata e adaptativa desenvolvem tumores espontaneamente (Mithoefer et al., 2002; Koebel et al., 2007) estabeleceu um papel importante do sistema imune nas etapas iniciais da tumorigênese. Estudando-se camundongos deficientes em componentes do sistema imune frente à indução de tumores por carcinógenos, foi observado que os tumores eram mais frequentes e/ou cresciam mais rapidamente nos camundongos imunodeficientes, comparando-os aos imunocompetentes.

Particularmente, deficiências no desenvolvimento ou funcionalidade de linfócitos T citotóxicos CD8+ ou células T helper $1\left(\mathrm{~T}_{\mathrm{H}} 1\right)$ ou células NK (do inglês, natural killer) resultaram no aumento da incidência de tumores e, além disso, camundongos com imunodeficiência combinada de células T e células NK eram ainda mais suscetíveis ao desenvolvimento de câncer. Estes resultados demonstraram que, pelo menos em alguns modelos experimentais, a imunidade inata e a adaptativa contribuem significativamente para a eliminação do tumor (Kim et al., 2007; Teng et al., 2008). Em 2011, Hanahan e Weinberg incluíram, em sua revisão, “evasão do sistema imune" como uma nova característica do câncer. O potencial efeito do sistema imune de um paciente sobre seu estado clínico não é somente de interesse acadêmico, mas possui implicações relevantes na identificação de marcadores prognósticos e marcadores preditivos de respostas à quimioterapia e radioterapia. 
Os infiltrados de células do sistema imune são heterogêneos nos diferentes tipos de tumor e variam entre pacientes. Diferentes tipos celulares podem infiltrar-se no tumor, como macrófagos, células dendríticas, mastócitos, células NK, linfócitos B e células T efetoras. Essas células podem estar no centro do tumor, nas margens invasivas ou nas estruturas linfoides terciárias (TLS). Macrófagos são frequentemente abundantes no estroma e áreas de fibrose. Células NK encontram-se no estroma e linfócitos B são encontrados, sobretudo, nas margens invasivas e nas TLS. Células T CD8+ podem estar nas margens, mas também no centro do tumor. Células dendríticas imaturas podem localizar-se dentro do tumor ou no estroma adjacente, já as maduras, concentram-se nas TLS, em contato com as células T naive (Dieu-Nosjean et al., 2008; Mantovani et al., 2008).

Em muitos casos, ainda não se conhece o significado biológico destas distribuições diferenciadas. No entanto, a análise da localização, densidade e características funcionais de algumas das populações de células do sistema imune, em bancos de tumores humanos, tem permitido a identificação de fatores benéficos ou deletérios aos pacientes (Fridman et al., 2012).

Em estudo de meta-análise da correlação entre células $\mathrm{T}$ e a sobrevida de pacientes, estabeleceu-se claramente que uma alta densidade de células T de memória com orientações $\mathrm{T}_{\mathrm{H}} 1$ e citotóxica correlaciona-se com prognóstico favorável na grande maioria dos cânceres. No caso de outros tipos de células T, a correlação não é tão clara. Em praticamente metade dos tipos de câncer, a alta infiltração de linfócitos T regulatórios ( $\left.\mathrm{T}_{\mathrm{reg}}\right), \mathrm{T}_{\mathrm{H}} 17$ e $\mathrm{T}_{\mathrm{H}} 2$ associa-se a um prognóstico desfavorável, enquanto que na outra metade, pode estar associada a um bom prognóstico ou pode não haver correlação (Fridman et al., 2012). 
O suprimento sanguíneo é essencial para o desenvolvimento e crescimento tumoral, sendo a angiogênese o processo no qual novos vasos sanguíneos são formados a partir de outros preexistentes. O "gatilho angiogênico" é gerado quando algumas células presentes no tumor em etapas iniciais adquirem um fenótipo angiogênico, caracterizado pela produção aumentada de fatores pró-angiogênicos e pela inibição de reguladores negativos deste processo (Bussolino et al., 1997; Stockmann et al., 2014).

\subsection{Angiogênese e macrófagos}

Durante a embriogênese, o desenvolvimento da vasculatura envolve o aparecimento de novas células endoteliais e sua organização em estruturas tubulares, além da formação de novos vasos sanguíneos a partir de outros preexistentes. Após este período, em geral, a vasculatura normal torna-se quiescente. No adulto, como parte de processos fisiológicos como cicatrização e ciclo reprodutivo feminino, a angiogênese ocorre de maneira transiente. Em contraste, durante a progressão tumoral, o "gatilho angiogênico" está quase sempre ativado, resultando na formação praticamente contínua de novos vasos e contribuindo para o crescimento da neoplasia (Hanahan e Folkman, 1996).

Os vasos sanguíneos intratumorais são caracterizados por anormalidades estruturais e funcionais, como tamanho e forma irregulares, são geralmente mais calibrosos, apresentando excessivas e tortuosas ramificações e ausência da organização hierárquica em arteríolas, capilares e vênulas. Caracterizam-se também por um fluxo sanguíneo irregular e uma cobertura mais frouxa de pericitos, os quais fornecem às células endoteliais um suporte mecânico e fisiológico (Nagy et al., 2010). As células 
endoteliais que compõem os vasos intratumorais apresentam uma maior taxa de proliferação em comparação às células endoteliais normais, o que também contribui para uma vascularização aberrante. Este fenótipo vascular geralmente está associado a uma hiperpermeabilidade, facilitando a entrada de células tumorais na circulação sanguínea (De Bock et al., 2011; Kushner e Bautch, 2013).

Por se tratar de um fenômeno complexo que envolve uma série de eventos, apenas a análise da densidade vascular não é suficiente para determinação da atividade anti-angiogênica (Hlatky et al., 2002). Portanto, a funcionalidade vascular é provavelmente um fator mais relevante na avaliação da atividade anti-angiogênica do que a presença de vasos em si. De fato, alguns estudos demonstraram que a redução do crescimento tumoral e do fluxo sanguíneo não está sempre associada a uma menor densidade vascular (Noguera-Troise et al., 2006; Hicklin, 2007; Li et al., 2007).

A angiogênese é induzida nas fases iniciais do desenvolvimento tumoral em modelos animais e em humanos. Análises histológicas de lesões pré-malignas, não invasivas, como displasias e carcinomas in situ originados em diferentes órgãos, revelaram a ativação precoce do "gatilho angiogênico" (Hanahan e Folkman, 1996; Raica et al., 2009). Os fatores de crescimento e citocinas que induzem a angiogênese podem ser secretados tanto por células tumorais quanto por células do estroma. Dentre os fatores pró-angiogênicos, o VEGF-A é considerado o principal. Ele está envolvido na regulação do crescimento de novos vasos sanguíneos durante o desenvolvimento embrionário e pós-natal, na homeostase e sobrevivência de células endoteliais, assim como em situações fisiológicas e patológicas no adulto (Ferrara, 2009). As isoformas de VEGF induzem o alargamento e a ramificação dos vasos sanguíneos (Stockmann et al., 2008). 
Nas células endoteliais, VEGF e seus receptores (VEGFR-1 e VEGFR-2) são superexpressos na maioria dos tumores malignos e frequentemente em lesões prémalignas (Nagy et al., 2010). A expressão do VEGF pode ser induzida em células tumorais pela ativação de oncogenes, pela inativação de genes supressores tumorais, por hormônios, outras citocinas e pelo fator de transcrição fator induzido por hipóxia (HIF)1 (Arbiser et al., 1997; Laughner et al., 2001). O uso de anticorpos anti-VEGF ou drogas que têm como alvo o VEGF ou seus receptores mostrou inibir fortemente o crescimento tumoral em camundongos, mas o efeito em humanos é mais limitado (Zhang et al., 2002; Jain et al., 2006).

Comumente se observa um número mais elevado de leucócitos inflamatórios em tumores murinos e humanos em comparação aos tecidos normais adjacentes (Coussens e Werb, 2002). Dentre as células inflamatórias, os macrófagos associados a tumores (TAMs) são a população celular mais abundante em tumores sólidos e têm sido alvo de estudos no contexto da iniciação da inflamação crônica no microambiente tumoral, pela produção de citocinas e fatores de crescimento. Cada vez mais evidências indicam um papel importante dos TAMs na ativação do "gatilho angiogênico" e na indução da angiogênese (Fang et al., 2014; Sun et al., 2014). É importante ressaltar que o VEGF atua no recrutamento de monócitos para o microambiente tumoral, além de citocinas e quimiocinas como CCL2 (do inglês, C-C motif chemokine ligand) ou a proteína quimiotática de monócitos (MCP)-1 (Huang et al., 2007), CCL5, CCL7, CCL8, CXCL12 (do inglês, $C-X$-C motif chemokine ligand), fator de crescimento derivado de plaquetas (PDGF) e fator estimulador de colônias de macrófagos (M-CSF) (Sica et al., 2008).

Os macrófagos pertencem à linhagem celular mielóide e constituem a primeira linha de defesa inata contra patógenos, fagocitando-os ou apresentando antígenos às 
células T. São responsáveis pela fagocitose de células apoptóticas durante a embriogênese e no remodelamento tecidual durante o desenvolvimento dos órgãos (Torroella-Kouri et al., 2013). Os macrófagos residentes estão em praticamente todos os tecidos de organismos multicelulares e recebem diferentes nomes de acordo com a sua localização: em vertebrados, há macrófagos alveolares e intersticiais nos pulmões, osteoclastos nos ossos, micróglia no sistema nervoso central, células de Kupffer no fígado, células de Langerhans na pele, macrófagos na zona marginal, polpa vermelha e polpa branca no baço, entre outros (Davies et al., 2013).

Funções nicho-específicas são exercidas por macrófagos residentes, desde atividades que contribuem para a homeostase e reparo tecidual àquelas envolvidas na vigilância imunológica e detecção de danos ou infecções (Hunt et al., 1984; Mirza et al., 2009). Por apresentarem diversas especializações conforme o local em que se encontram, macrófagos formam uma população muito heterogênea. De maneira muito simplificada, foram estabelecidos dois principais fenótipos de polarização, sendo M1 os macrófagos ativados classicamente e M2 os ativados alternativamente (FIGURA 01). 


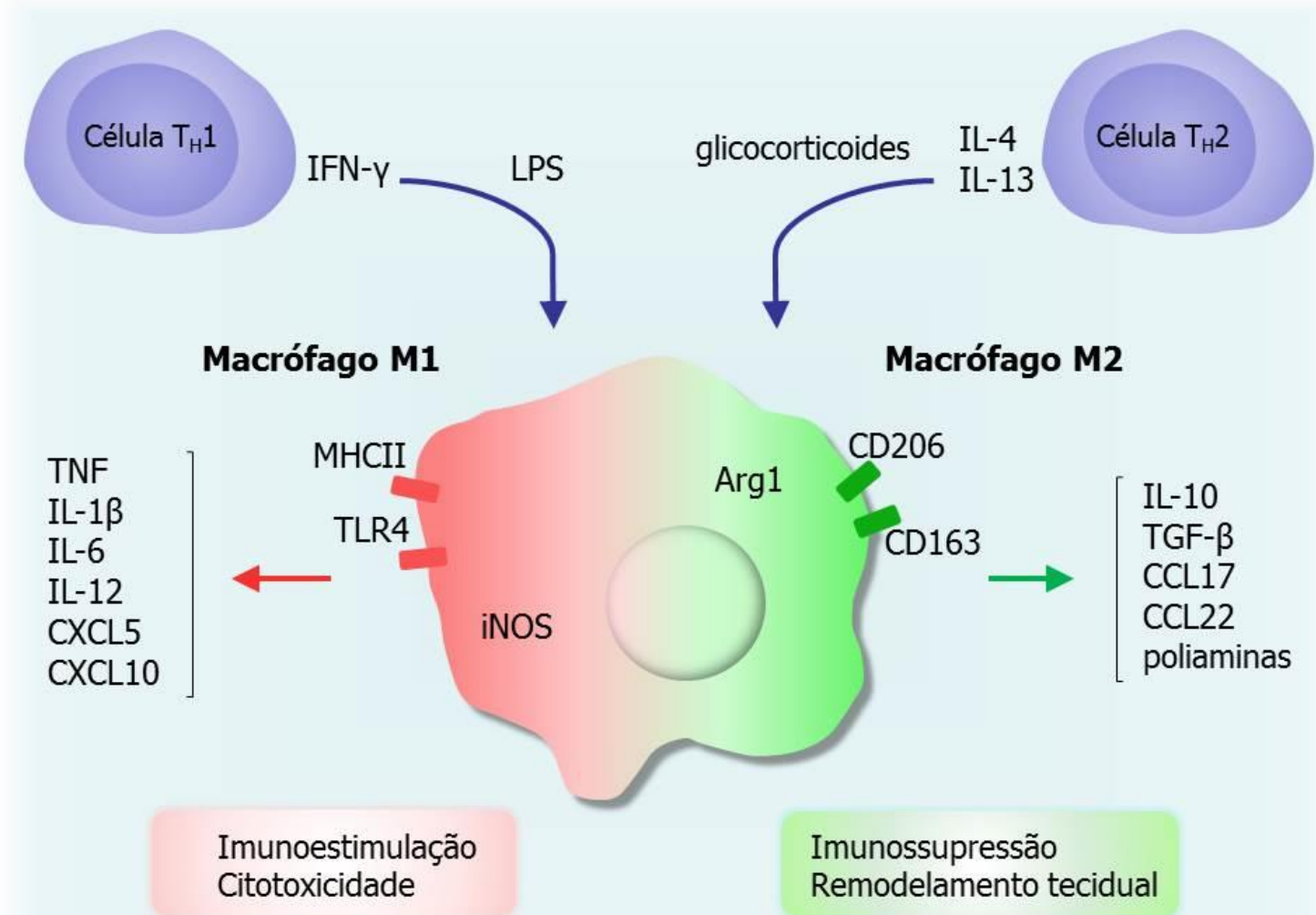

FIGURA 01. Representação esquemática da polarização M1/M2 de macrófagos. LPS e IFN- $\gamma$ induzem a polarização de macrófagos M1, os quais expressam níveis mais elevados de MHC de classe II, TLR4 e da enzima iNOS. Glicocorticoides e as citocinas IL-4 e IL-13, que podem ser secretadas por células $T_{H} 2$, induzem um fenótipo M2, caracterizado pela expressão elevada de CD206 e CD163. O perfil de citocinas e outros fatores secretados pelos macrófagos M1 e M2 contribui para um microambiente com propriedades imunoestimulatórias e imunossupressoras, respectivamente. É importante notar que a polarização de macrófagos não depende obrigatoriamente da presença de células $\mathrm{T}_{\mathrm{H}} 1$ ou $\mathrm{T}_{\mathrm{H}} 2$.

Macrófagos do tipo M1 são induzidos por citocinas relacionadas à resposta do tipo $\mathrm{T}_{\mathrm{H}} 1$, como interferon (IFN)- $\gamma$, sozinho ou combinado com LPSs (lipopolissacarídeos), moléculas associadas a patógenos. Estes macrófagos secretam citocinas pró-inflamatórias como fator de necrose tumoral (TNF), interleucina (IL)-1 $\beta$, IL-6, IL-12 e IL-23, além de CXCL5, CXCL10 e altos níveis de espécies reativas de oxigênio e de nitrogênio (Modolell et al., 1995; Mantovani et al., 2002; Mosser e 
Edwards, 2008). Macrófagos M1 apresentam melhor funcionalidade como células endocitárias e apresentadoras de antígeno, além de atuarem no recrutamento de células NK e linfócitos $\mathrm{T}_{\mathrm{H}} 1$. Por expressarem iNOS/NOS2 (óxido nítrico sintase induzível), produzem óxido nítrico (NO) e citrulina através do metabolismo da arginina, o que resulta em um microambiente com propriedades microbicidas (FIGURA 02).

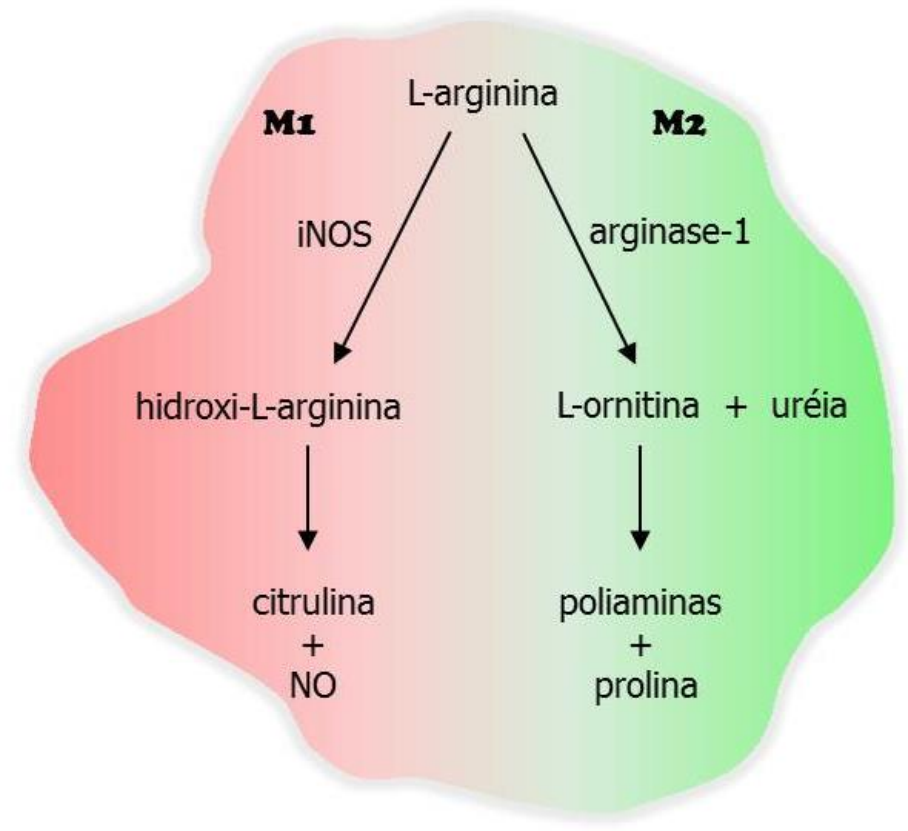

FIGURA 02. Representação esquemática do metabolismo da L-arginina em macrófagos M1 e M2. A L-arginina é metabolizada pela da atividade de iNOS (óxido nítrico sintase induzível) ou arginase-1, caracterizando macrófagos de fenótipo M1 ou M2, respectivamente. NO, óxido nítrico.

Macrófagos de fenótipo M1 são reguladores da eliminação de patógenos e expressam níveis mais elevados do complexo principal de histocompatibilidade (MHC) de classe II e do receptor do tipo Toll (TLR)-4, o qual reconhece LPS (Martinez et al., 2009; Duque e Descoteaux, 2014). 
Em contraste, os macrófagos com polarização M2 expressam maiores níveis de CD206 (receptor de manose) e CD163 e são induzidos por IL-4 e IL-13, citocinas da resposta $\mathrm{T}_{\mathrm{H}} 2$, e também por glicocorticoides. Estes macrófagos secretam as citocinas imunossupressoras IL-10 e fator transformador de crescimento (TGF)- $\beta$ e quimiocinas como CCL17 e CCL22 (Sica et al., 2000; Mantovani et al., 2009). A população M2 possui a habilidade de inibir a ativação e a produção de citocinas por células $\mathrm{T}$, promover angiogênese, degradação de ECM e sobrevivência celular, características consideradas pró-tumorais (Murdoch et al., 2008; Lu et al., 2011).

Macrófagos M2 apresentam alterações no metabolismo da arginina no sentido de diminuir a produção de NO. Por expressarem níveis mais elevados de arginase-1, produzem mais ornitina, que origina poliaminas e prolina, sendo esta precursora do colágeno (FIGURA 02). Desta maneira, os macrófagos M2 promovem a proliferação celular e o reparo tecidual (Mills, 2001; Ho e Sly, 2009).

A definição das polarizações M1 e M2 é limitada, tendo em vista a complexidade e plasticidade das populações de macrófagos. In vivo, estas células podem exibir uma variedade de fenótipos funcionais dependendo de alterações sutis e gradativas no microambiente tecidual. A nomenclatura M1/M2 pode ser considerada uma estrutura conceitual simplificada para descrever estados funcionais gradualmente distintos, onde M1 e M2 representariam os extremos (Italiani e Boraschi, 2014).

Em condições não inflamatórias, macrófagos residentes geralmente exibem um fenótipo M2, que contribui para a homeostase e o reparo tecidual (Lumeng et al., 2007). Se a transição de M1 para M2 ocorre normalmente in vivo ou se novos monócitos são recrutados para o tecido e passam posteriormente pela polarização, ainda é um assunto controverso, mas estas duas interpretações não são mutuamente exclusivas. Deve-se considerar que durante uma resposta inflamatória, esta plasticidade funcional dos 
macrófagos é fundamental para a regulação das fases iniciais da inflamação e do subsequente processo de reparo tecidual (Torroella-Kouri et al., 2013).

Especificamente, os TAMs originam-se de monócitos que se infiltram no tumor a partir dos vasos sanguíneos e passam a apresentar características distintas dependendo dos sinais no microambiente (Solinas et al., 2009). Estes sinais geralmente direcionam a polarização do fenótipo $\mathrm{M} 1$, relacionado a respostas anti-angiogênicas e antitumorigênicas, para o M2, que por sua vez está associado à promoção da angiogênese e imunossupressão (Gabrilovich et al., 2012; Ruffell et al., 2012). No entanto, TAMs podem apresentar fenótipos variados dependendo do estadio de desenvolvimento do tumor. Estudos indicam que estes macrófagos tendem à polarização M2 em tumores já estabelecidos, entretanto, nas fases iniciais da tumorigênese, a tendência é para o fenótipo M1 (Meira et al., 2008; Pollard, 2009).

Expressão mais elevada de marcadores relacionados a macrófagos (e.g. CD68) tem sido observada em câncer de mama, próstata, bexiga, linfoma e glioma, demonstrando, nestes casos, uma associação de TAMs a prognósticos ruins (Paik et al., 2009; Kamper et al., 2011, Prosniak et al., 2013; Gollapudi et al., 2013; Boström et al., 2015). Estes macrófagos participam do remodelamento da ECM através da produção de enzimas proteolíticas como metaloproteinase de matriz (MMP)-2, MMP-7, MMP-9 e MMP-12 (Lewis e Pollard, 2006), tendo a MMP-9 um papel muito importante na angiogênese e na progressão tumoral (Bergers et al., 2000; Wang et al., 2011). Assim como as células tumorais, os TAMs produzem mediadores como TGF- $\beta 1$, IL-13, IL-4 e IL-10, que podem estimular a liberação de VEGF e favorecer uma resposta do tipo M2 (Solinas et al., 2009).

TGF- $\beta 1$ induz angiogênese ao estimular a produção de reguladores positivos como VEGF e fator de crescimento de fibroblastos básico (bFGF) por células estromais 
e através do recrutamento de monócitos derivados da medula óssea (Watnick, 2012). Além disso, TGF- $\beta 1$ atrai macrófagos direta (Wiseman et al., 1988) ou indiretamente induzindo a produção de CCL5/RANTES por células estromais (Happel et al., 2008). Em regiões de hipóxia, o fator de transcrição HIF-1 $\alpha$ atua no recrutamento de monócitos/macrófagos, nos quais é constitutivamente expresso, e regula a expressão de muitos genes relacionados à angiogênese, como o VEGF (Murdoch et al., 2004).

Uma quantidade mais elevada de TAMs foi associada a uma densidade vascular mais alta em neoplasias de esôfago, bexiga, mama, linfoma e glioma (Leek et al., 1996; Nishie et al., 1999; Hanada et al., 2000; Koide et al., 2004; Koh et al., 2014). Um estudo utilizando esferoides de carcinoma mamário identificou níveis elevados de VEGF e de conexões vasculares quando incubados com populações de macrófagos (Bingle et al., 2006). Similarmente, Lewis et al. (2000) observaram, em câncer de mama humano, maior presença de macrófagos em regiões pouco vascularizadas, além de níveis aumentados de VEGF produzidos por estes macrófagos. Em tumor pancreático, a inibição de VEGF e VEGFR-2 com anticorpos monoclonais reduziu a infiltração de macrófagos in vivo (Dineen et al., 2008). A interação entre macrófagos e células endoteliais foi vista por He et al. (2012), ao demonstrarem que a incubação in vitro de células hematopoiéticas derivadas de medula óssea com camadas de células endoteliais resultou na geração de colônias de macrófagos com fenótipo M2.

Reforçando a noção da complexidade das interações entre diferentes tipos celulares, Tiemessen et al. (2007) demonstraram que monócitos humanos cultivados na presença de células $\mathrm{T}_{\text {reg }}$ diferenciam-se em macrófagos M2. Além disso, macrófagos com fenótipo M2 produzem citocinas e quimiocinas, como CCL17, CCL22 e CCL24, que favorecem o recrutamento de células $\mathrm{T}_{\text {reg }}$ (Mantovani et al., 2004; Savage et al., 2008), as quais são células T CD4+ que apresentam níveis elevados de CD25 (receptor 
de IL-2) e do fator de transcrição Foxp3. Estas células possuem um papel importante no crescimento e progressão tumoral e inibem a ativação de células efetoras do sistema imune específicas para antígenos próprios, limitando a autoimunidade e a inflamação em condições fisiológicas (Zamarron e Chen, 2011). As propriedades pró-tumorais podem ser resultado, entre outros fatores, da atuação de células $T_{\text {reg }}$ como promotoras da angiogênese (Facciabene et al., 2011).

\subsection{Galectina-3 e câncer}

Em metazoários, foram identificados 15 tipos de galectinas, a classe de lectinas cuja expressão é a mais abrangente em todos os organismos. Algumas destas proteínas estão distribuídas em diversos tecidos, enquanto outras possuem uma localização mais específica. As galectinas apresentam um domínio de reconhecimento de carboidratos (CRD) conservado, com aproximadamente 130 aminoácidos, e se ligam a glicoconjugados que possuem $\beta$-galactosídeos.

As galectinas-1, 2, 5, 7, 10, 11, 13, 14 e 15 são do grupo protótipo, pois possuem um CRD e podem associar-se formando homodímeros; galectinas-4, 6, 8, 9 e 12 são do tipo de repetição em tandem e possuem dois CRDs unidos por um pequeno domínio peptídico. Por fim, a galectina-3 (gal-3) é a única do tipo quimera, possuindo apenas um CRD e um domínio rico em prolina, glicina e tirosina conectado à região C-terminal, onde se encontra o CRD (Hirabayashi e Kasai, 1993; Elola et al., 2007) (FIGURA 03). Gal-3 pode formar oligômeros, ligando-se a carboidratos multivalentes e, assim, pode formar estruturas de rede em malha na membrana plasmática, o que contribui para sua estabilidade e funções biológicas (Rabinovich et al., 2007). 


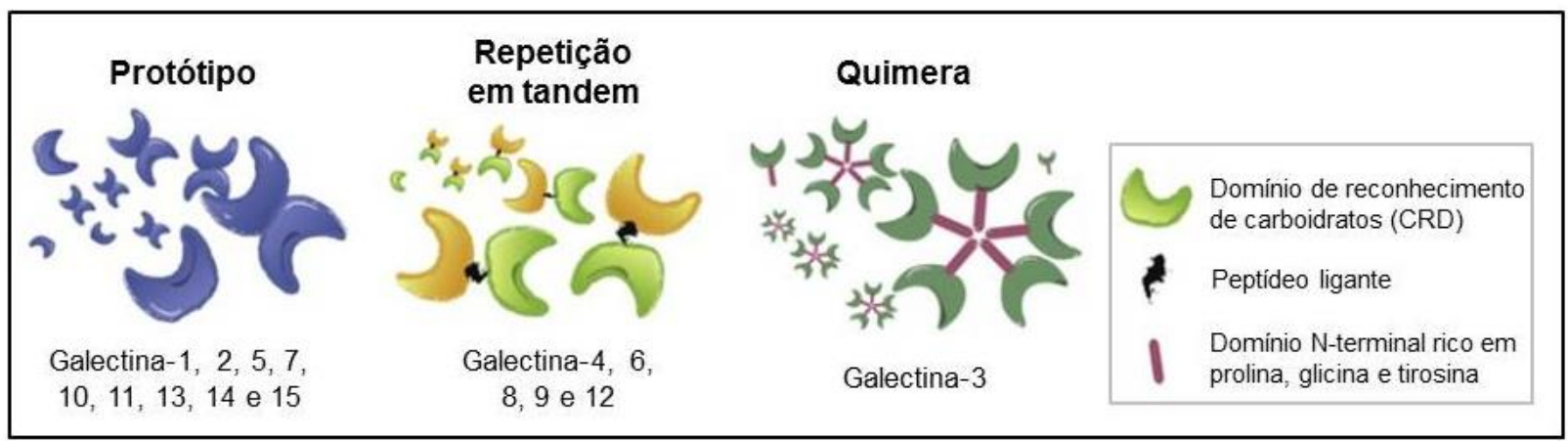

FIGURA 03. Representação esquemática da estrutura dos diferentes membros da família de galectinas. As galectinas são subdivididas em três grupos: protótipo, que possui apenas um CRD, do tipo repetição em tandem, com dois CRDs e um peptídeo ligante e o tipo quimera, com um CRD e um domínio N-terminal rico em prolina, glicina e tirosina (adaptado de Rabinovich e Croci, 2012).

As galectinas não possuem uma sequência-sinal clássica e podem ser secretadas por mecanismos pouco conhecidos (Hughes, 1997; Delacour et al., 2009). São encontradas no citoplasma e núcleo, mas também no meio extracelular e na superfície celular. Atuando no meio extracelular através da ligação com glicoproteínas ou glicolipídeos, as galectinas desencadeiam vias de sinalização intracelulares e regulam interações célula-célula e célula-matriz extracelular (Perillo et al., 1998). No meio intracelular, estas proteínas podem ser transportadas do núcleo para o citoplasma e participar de processos fundamentais como a remodelação de pré-mRNA (RNA mensageiro), assim como a regulação da mitose, apoptose e progressão do ciclo celular. Em muitos casos, a expressão alterada de galectinas correlaciona-se com a agressividade de um tumor e a aquisição de um fenótipo metastático (Liu e Rabinovich, 2005; Yang et al., 2008).

A gal-3 apresenta diversas funções, que dependem do tipo celular e da sua localização, regulando importantes processos biológicos como adesão celular, proliferação, apoptose, inflamação e progressão tumoral (Ochieng et al., 2004; Dumic et 
al., 2006). Corroborando com as propriedades contexto-específicas da gal-3, em alguns tipos de câncer, sua expressão é aumentada, como em tireóide, fígado, estômago e no sistema nervoso central; já no câncer de mama, ovário, útero e de próstata, sua expressão é reduzida (van den Brûle et al., 2004; Liu e Rabinovich, 2005; Nakahara et al., 2005).

A expressão desta proteína é mais abundante durante a embriogênese e desenvolvimento em comparação à vida adulta, sendo expressa em células epiteliais (pele, tratos respiratório e digestivo), fibroblastos, cartilagens, ossos, células inflamatórias e miocárdicas (Aubin et al., 1995; Hughes et al., 1997; Liu et al., 2002). Gal-3 pode aumentar sinais inflamatórios atuando na fagocitose de neutrófilos apoptóticos, induzindo a liberação de fatores pró-inflamatórios por mastócitos e neutrófilos ou através da quimiotaxia que exerce sobre macrófagos e monócitos (Sano et al., 2003). Gal-3 geralmente é ubíqua na atividade fagocitária, sendo encontrada nos fagossomos de macrófagos (Karlsson et al., 2009).

A localização desta proteína depende do tipo celular e de seu estado proliferativo (Moutsatsos et al., 1987; Sato e Hughes, 1994; Perillo et al., 1998). No núcleo, gal-3 participa da remodelação de pré-mRNA e da expressão gênica (Dagher et al., 1995; Paron et al., 2003). Os mecanismos envolvidos na sua translocação para o núcleo não estão bem estabelecidos, mas estudos indicam a participação de transporte ativo e de difusão passiva (Nakahara et al., 2006). Em seu CRD, há uma região conservada NWGR (asparagina, triptofano, glicina e arginina), presente também no domínio BH1 da proteína linfoma de células B (Bcl)-2; por isto, no citoplasma, pode ligar-se a Bcl-2 e exercer seu papel anti-apoptótico (Yang et al., 1996). Outras moléculas que participam da via de sinalização de apoptose foram identificadas como ligantes de gal-3, como as proteínas citoplasmáticas nucling e Alix/AIP1 (Liu et al., 2004; Chen et al., 2009). 
Após exposição a estímulos apoptóticos, foi observado que gal-3 transloca-se do núcleo ou citoplasma para a mitocôndria (Yu et al., 2002), onde inibe alterações no potencial de membrana, exercendo um papel anti-apoptótico (Matarrese et al., 2000). Gal-3 também pode interagir com a proteína oncogênica K-Ras ativada, influenciando na sinalização de Akt (Elad-Sfadia et al., 2004), tanto suprimindo (Lee et al., 2003), quanto estimulando esta via (Oka et al., 2005), demonstrando que o efeito da gal-3 na proliferação celular depende muito das propriedades de cada tipo celular e do contexto em que se encontra.

Gal-3 não possui uma sequência-sinal clássica e uma possível via alternativa de secreção, observada em células dendríticas, é através de exossomos (Théry et al., 2001). No meio extracelular, gal-3 promove a proliferação de fibroblastos e a síntese de colágeno. Através da interação com integrinas na superfície celular ou com proteínas da matriz como laminina, fibronectina (Sato e Hughes, 1992), elastina e colágeno IV (Ochieng et al., 1998), a gal-3 aumenta a adesão das células tumorais à ECM, estimulando o fenótipo migratório destas células. A capacidade invasiva das células neoplásicas pode ser favorecida pela ligação de gal-3 com o receptor do fator de crescimento epidérmico (EGFR) e o receptor de TGF- $\beta$ (Newlaczyl e Yu, 2011). Na circulação sanguínea, gal-3 pode contribuir com a metástase ao estimular a adesão de células tumorais ao endotélio vascular (Khaldoyanidi et al., 2003).

A gal-3 também pode restringir a sinalização mediada por receptores de células T (TCRs), promovendo a anergia de células T e distanciando o TCR do seu co-receptor CD8 na superfície de células T citotóxicas (Demotte et al., 2008). Gal-3 contribui com a tolerância imunológica ao se ligar a CD45 e CD71 e induzir a apoptose de células T humanas (Stillman et al., 2006). Além disso, inibe receptores citotóxicos em células NK, como NKG2D e NKp30 (Tsuboi et al., 2011; Wang et al., 2014). 
Dentre as múltiplas propriedades desta proteína, tem sido demonstrado seu papel no controle da angiogênese associada a tumores. Entretanto, pouco se sabe sobre os mecanismos de ação envolvidos neste processo. A regulação do processo angiogênico é altamente dependente da interação entre dois tipos celulares: células endoteliais e pericitos. A comunicação entre estas células é mediada por fatores de crescimento solúveis e moléculas de adesão celular (Gerhardt e Betsholtz, 2003). Estudos em linhagens de melanoma e glioblastoma indicaram que o proteoglicano NG2 presente em pericitos microvasculares estimula a morfogênese e a motilidade de células endoteliais ao formar um complexo com integrina $\alpha 3 \beta 1$ e gal-3 (Fukushi et al., 2004; Wen et al., 2006).

Evidências indicam que a angiogênese é regulada por gal-3 mesmo em seus estágios iniciais, através da sua interação com as células endoteliais (Yang et al., 2007). Em estudos com células endoteliais humanas de cordão umbilical (HUVECs), NangiaMakker et al. (2000) descreveram que a neutralização de gal-3 com carboidratos específicos e anticorpos afeta a quimiotaxia e a morfologia de células endoteliais e a formação de estruturas tubulares in vitro. A atividade pró-angiogênica de gal-3 poderia estar relacionada à sua habilidade de induzir a migração celular. Além disso, estes pesquisadores mostraram que o xenotransplante de células de carcinoma mamário superexpressando gal-3, em camundongos, promove o desenvolvimento vascular mais eficientemente. Em outro trabalho, evidenciou-se a inibição da angiogênese pelo uso de competidores de gal-3 (lactose ou pectina cítrica modificada), o que sugere a participação de seu CRD neste processo (Nangia-Makker et al., 2002).

In vivo, as células endoteliais no microambiente tumoral são enriquecidas de ligantes de gal-3 (de Melo et al., 2007). Em modelo experimental, vascularização ótima foi observada em tumores onde tanto células tumorais quanto estromais expressam gal-3 
(Machado et al., 2014). Markowska et al. (2010) mostraram que gal-3 promove angiogênese pela interação de seu CRD com N-glicanos da integrina $\alpha v \beta 3$ e pela ativação da via de sinalização da quinase de adesão focal (FAK), que influencia a atividade angiogênica de VEGF e bFGF. Estes pesquisadores também relataram que gal-3 contribui para a retenção de VEGFR-2 na membrana plasmática, potencializando o efeito de VEGF-A em células endoteliais (Markowska et al., 2011). Em outro estudo, o uso combinado de gal-1 e gal-3 in vitro promoveu a retenção de VEGFR-1 e VEGFR2 na membrana plasmática, estimulando a formação de estruturas tubulares e o crescimento das células endoteliais (D’Haene et al., 2013).

Ainda não se sabe ao certo se os efeitos de gal-3 na angiogênese estão relacionados ao seu processamento pós-traducional. O domínio N-terminal de gal-3, similar ao colágeno, é suscetível à clivagem extracelular pela MMP-2 e MMP-9 (Ochieng et al., 1994; Nangia-Makker et al., 2007), apresentando, na forma clivada, afinidade muito maior por células endoteliais (Shekhar et al., 2004) e promovendo maior quimiotaxia, invasão e interações com células endoteliais (Nangia-Makker et al., 2010). 


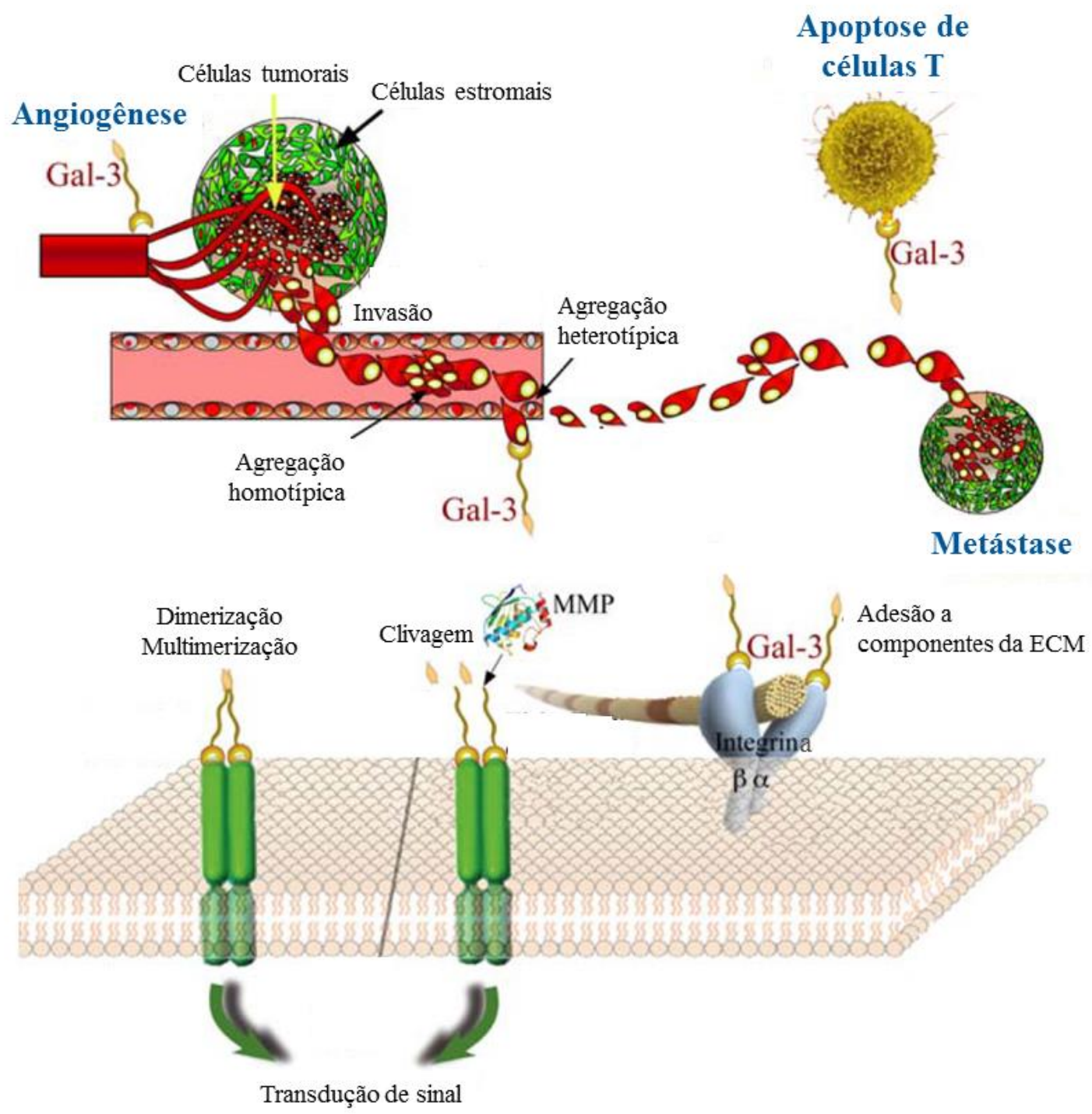

FIGURA 04. Funções extracelulares mediadas por gal-3. Gal-3 potencializa a angiogênese ao promover a migração, quimiotaxia e morfogênese de células endoteliais. Possui um papel importante na indução de apoptose em células T. Na superfície celular, está envolvida na agregação homotípica e heterotípica (entre um mesmo tipo celular e entre tipos celulares diferentes, respectivamente), invasão e metástase. Gal-3 extracelular forma dímeros e multímeros, ligando-se a glicoconjugados e desencadeando cascatas de sinalização intracelular. Comparada à proteína intacta, gal-3 clivada tem ainda mais afinidade por seus receptores. MMP, metaloproteinase de matriz; ECM, matriz extracelular (adaptado de Nangia-Makker et al., 2008). 
Estudos também indicam um papel de gal-3 no mimetismo vasculogênico, processo caracterizado pela plasticidade funcional de células neoplásicas que se comportam como células endoteliais nos vasos tumorais (Maniotis et al., 1999). A expressão gênica de células de melanoma deficientes em gal-3, comparada à de células selvagens, indicou a co-expressão de gal-3 com diversos marcadores de células endoteliais envolvidos na angiogênese tumoral, na diferenciação de células endoteliais e, portanto, no fenômeno de mimetismo vasculogênico (Mourad-Zeidan et al., 2008).

Além do seu papel em células endoteliais, gal-3 também é expressa pelos TAMs, os quais tem sido relacionados à angiogênese tumoral e maturação vascular de maneira dependente da densidade celular no tumor e do fenótipo (Chen e Bonaldo, 2013). Com a finalidade de estabelecer in vivo um gradiente de concentração de gal-3, pesquisadores realizaram o implante de células tumorais que expressam esta proteína em camundongos knockout para gal-3. Os resultados mostraram que gal-3 promove a angiogênese e o crescimento tumoral, além de aumentar a densidade de macrófagos de fenótipo M2 na massa tumoral (Jia et al., 2013). MacKinnon et al. (2008) demonstraram que através da interação com CD98, gal-3 é necessária para uma ativação ótima do fenótipo M2.

Estudos realizados por nosso grupo mostraram que macrófagos derivados da medula óssea de camundongos knockout para gal-3 (KO-BMDMs) apresentam uma secreção basal de VEGF reduzida quando comparados aos macrófagos de camundongos selvagens (WT-BMDMs). Ainda, sob estímulo de TGF $\beta$-1, o qual induz quimiotaxia e secreção de VEGF em monócitos e macrófagos (Wiseman et al., 1988; Harmey et al., 1998), WT-BMDMs são mais responsivos, pois secretam mais VEGF em comparação aos KO-BMDMs (Machado et al., 2014). 
Em modelo experimental, tumores que não expressam gal-3 nem no parênquima, nem no estroma, exibiram níveis mais elevados do homodímero ativo de TGF $\beta$-1, no entanto, os níveis de VEGF encontravam-se diminuídos em comparação aos tumores positivos para gal-3. Corroborando este resultado, os tumores sem gal-3 apresentaram uma densidade vascular reduzida, acompanhada de maiores áreas necróticas, além de expressarem menos VEGFR-2 e sua forma fosforilada. Interessantemente, verificou-se que mesmo no modelo no qual gal-3 é expressa apenas no parênquima tumoral e não no estroma, a produção de VEGF foi suficiente para promover a organização de uma ampla área vascular (Machado et al., 2014).

Ao investigar o papel dos macrófagos neste modelo experimental, foi observada densidade mais elevada de macrófagos no interior do tumor que expressa gal-3 apenas no parênquima, mas não no estroma. Por sua vez, na periferia do tecido tumoral, foi observado um número muito elevado de macrófagos apenas no microambiente com completa ausência de gal-3. Além disso, a presença de gal-3 tanto nas células neoplásicas, quanto nas células estromais, refletiu no aumento da produção do transcrito da arginase-1, indicativo de macrófagos M2 (Machado et al., 2014).

Estendendo estes estudos prévios com inóculo de células tumorais em camundongos, o presente trabalho teve como modelo experimental o sarcoma induzido pelo carcinógeno 3-metilcolantreno (MCA). A administração subcutânea deste composto gera, no local da injeção, lesões caracterizadas como fibrossarcoma. No entanto, o MCA também é utilizado na indução de tumores em modelos experimentais de mesotelioma e câncer de pulmão (Ebenstein et al., 1979; Rice et al., 1989; Qin et al., 2002).

Os sarcomas formam um grupo de tumores sólidos raros oriundos de tecidos mesenquimais ou conjuntivos, e representam $<1 \%$ de todas as neoplasias em adultos. 
Dentre os sarcomas, 20\% originam-se em ossos e cartilagens e $80 \%$ em partes moles, sendo que estes compõem um grupo extremamente heterogêneo, tornando o tratamento e o prognóstico um grande desafio (Schöffski et al. 2014).

A maior incidência é observada em pacientes entre 45 e 90 anos, mas, quando comparados a tumores epiteliais, os sarcomas de partes moles ocorrem mais frequentemente em crianças, adolescentes e jovens adultos. Estes tumores podem ocorrer em praticamente qualquer sítio anatômico, embora sejam mais frequentes nas extremidades (Clark et al., 2005). Especificamente, o fibrossarcoma origina-se de fibroblastos e como não há marcadores específicos, o seu diagnóstico é uma questão de exclusão por imunoistoquímica (Daugaard, 2004). 


\subsection{Justificativa}

Muitas evidências em tumores murinos e humanos têm estabelecido o papel crucial dos macrófagos no desenvolvimento e progressão tumoral. Sabe-se que fatores liberados no microambiente atraem e educam os macrófagos a orquestrar processos como vascularização, metastização e imunossupressão. No entanto, ainda há muito que se aprender sobre a interação de TAMs e outros tipos celulares, como neutrófilos e células T, assim como interações entre as subpopulações de TAMs.

No trabalho de Machado et al. (2014), foi demonstrado que gal-3 influencia a quantidade de macrófagos na massa tumoral e tem um grande impacto na sinalização celular de VEGF e TGF $\beta$-1. Estes fatores, liberados pelas células tumorais ou por macrófagos, podem ser decisivos para o desenvolvimento de uma neoplasia, tanto na fase de iniciação, promoção e de progressão.

Visando estender os estudos prévios, o presente trabalho tem como modelo experimental o sarcoma induzido quimicamente por MCA. Diferente do implante de células tumorais, este modelo possibilita o estudo do microambiente desde as fases iniciais da tumorigênese, antes mesmo do aparecimento da massa tumoral e, ainda tem como característica a sua origem mesenquimal, ocorrendo no estroma já vascularizado. Além disso, a indução de tumores por carcinógenos em camundongos assemelha-se mais à dinâmica da progressão tumoral em humanos (Maronpot et al., 2004). Este modelo experimental foi proposto para se descrever o envolvimento de gal-3 em diferentes fases do desenvolvimento de sarcomas experimentais, com ênfase no processo de angiogênese associada a tumores. 


\section{OBJETIVO GERAL}

O presente trabalho teve como objetivo geral investigar o impacto do papel de galectina-3 na angiogênese tumoral, em modelo de sarcoma quimicamente induzido, assim como no padrão de recrutamento e polarização de macrófagos neste microambiente.

\section{OBJETIVOS ESPECÍFICOS}

- Avaliar o crescimento tumoral em camundongos selvagens (WT) e knockout para gal-3 (Gal-3 KO) após indução química de sarcomas e, nestes tumores:

- Analisar as áreas de necrose e aspectos de proliferação celular;

- Avaliar a densidade vascular tumoral e a produção do fator pró-angiogênico VEGF;

- Determinar in vivo a velocidade média de fluxo sanguíneo em vasos tumorais;

- Quantificar in vivo a incorporação de fluodeoxiglicose, um análogo da glicose, pelos tumores;

- Avaliar a localização de macrófagos (periferia ou interior do tumor);

- Quantificar a expressão de marcadores relacionados à polarização de macrófagos; 
- Avaliar se gal-3 influencia na densidade de macrófagos em geral e de macrófagos M2 nas fases iniciais da tumorigênese, no local de injeção do carcinógeno em animais WT e Gal-3 KO. 


\section{MATERIAIS E MÉTODOS}

\subsection{Animais e indução tumoral com carcinógeno}

O carcinógeno utilizado para indução química dos sarcomas foi o MCA, um hidrocarboneto aromático policíclico que se liga ao receptor de aril hidrocarboneto (AhR). A interação com um ligante provoca a translocação do AhR do citoplasma para o núcleo, onde forma dímeros com ARNT (translocador nuclear de AhR). Este heterodímero liga-se a elementos responsivos a xenobióticos (XREs) nas regiões promotoras de genes alvos, dentre os quais estão as enzimas do citocromo P450 (CYP1A1, CYP1A2 e CYP1B1) que metabolizam xenobióticos (Quattrochi et al., 1994). Os metabólitos resultantes apresentam propriedades carcinogênicas e causam danos ao DNA, por exemplo, formando adutos de DNA, os quais estão associados a transversões (substituição de uma purina por pirimidina e vice-versa) (Flesher et al., 1998). A ativação do AhR também contribui para o aumento da produção de espécies reativas de oxigênio (ROS), promovendo danos ao DNA devido ao estresse oxidativo (Park et al., 1996).

Os grupos experimentais foram formados com camundongos C57BL/6 machos, de 8 a 10 semanas de idade, pesando entre 20 e 25 g, fornecidos pelo Biotério Central da Faculdade de Medicina da Universidade de São Paulo (FMUSP). Os animais foram mantidos no Biotério de Experimentação do Centro de Medicina Nuclear (InRad HCFMUSP) sob temperatura de 20 a $25^{\circ} \mathrm{C}$, com ciclo de fotoperíodo de 12/12 horas e fornecimento de água e ração estéreis ad libitum. Foram utilizados grupos de camundongos knockout para o gene da galectina-3 (Lgals3 ${ }^{-/}$; Gal-3 KO) (Hsu et al., 
2000) e de camundongos selvagens (Lgals ${ }^{+/+}$; WT). Para os experimentos realizados com tumores que atingiram volume de aproximadamente $1 \mathrm{~cm}^{3}$, foram utilizados 68 camundongos WT e 69 camundongos Gal-3 KO. Para os experimentos de tumorigênese em fases iniciais, foram utilizados 20 camundongos WT e 18 camundongos Gal-3 KO.

Os animais receberam, no flanco esquerdo, inóculo subcutâneo de MCA em óleo tricaprílico (200 ㅆg de MCA em $100 \mu \mathrm{L}$ ) ou apenas óleo, sendo duas injeções com intervalo de oito semanas (Melo et al., 2011). Após a segunda injeção de MCA, o acompanhamento para observar o aparecimento de tumor ocorreu duas vezes por semana. Os tumores foram medidos com paquímetro e o volume foi determinado através da aproximação a uma figura de elipse, de acordo com a fórmula $\mathrm{D} \times \mathrm{d}^{2} \mathrm{x}$ 0,52 (onde D é o diâmetro maior e d, o diâmetro menor).

\subsection{Análise da velocidade de fluxo sanguíneo intratumoral por ultrassonografia (US) com color Doppler}

Imageamento por US com color Doppler foi realizado com o sistema Vevo 2100 (VisualSonics, Canadá) em animais que desenvolveram tumores com volume aproximado de $1 \mathrm{~cm}^{3}$. Os camundongos foram inicialmente anestesiados com 3\% de isoflurano em oxigênio e durante o imageamento manteve-se 1,5 a 2\% de isoflurano. Os animais foram mantidos em decúbito dorsal sobre uma plataforma aquecida e as patas foram posicionadas sobre eletrodos de eletrocardiograma para monitoração das frequências cardíaca e respiratória. A temperatura corporal foi mantida a $37^{\circ} \mathrm{C}$ e a região onde se encontrava o tumor foi depilada. As imagens foram adquiridas com um transdutor de alta frequência, para medição da velocidade de fluxo sanguíneo em vasos 
na periferia e no interior do tumor. A periferia foi considerada como a área peritumoral determinada pelos limites da neoplasia até no máximo $0,8 \mathrm{~mm}$ em direção ao centro da lesão. As análises foram realizadas pelo software VeVo CQ (Visual Sonics) acoplado ao equipamento.

\subsection{Tomografia por Emissão de Pósitrons/Tomografia Computadorizada} (PET/CT)

A PET é uma técnica de imageamento funcional da medicina nuclear, utilizada para observar processos metabólicos no organismo. O sistema detecta raios gama emitidos por radionuclídeos emissores de pósitrons, introduzidos no organismo em moléculas biologicamente ativas. Neste caso, a molécula é a fluodeoxiglicose (FDG), um análogo da glicose, e a concentração de radionuclídeo (flúor-18 ou ${ }^{18} \mathrm{~F}$ ), que corresponde à captação regional de glicose, indicará a atividade metabólica tecidual. A

utilização de ${ }^{18}$ F-FDG fornece informações funcionais importantes baseadas no aumento da captação de glicose e da glicólise em células tumorais, muitas vezes identificando anomalias metabólicas antes que ocorram alterações morfológicas. Além disso, a integração com o sistema de CT permite a localização anatômica exata das lesões detectadas (Almuhaideb et al., 2011).

Neste trabalho, as imagens foram adquiridas em animais WT e Gal-3 KO que desenvolveram tumores com volume aproximado de $1 \mathrm{~cm}^{3}$. O radiofármaco ${ }^{18}$ F-FDG foi administrado via intravenosa, sendo que a atividade injetada foi de 18,5 a $37 \mathrm{MBq}$ (megabecquerel) ou 0,5 a 1,0 mCi (milicurie). Considerando que a meia-vida é de 110 minutos, as imagens foram adquiridas aproximadamente uma hora após a sua 
administração. Durante a injeção de ${ }^{18}$ F-FDG e ao longo da aquisição das imagens, os animais foram anestesiados com 1,5 a 2\% de isoflurano em oxigênio e monitorados quanto à frequência respiratória. As imagens foram processadas utilizando o software de imageamento Amide 1.0.2.1 (Loening \& Gambhir, 2003), segundo as instruções do fabricante. Para análise quantitativa das imagens, o tumor foi definido como uma região de interesse (ROI) elipsóide, assim como uma região contralateral isovolumétrica. A quantificação da incorporação de ${ }^{18}$ F-FDG pelo tecido tumoral foi calculada de três maneiras: a) atividade total $(\mathrm{kBq})$ /volume; b) atividade máxima $(\mathrm{kBq}) /$ volume e c) SUV (do inglês, standardized uptake value). No caso de a e b, os cálculos foram feitos para a ROI do tumor e para a ROI contralateral, por fim dividindo-se o valor do tumor pelo valor do contralateral. O SUV foi calculado segundo a fórmula:

$$
\mathrm{SUV}=\frac{C}{A I / m}
$$

onde AI é a atividade injetada, m é a massa corporal e C, a concentração do radiofármaco dentro da ROI (Zheng et al., 2011).

\subsection{Eutanásia e excisão cirúrgica}

Os camundongos foram sacrificados ao final de 8 a 11 semanas após a segunda injeção de MCA ou quando o tumor atingiu um volume aproximado de $1 \mathrm{~cm}^{3}$. Para os estudos realizados nas fases iniciais da tumorigênese, foi retirado um fragmento de aproximadamente $0,6 \mathrm{~cm}^{2}$ da pele e tecido subcutâneo, na região de inóculo do MCA ou veículo: uma semana após a primeira injeção ou uma semana após a segunda injeção. Para tais procedimentos cirúrgicos, foi realizada anestesia intraperitoneal com 
quetamina (100 mg/kg) e xilazina (10 mg/kg) e a eutanásia ocorreu em câmara de dióxido de carbono $\left(\mathrm{CO}_{2}\right)$. Os animais submetidos a PET/CT foram sacrificados após decaimento de 10 meias-vidas do radiofármaco e os submetidos à US, logo após o procedimento. Após eutanásia, o tecido foi removido cirurgicamente e processado para análises posteriores.

Todos os procedimentos foram executados de acordo com as normas éticas estabelecidas pelo Colégio Brasileiro de Experimentação Animal (COBEA) e aprovados pelo Comitê de Ética em Pesquisa da Faculdade de Medicina da Universidade de São Paulo (protocolo 020/14) (APÊNDICE). O descarte das carcaças dos animais foi feito de acordo com a política institucional, com encaminhamento para o setor de descarte de carcaças do complexo FMUSP.

\subsection{Processamento em parafina e análises histológicas}

Após dissecção, os espécimes foram mergulhados em solução de formol 10\% tamponado, onde permaneceram por seis horas ou overnight, dependendo do tamanho. Em seguida, foram lavados em tampão fosfato salino (PBS) e mantidos em etanol $70 \%$ até o processamento de inclusão em parafina. As amostras passaram por etanol 100\% a $40^{\circ} \mathrm{C}$, quatro vezes por 20 minutos, e banhos de xilol a $40^{\circ} \mathrm{C}$, três vezes por 25 minutos. Em seguida, passaram por banhos em parafina a $65^{\circ} \mathrm{C}$, quatro vezes por 30 minutos e, posteriormente, emblocadas. Utilizando-se o micrótomo, foram obtidos cortes de $3 \mu \mathrm{m}$ de espessura, os quais foram mantidos em estufa a $80^{\circ} \mathrm{C}$ por pelo menos 12 horas. Para análise morfológica, realizou-se a coloração com hematoxilina e eosina (H\&E). 
A observação e documentação das lâminas foram realizadas em microscópio óptico Olympus acoplado a um sistema de Captura Nikon DMX1200 e software ACT-1. Para contagem de figuras mitóticas, foram analisados 10 campos de grande aumento (CGA) por animal, com lente objetiva de 40x. Para análise de áreas necróticas, 20 campos independentes de cada secção de tecido (uma secção por animal) foram capturados utilizando-se lente objetiva de 20x. Utilizou-se uma grade com 80 intersecções sobre a imagem de cada campo, calculando-se a porcentagem de intersecções que se localizavam sobre áreas de necrose. Todas estas análises foram realizadas com o auxílio do software ImageJ (National Institutes of Health, NIH).

\subsection{Análises imunoistoquímicas (gal-3, PCNA e CD34)}

As lâminas contendo as secções de tecido foram mantidas em estufa a $60^{\circ} \mathrm{C}$ por 24 horas e desparafinadas em banhos de xilol por 20 minutos a $60^{\circ} \mathrm{C}$ e 20 minutos à temperatura ambiente, hidratadas em etanol nas concentrações decrescentes de 100\%, 85\% e 70\% por 30 segundos cada e lavadas em água corrente e destilada. A recuperação antigênica foi realizada em tampão citrato 10 mM pH 6,0 em panela de pressão (A La Carte, Rochedo), por três minutos após pressurização total. Após lavagem em água corrente e destilada, a atividade da peroxidase endógena foi bloqueada por $\mathrm{H}_{2} \mathrm{O}_{2}$ (peróxido de hidrogênio) 6\%, com quatro trocas de cinco minutos. Após lavagem por cinco minutos com PBS $10 \mathrm{mM}$ pH 7,4, foi realizado bloqueio com Novocastra Protein Block (Leica) por cinco minutos. Incubaram-se os cortes com os anticorpos primários: anti-PCNA (clone PC10, M0879, Dako, 1:3000) e anti-CD34 (sc-18917, Santa Cruz Biotechnology, 1:100) ou anti-galectina-3 (clone M3/38, 1:10), diluídos em PBS-1\% de 
albumina bovina (BSA) (Sigma-Aldrich) e 0,1\% de azida sódica, por 30 minutos a $37^{\circ} \mathrm{C}$ e por 18 horas a $4^{\circ} \mathrm{C}$ em câmara úmida. Após lavagens com PBS, foi realizada incubação por 20 minutos a $37^{\circ} \mathrm{C}$ com Primary Antibody Enhancer (UltraVision LP Detection System, Thermo Scientific), seguida de lavagens com PBS e incubação por 30 minutos com HRP Polymer do mesmo kit. Ao abrigo da luz, os cortes foram incubados por cinco minutos a $37^{\circ} \mathrm{C}$ com solução substrato: $100 \mathrm{mg}$ de 3, 3'diaminobenzidina tetrahidrocloreto (Sigma-Aldrich); $1 \mathrm{~mL}$ de dimetilsulfóxido; $1 \mathrm{~mL}$ de $\mathrm{H}_{2} \mathrm{O}_{2} 6 \% ; 100 \mathrm{~mL}$ de PBS. Seguida de lavagem em água corrente e destilada e contracoloração com hematoxilina de Harris por um minuto. Após lavagem em água corrente, as lâminas foram imersas em água amoniacal (solução de hidróxido de amônio 0,5\%) e lavadas novamente. A desidratação foi realizada em banhos de 30 segundos de etanol 80\%, 95\%, 100\% (duas vezes), xilol (quatro vezes) e a montagem das lâminas com Entellan new (Merck). Os controles negativos foram obtidos pela omissão dos anticorpos primários.

A observação e documentação das lâminas foram realizadas em microscópio óptico Olympus acoplado a um sistema de Captura Nikon DMX1200 e software ACT-1. Para quantificação das reações, 20 campos independentes de cada secção de tecido em cada situação foram capturados utilizando-se lente objetiva de 20x (uma secção por animal). Para análise de porcentagem de células positivas para PCNA, foram contadas todas as células marcadas e todas as células nos campos fotografados. Para quantificação da área relativa positiva para CD34, utilizou-se uma grade com 80 intersecções sobre a imagem de cada campo. Por fim, calculou-se a porcentagem de intersecções que se localizavam dentro de vasos positivos para CD34. Todas estas análises foram realizadas com o auxílio do software ImageJ (NIH). 


\subsection{Análises imunoistoquímicas (CD68, CD206 e Foxp3) - Academia Sinica,}

\section{Taiwan}

Esta etapa do presente estudo foi realizada durante o período de doutorado sanduíche, em colaboração com o Dr. Fu-Tong Liu, no Instituto de Ciências Biomédicas da Academia Sinica, em Taiwan.

As lâminas com cortes de tecido de $5 \mu \mathrm{m}$ foram incubadas com Hemo-De (HD150A, Scientific Safety Solvents), um solvente de baixa toxicidade derivado de Dlimoneno, duas vezes por cinco minutos. Em seguida, foram hidratadas em etanol 100\%, 95\% e 70\%, duas vezes de três minutos em cada um dos banhos e lavadas em água corrente por um minuto. Para recuperação antigênica, utilizou-se panela de pressão elétrica (SR-P37, Panasonic) e tampão citrato pH 6,0 (AP-9003-500, Thermo Scientific), por 10 minutos, posteriormente mantendo as lâminas no tampão por 20 minutos à temperatura ambiente. Após lavagem em água corrente e em PBS Tween 0,1\%, por 10 minutos, incubou-se com solução de bloqueio da peroxidase endógena (TA-125-H2O2Q, ThermoFisher Scientific) por 15 minutos, seguida de lavagem em PBS Tween 0,1\% por 10 minutos e solução de bloqueio de ligações inespecíficas (Ultra V Block, TA-060-UB, ThermoFisher Scientific) por 15 minutos. Em seguida, incubouse com anticorpo primário (ou controles de isotipo) por 1h30: anti-CD68 (bs-0649R,

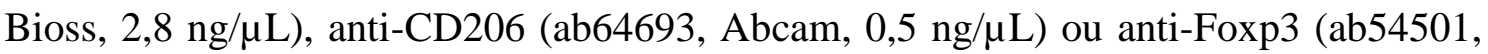
Abcam, 2,8 ng/ $\mu \mathrm{L})$. Após lavagem em tampão PBS Tween $0,1 \%$ por 10 minutos, incubou-se com o polímero de HRP (do inglês, horseradish peroxidase) anti-coelho (Histofine Simple Stain Mouse MAX PO, Nichirei Biosciences) por 30 minutos, lavando-se novamente em tampão por 10 minutos. Adicionou-se a solução de substrato da peroxidase ImmPACT DAB (SK-4105), na marcação para CD68 e CD206 nos 
tumores, ou VECTOR VIP (SK-4600), na marcação para Foxp3 nos tumores e CD68 e CD206 nas peles (Vector Laboratories). ImmPACT DAB por um minuto ou VECTOR VIP por 5 minutos, lavando-se em água corrente. A contracoloração foi com hematoxilina (QS H-3404, Vector Laboratories) quando se usou ImmPACT DAB ou com verde de metilo 0,5\% (em acetato de sódio $0,1 \mathrm{M}, \mathrm{pH} 4,2$ ) a $65^{\circ} \mathrm{C}$ quando se usou VECTOR VIP. Após lavagem em água corrente, os cortes foram desidratados em etanol 70\%, 95\% e 100\% por cinco minutos cada e em Hemo-De por três vezes de cinco minutos. Utilizou-se Entellan new para a montagem das lâminas. Para quantificação das reações, 20 (tumor) ou 10 (pele) campos independentes de cada secção de tecido em cada situação foram capturados utilizando-se lente objetiva de 40x. Para quantificação do número de células positivas por área $\left(\mathrm{em} \mathrm{mm}^{2}\right.$ ), foram contadas as células com marcação positiva, dividindo-se este valor pela área total dos campos fotografados. Para análise de área relativa positiva, calculou-se a porcentagem da área com positividade (estabelecendo um limiar específico para cada marcador) em relação à área total dos campos fotografados.

\subsection{Coloração com Picrossirius}

Realizou-se esta coloração para visualização das fibras de colágeno, principal componente do tecido conjuntivo. Primeiramente, as lâminas foram desparafinadas em dois banhos de xilol de 10 minutos, seguidos de etanol 100\% e 95\% por cinco minutos, etanol 70\% por 10 minutos e lavagem em água corrente. As lâminas foram imersas por uma hora no corante Picrossirius (0,2 g de Sirius Red em 100 mL de solução saturada de ácido pícrico), lavadas em água corrente e contra-coradas com hematoxilina de 
Harris por três minutos. Em seguida, foram lavadas novamente em água corrente e desidratadas em banhos de etanol $70 \%$ e $95 \%$ por cinco minutos, etanol $100 \%$ por 10 minutos, etanol:xilol (v:v) por cinco minutos e dois banhos de xilol por 10 minutos. A montagem das lâminas foi feita com Entellan new (Merck).

A observação e documentação das lâminas foram realizadas em microscópio óptico Olympus acoplado a um sistema de Captura Nikon DMX1200 e software ACT-1. Para quantificação das reações, 20 campos independentes de cada secção de tecido foram capturados utilizando-se lente objetiva de 20x e analisados calculando-se a área relativa das fibras colágenas coradas em vermelho, com o auxílio do software ImageJ (NIH).

\subsection{ELISA (Enzyme-Linked Immunosorbent Assay) para VEGF}

Os fragmentos tumorais destinados ao ensaio de ELISA "sanduíche" para detecção de VEGF-A (900-K99, kit PeProtech) foram primeiramente processados para extração proteica. Após armazenamento em freezer a $-80^{\circ} \mathrm{C}$, adicionou-se o tampão de extração proteica NP40 (Life Technologies) e as amostras passaram pelo sonicador (Sonic Dismembrator Model 100, Fisher Scientific). Em seguida, foram mantidas em gelo por 30 minutos e centrifugadas a $13000 \mathrm{rpm}$ por 10 minutos a $4^{\circ} \mathrm{C}$. O sobrenadante corresponde ao extrato proteico total. A quantificação de proteínas totais foi realizada pelo ensaio de BCA (ácido bicinconínico).

Placas de 96 poços foram incubadas overnight com anticorpo de captura do kit $(1 \mu \mathrm{g} / \mathrm{mL})$, lavadas quatro vezes e incubadas com PBS-1\% BSA para bloqueio por uma hora. Os extratos proteicos foram adicionados às placas por duas horas, lavados, 
seguindo-se a incubação com anticorpo de detecção $(0,5 \mu \mathrm{g} / \mathrm{mL})$ por duas horas. Incubou-se com conjugado avidina-HRP por 30 minutos e após lavagem, utilizou-se a solução substrato: 2 mg de o-fenilenodiamina diidrocloreto (OPD) (Sigma-Aldrich) e 2 $\mu \mathrm{L}$ de $\mathrm{H}_{2} \mathrm{O}_{2} 30 \%$ em $5 \mathrm{~mL}$ de tampão citrato-fosfato $\mathrm{pH}$ 5,0. Todas as lavagens foram realizadas com PBS-0,1\% BSA-0,05\% Tween 20. Para parar a reação, utilizou-se ácido sulfúrico 2 M e a leitura foi realizada em espectrofotômetro com filtro de $492 \mathrm{~nm}$. Calculou-se a razão da concentração de VEGF pela concentração de proteínas totais para cada amostra.

\subsection{Análises de expressão gênica por PCR quantitativo em tempo real (qPCR)}

Para a extração do RNA total dos tumores armazenados a $-80^{\circ} \mathrm{C}$ utilizou-se a metodologia de Trizol. Inicialmente, cada amostra (100 a $400 \mathrm{mg}$ ) foi homogeneizada em Polytron com 1,5 mL de Trizol (Invitrogen), lavando-se com etanol 70\% e água DEPC (dietilpirocarbonato, Merck) entre as amostras. Em seguida, permaneceram à temperatura ambiente por cinco minutos e foram centrifugadas a 12000 g por 10 minutos a $4^{\circ} \mathrm{C}$. O sobrenadante foi coletado e adicionou-se $300 \mu \mathrm{L}$ de clorofórmio em cada amostra, homogeneizando-as por inversão por 15 segundos e incubando-as por 2 minutos à temperatura ambiente. Após centrifugação a 12000 g por 15 minutos a $4^{\circ} \mathrm{C}$, coletou-se a fase aquosa (superior) contendo RNA, adicionando-se $750 \mu \mathrm{L}$ de álcool isopropílico (Merck) por amostra. Após incubação à temperatura ambiente por 10 minutos, centrifugou-se a 12000 g por 10 minutos a $4^{\circ} \mathrm{C}$ e o sobrenadante foi descartado cuidadosamente. O pellet foi lavado duas vezes com $1,5 \mathrm{~mL}$ de etanol $75 \%$ e homogeneizado utilizando-se o vortex. Após centrifugação a 7500 g por 5 minutos a 
$4^{\circ} \mathrm{C}$, descartou-se o sobrenadante e o tubo com o pellet de RNA permaneceu aberto para evaporação do etanol à temperatura ambiente. Por fim, dissolveu-se o RNA em $100 \mu \mathrm{L}$ de água DEPC, homogeneizando e incubando-se por 10 minutos a $60^{\circ} \mathrm{C}$ em banho seco.

A quantificação do RNA obtido foi determinada por espectrofotometria a 260 nm, sendo avaliadas as razões 260/280 e 260/230 (NanoDrop 1000, Thermo Scientific) e a integridade do RNA, por gel de agarose.

Para a reação de transcrição reversa, utilizou-se o kit High Capacity RNA-tocDNA (4387406, ThermoFisher Scientific). Para cada reação, foram utilizados $10 \mu \mathrm{L}$ de tampão, $1 \mu \mathrm{L}$ de mix de enzimas, $2 \mu \mathrm{g}$ de RNA, completando-se com água ultrapura para um volume de $20 \mu \mathrm{L}$. As amostras foram incubadas no termociclador a $37^{\circ} \mathrm{C}$ por 60 minutos e $95^{\circ} \mathrm{C}$ por 5 minutos e o cDNA (DNA complementar) sintetizado foi estocado a $-20^{\circ} \mathrm{C}$.

Para a Reação em Cadeia da Polimerase (PCR) quantitativa utilizou-se a metodologia do SYBR Green, na qual um fluoróforo se liga ao DNA dupla fita, aumentando sua fluorescência ao longo da reação. Primeiramente, foram realizadas as curvas padrão para testar as eficiências para cada par de primers, utilizando-se 5 pontos de diluição em triplicata (100 ng, 50 ng, 25 ng, 12,5 ng e 6,25 ng de cDNA), 6,25 $\mu \mathrm{L}$ de Power SYBR Green PCR Master Mix (Life Technologies), 240 nM de cada primer, completando-se com água ultra-pura para um volume final de 12,5 $\mu \mathrm{L}$. 
TABELA 01. Primers utilizados nos experimentos de PCR quantitativa:

\begin{tabular}{ccc}
\hline Primer & Senso 5' $\mathbf{-}$ ' & \multicolumn{1}{c}{ Anti-senso 5' $\mathbf{~} \mathbf{3}$} \\
\hline Lgals3 & GAGAGTGGCAAACCATTCAAA & ACTGCAGTAGGTGAGCATCGT \\
Nos2/iNOS & CAGGAACCTACCAGCTCACTCT & ATGTGCTGAAACATTTCCTGTG \\
Il1b & TGGGATCCTCTCCAGCCAAGCTT & TCAGGACAGCCCAGGTCAAAGG \\
Ifng & TCAAGTGGCATAGATGTGGAAG & GGATTTTCATGTCACCATCCTT \\
Arg1 & GAACCCAACTCTTGGGAAGAC & GGAGAAGGCGTTTGCTTAGTT \\
Cd206 & TTTGCAAGCTTGTAGGAAGGA & CCAATCCACAGCTCATCATTT \\
Il10 & ACTTGCTCTTGCACTACCAAAGCC & GCATGTGGCTCTGGCCGACTG \\
Hprt & AGGCCAGACTTTGTTGGATTT & GGCTTTGTATTTGGCTTTTCC \\
\hline
\end{tabular}

As condições de amplificação foram: $50^{\circ} \mathrm{C}$ por dois minutos, $95^{\circ} \mathrm{C}$ por 10 minutos, 40 ciclos de $95^{\circ} \mathrm{C}$ por 15 segundos e $60^{\circ} \mathrm{C}$ por um minuto. As eficiências de amplificação dos primers foram calculadas de acordo com a equação $\mathrm{E}=10^{(-1 / \text { slope })}$, onde o slope corresponde à inclinação da reta obtida quando se analisa a variação do $\mathrm{C}_{\mathrm{T}}$ (do inglês, Cycle Threshold) do transcrito alvo e do normalizador em função do log de diferentes quantidades de cDNA. Como normalizador, foi utilizado o gene endógeno Hprt, não havendo expressão relativa diferenciada deste gene entre os grupos experimentais.

Na análise de expressão diferencial dos genes, utilizou-se 12,5 ng de cDNA. A quantificação relativa baseou-se no cálculo da expressão dos genes alvos no grupo de animais Gal-3 KO (grupo de interesse) em relação aos animais WT (grupo referência), utilizando-se o modelo matemático $2^{-\Delta \Delta \mathrm{CT}}$ de Livak e Schmittgen (2001), sendo:

$\Delta \mathrm{C}_{\mathrm{T}}=$ média $\mathrm{C}_{\mathrm{T}}$ do gene alvo - média do $\mathrm{C}_{\mathrm{T}}$ do gene endógeno

$\Delta \Delta \mathrm{C}_{\mathrm{T}}=\Delta \mathrm{C}_{\mathrm{T} \text { grupo de interesse }}-\Delta \mathrm{C}_{\mathrm{T} \text { grupo referência }}$ 
Este modelo matemático foi utilizado porque os primers apresentaram eficiência de $100 \%$ (considerado entre 90 e 110\%).

\subsection{Análises estatísticas}

As curvas de Kaplan-Meier foram submetidas ao teste de log-rank. Os demais dados foram comparados e analisados pelo teste não paramétrico de Mann-Whitney, para dois grupos independentes. Foram consideradas estatisticamente significativas as comparações com valor de p menor que 0,05 ( $\mathrm{p}<0,05)$. Utilizou-se o software GraphPad Prism 5 para o tratamento estatístico. 


\section{RESULTADOS}

A indução química de sarcomas foi realizada utilizando-se o carcinógeno MCA, em camundongos WT e Gal-3 KO, os quais receberam duas injeções subcutâneas, com oito semanas de intervalo entre elas. Os animais começaram a apresentar o crescimento de tumores após a segunda injeção de MCA. Na FIGURA 05, estão representadas as curvas de Kaplan-Meier dos animais utilizados em três experimentos independentes, iniciando-se a análise após a segunda injeção de MCA (quando geralmente se inicia o crescimento tumoral). Nenhum dos animais inoculados apenas com veículo de diluição (grupos WT CTL e KO CTL) desenvolveu tumor até o final de cada experimento. Dentre os animais WT (n=34) e Gal-3 KO $(n=35)$ que foram inoculados com MCA, $64,71 \%$ e 62,86\%, respectivamente, desenvolveram tumor ao longo do período de estudo (TABELA 02), que variou de 8 a 11 semanas após a segunda injeção de MCA. As curvas de Kaplan-Meier não apontam diferenças significativas entre o grupo de animais WT e o grupo de animais Gal-3 KO que receberam MCA. Portanto, a presença ou ausência de gal-3 neste modelo não interferiu no aparecimento e crescimento das massas tumorais.

Nos grupos de camundongos inoculados apenas com veículo de diluição (CTL), um animal WT e seis animais Gal-3 KO apresentaram apenas granulomas (pequenas e delimitadas agregações nodulares compostas principalmente por macrófagos), resultado de uma reação inflamatória localizada. 


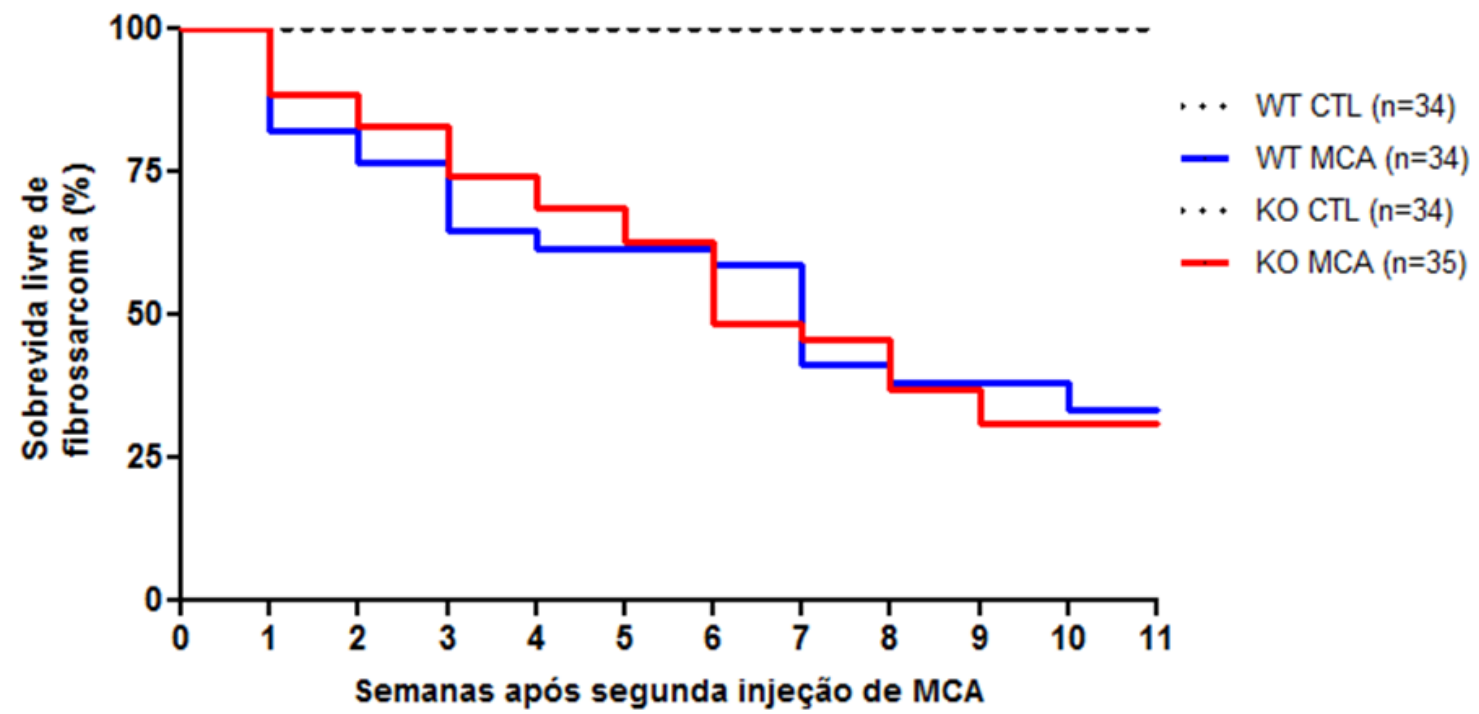

FIGURA 05. Curvas de Kaplan-Meier de camundongos WT e Gal-3 KO após segunda injeção de MCA ou veículo. Os animais receberam duas injeções subcutâneas de MCA ou apenas veículo (CTL), com um intervalo de oito semanas entre elas. Estão representados três grupos experimentais independentes. Resultados submetidos ao teste de log-rank.

TABELA 02. Número e porcentagem de animais que desenvolveram tumor nos grupos de camundongos WT e Gal-3 KO que foram inoculados com MCA, nos três experimentos independentes.

\begin{tabular}{ccc}
\hline Animais & $\begin{array}{c}\mathbf{N}^{\text {o }} \text { de animais que } \\
\text { desenvolveram } \\
\text { tumor (total) }\end{array}$ & $\begin{array}{c}\text { Porcentagem de } \\
\text { animais que } \\
\text { desenvolveram tumor }\end{array}$ \\
\hline WT & $22(34)$ & $64,71 \%$ \\
\hline Gal-3 KO & $22(35)$ & $62,86 \%$ \\
\hline
\end{tabular}

As curvas de crescimento tumoral com os volumes aferidos semanalmente estão representadas na FIGURA 06, incluindo todos os animais inoculados com MCA que desenvolveram tumor, em três experimentos independentes. Cada linha é representativa de um animal. Nota-se que não houve um padrão diferenciado quanto ao tempo 
decorrido para o aparecimento do tumor, nem quanto à taxa de crescimento tumoral, quando comparados camundongos WT e Gal-3 KO.

\section{Curvas de crescimento tumoral após indução com MCA}

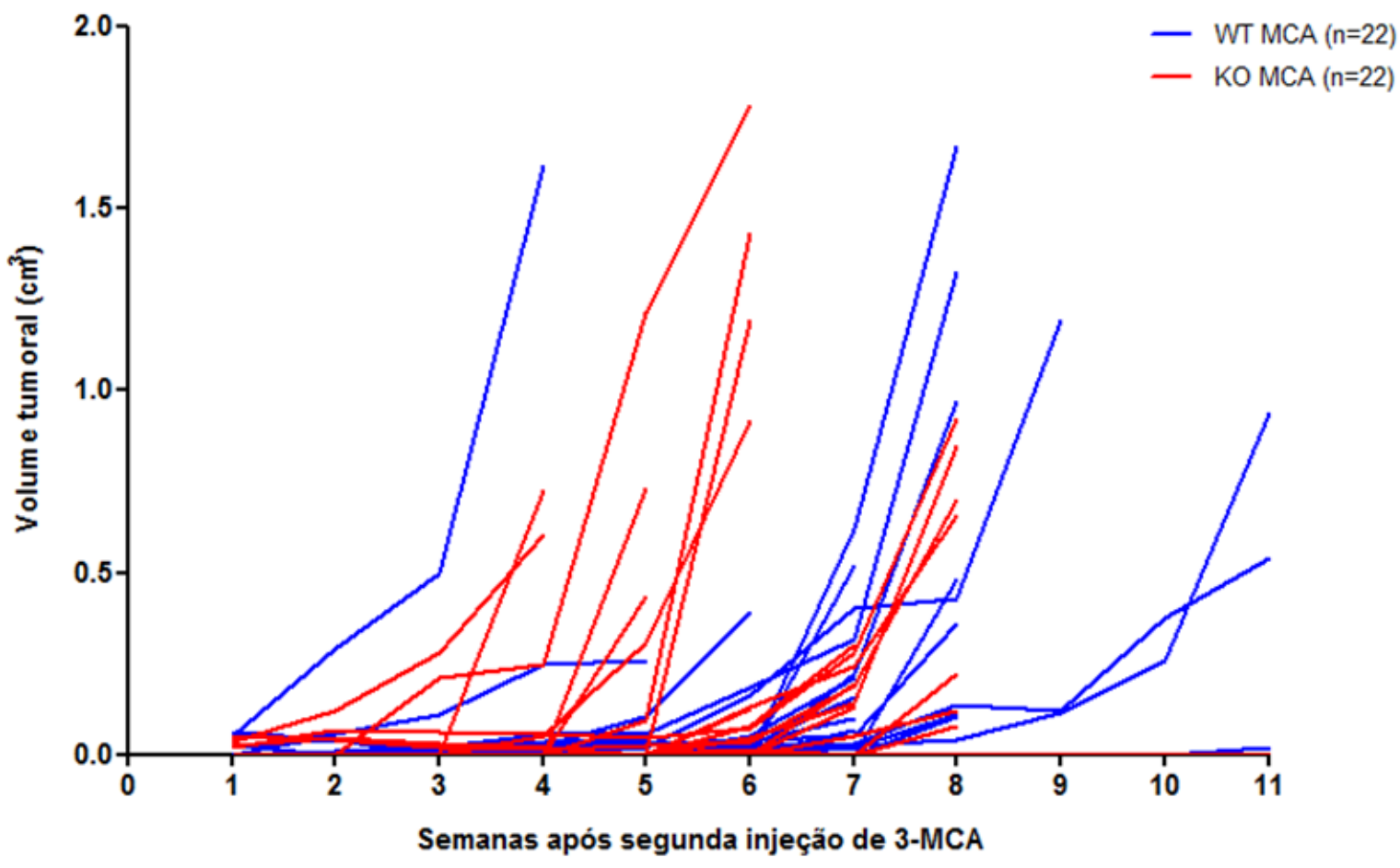

FIGURA 06. Curvas individuais de crescimento tumoral de camundongos WT ou Gal-3 KO que receberam injeção subcutânea de MCA. Estão representados no gráfico três grupos experimentais independentes, sendo cada linha representativa de um animal. As aferições de volume tumoral ocorreram a partir da segunda injeção de MCA.

Os tumores que se desenvolveram tinham contornos regulares, coloração esbranquiçada e consistência firme. Raramente apresentaram ulceração. A análise dos cortes histológicos corados com hematoxilina e eosina evidenciou que as lesões eram bem delimitadas. Especificamente, os sarcomas apresentaram características de uma neoplasia maligna sólida, com aspecto predominantemente fusocelular e alta densidade celular (FIGURA 07). Foram observadas células anaplásicas com elevada relação 
núcleo/citoplasma e presença de figuras de mitose típicas e atípicas. Áreas de necrose eram raras e os vasos capilares apresentavam paredes finas.
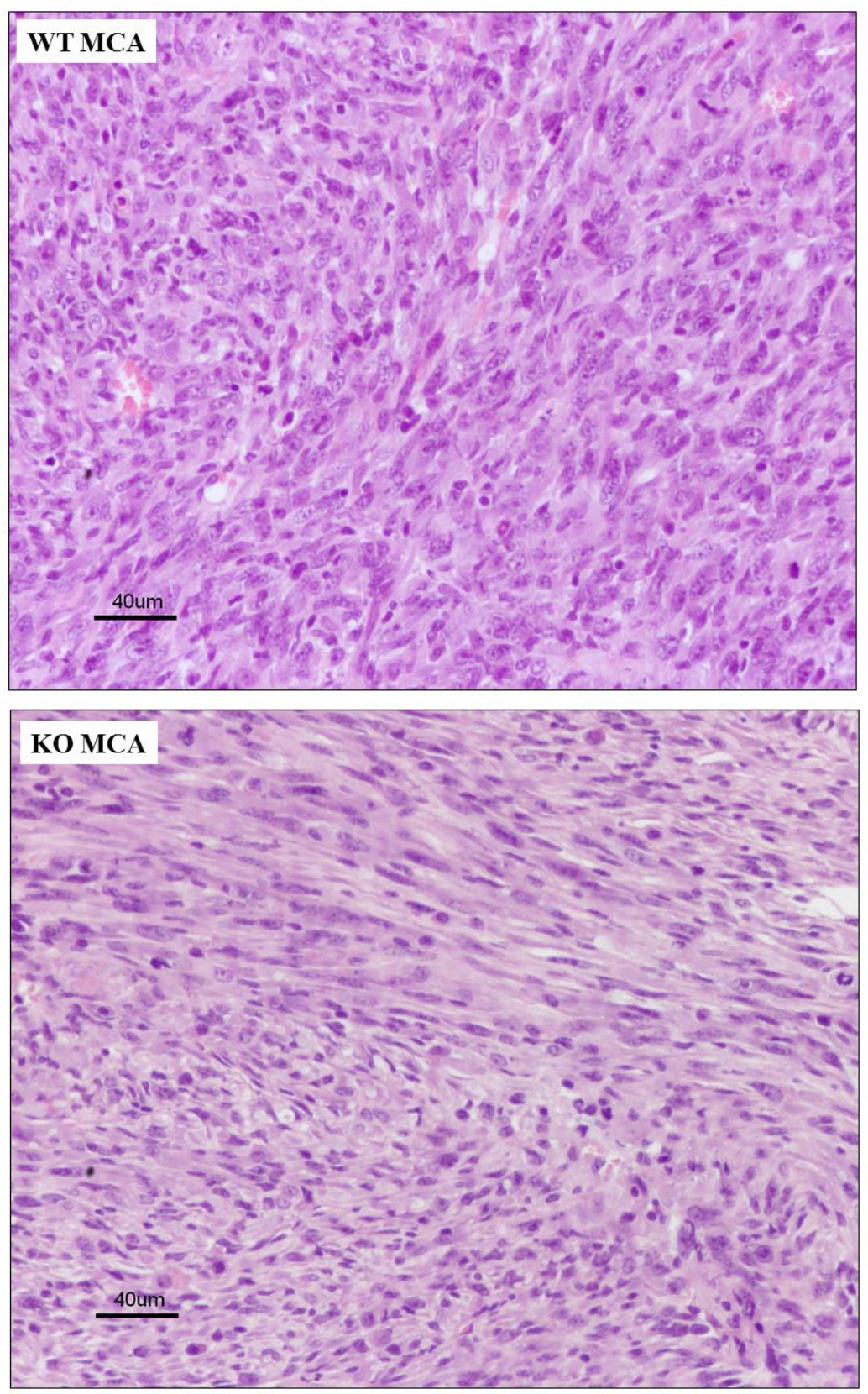

FIGURA 07. Seç̧ões histológicas de sarcomas induzidos por MCA em camundongos WT (WT MCA) e Gal-3 KO (KO MCA). A coloração com hematoxilina e eosina evidencia uma neoplasia sarcomatosa de aspecto fusocelular. 
O próximo passo foi analisar os sarcomas oriundos de camundongos WT e Gal$3 \mathrm{KO}$ quanto à expressão da proteína e do transcrito de gal-3 no microambiente. A análise qualitativa da proteína por imunoistoquímica (IHC) mostrou que gal-3 é altamente expressa nos sarcomas de animais WT, sendo a sua expressão ausente nos animais Gal-3 KO (FIGURA 08A). Nos tumores positivos para gal-3, esta foi observada tanto no núcleo, quanto no citoplasma das células neoplásicas, distribuídas por toda a massa tumoral. A análise de expressão gênica de Lgals3, gene que codifica para gal-3, mostrou que sua expressão em tumores de animais Gal-3 KO representa 0,68\% da expressão que ocorre em tumores de animais WT (FIGURA 08B). 

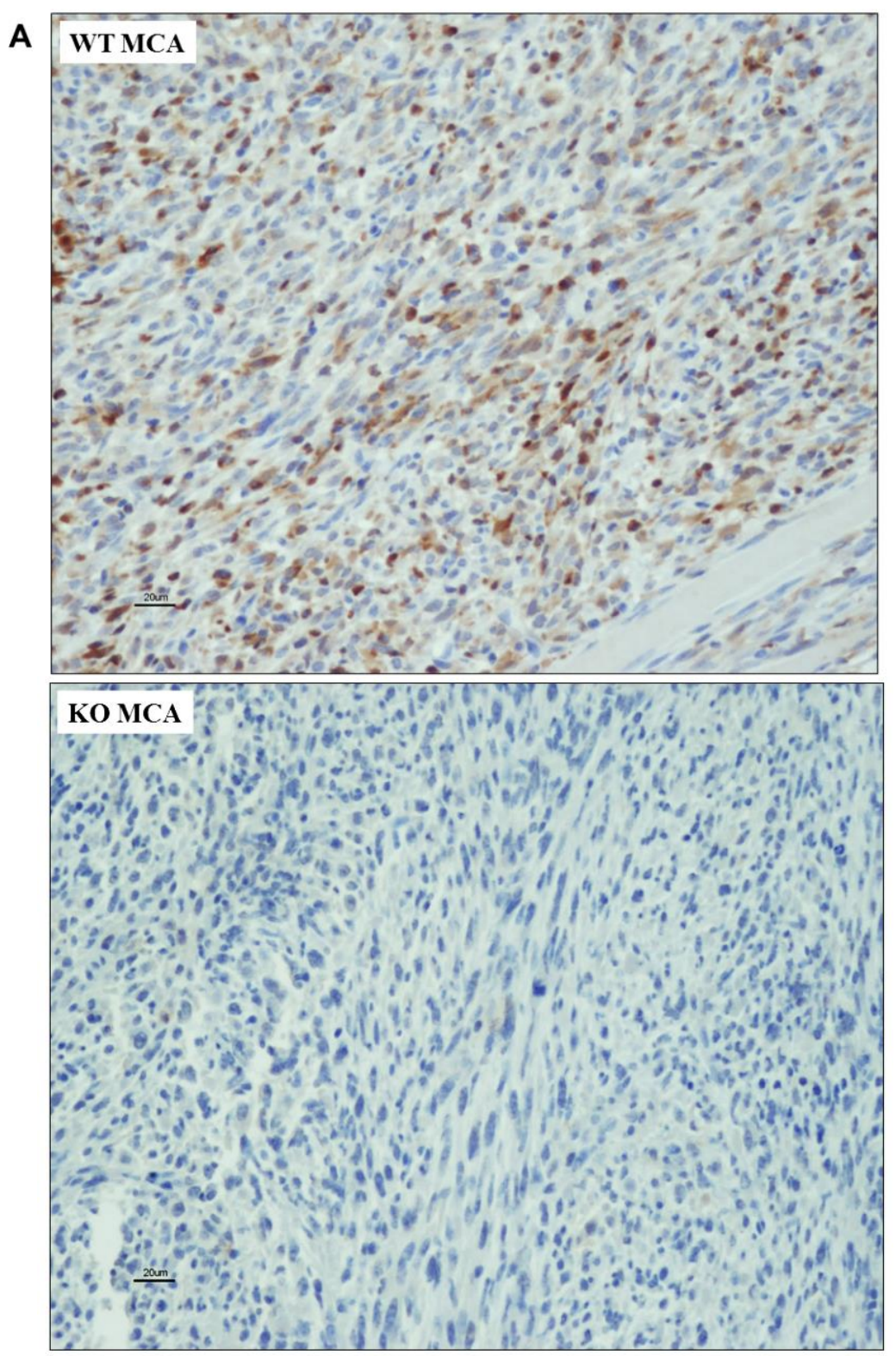

B Expressão relativa de gal-3

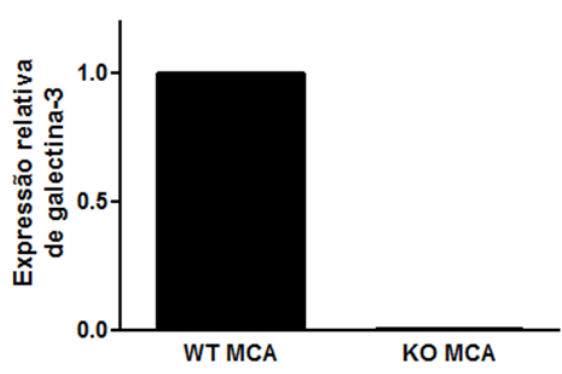

FIGURA 08. Expressão de gal-3 nos sarcomas induzidos por MCA em animais WT (WT MCA) e Gal-3 KO (KO MCA). A) Imunoistoquímica em secções de tumor, onde células positivas para gal-3 apresentam marcação em castanho; B) Expressão do gene Lgals3 por PCR quantitativa (qPCR) normalizada por Hprt, considerando o tumor de animal WT como grupo referência. Dados submetidos ao teste de Mann-Whitney; $\mathrm{p}=0,0159$. 
Considerando-se que gal-3 no meio extracelular pode influenciar na síntese de colágeno, um importante componente da ECM cuja produção é característica do fibrossarcoma, utilizou-se a coloração com Picrossirius para quantificação das fibras de colágeno nos tumores de animais que receberam MCA. As fibras, coradas em vermelho, encontram-se heterogeneamente dispersas pelo tecido tumoral (FIGURA 09A). A quantificação da área relativa ocupada pelas fibras de colágeno nos tumores analisados não indicou diferença significativa $(\mathrm{p}>0,05)$ entre os grupos de animais WT e Gal-3 KO (FIGURA 09B). 

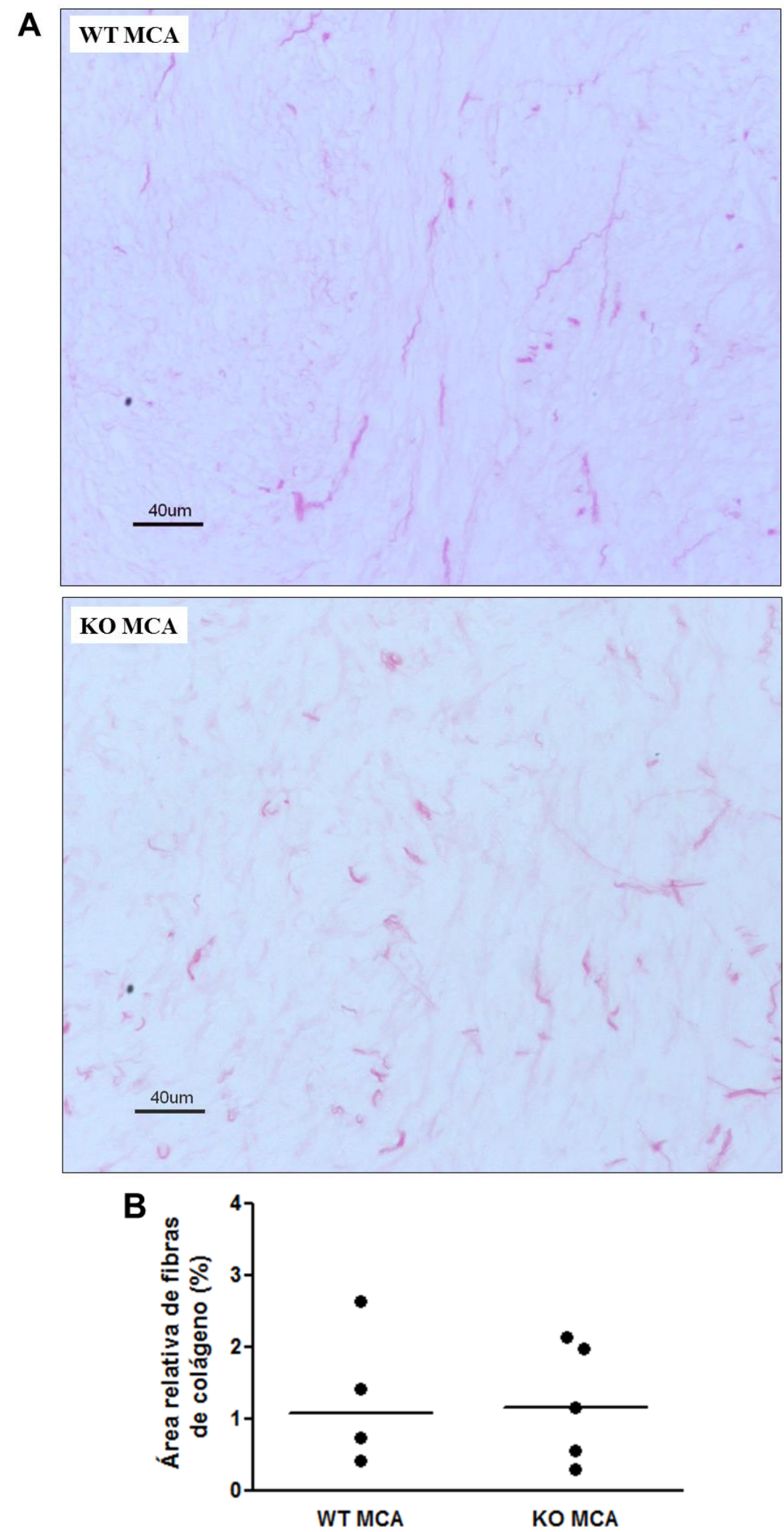

FIGURA 09. Quantificação de fibras de colágeno em sarcomas induzidos por MCA em camundongos WT (WT MCA) e Gal-3 KO (KO MCA). A) Coloração com Picrossirius em secções de tumor, com fibras de colágeno coradas em vermelho; B) Quantificação da área relativa de fibras de colágeno nos tumores. A linha indica a mediana e os dados foram submetidos ao teste de Mann-Whitney. 
A presença de gal-3 no microambiente também não influenciou significativamente no caráter proliferativo dos tumores oriundos de animais WT em comparação aos dos animais Gal-3 KO, sendo a análise realizada pela quantificação de células positivas para o marcador PCNA (antígeno nuclear de proliferação celular), proteína nuclear importante para a síntese de DNA (FIGURA 10). Este resultado foi reforçado pela quantificação de figuras de mitose em cortes histológicos de sarcomas oriundos de camundongos WT e Gal-3 KO (p>0,05; FIGURA 11). 

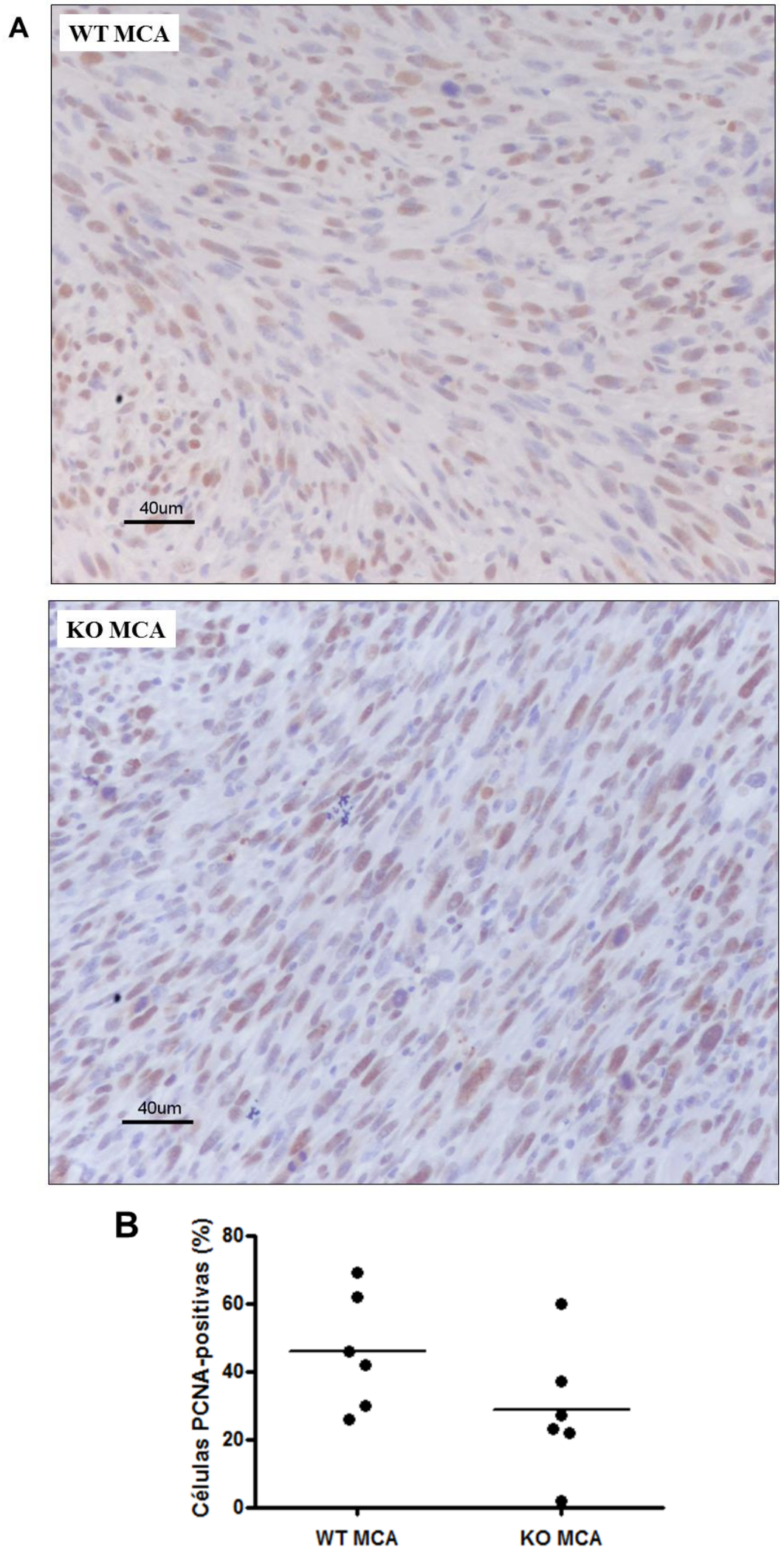

FIGURA 10. Expressão do marcador de proliferação celular PCNA em sarcomas induzidos por MCA em camundongos WT (WT MCA) e Gal-3 KO (KO MCA). A) Imunoistoquímica para PCNA em secções de tumor, com marcação nuclear em castanho; B) Porcentagem de células positivas para PCNA nos tumores. A linha indica a mediana e os dados foram submetidos ao teste de Mann-Whitney. 


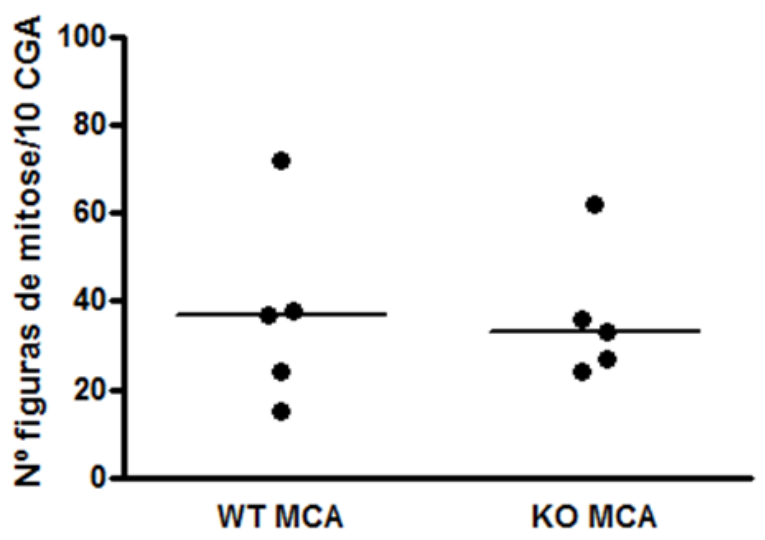

FIGURA 11. Quantificação de figuras mitóticas em sarcomas induzidos por MCA em camundongos WT (WT MCA) e Gal-3 KO (KO MCA). Número de figuras de mitose por 10 campos de grande aumento (CGA) em secções histológicas de tumor coradas com hematoxilina e eosina. A linha indica a mediana e os dados foram submetidos ao teste de Mann-Whitney.

Corroborando o fato de que não houve diferença significativa no crescimento tumoral entre os grupos WT e Gal-3 KO, a quantificação de áreas necróticas nos sarcomas indicou que a presença de gal-3 no microambiente não alterou a necrose neste modelo. Ambos os grupos de animais apresentaram baixas porcentagens de áreas de necrose (FIGURA 12). Dentre os camundongos WT (n=5), um teve $1 \%$ e, dentre os Gal-3 KO (n=7), dois tiveram 0,81\% de área necrótica relativa. Os demais não apresentaram necrose quantificável através deste método. 


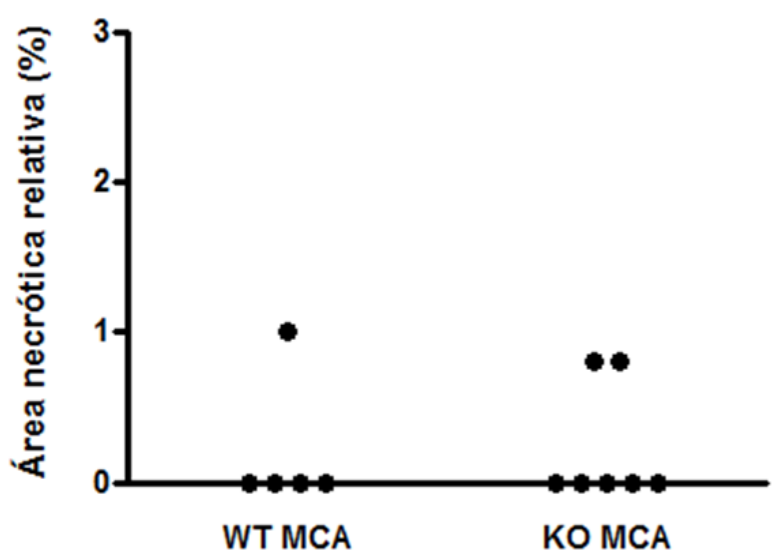

FIGURA 12. Quantificação de áreas necróticas em sarcomas induzidos por MCA em camundongos WT (WT MCA) e Gal-3 KO (KO MCA). A quantificação da área necrótica relativa foi calculada em porcentagem, em relação à área total das imagens analisadas. Dados submetidos ao teste de Mann-Whitney.

Visto que não houve diferenças significativas no caráter proliferativo e nas áreas de necrose nos sarcomas que se desenvolveram na presença de gal-3 ou em sua ausência, o próximo passo foi avaliar a densidade vascular destes tumores. Utilizou-se o marcador de células endoteliais vasculares, CD34, cuja expressão foi observada em ambos os grupos (FIGURA 13A). A quantificação de células positivas para este marcador mostrou que os tumores de animais Gal-3 KO apresentam uma densidade vascular significativamente menor, em comparação aos dos animais WT (FIGURA 13B). 

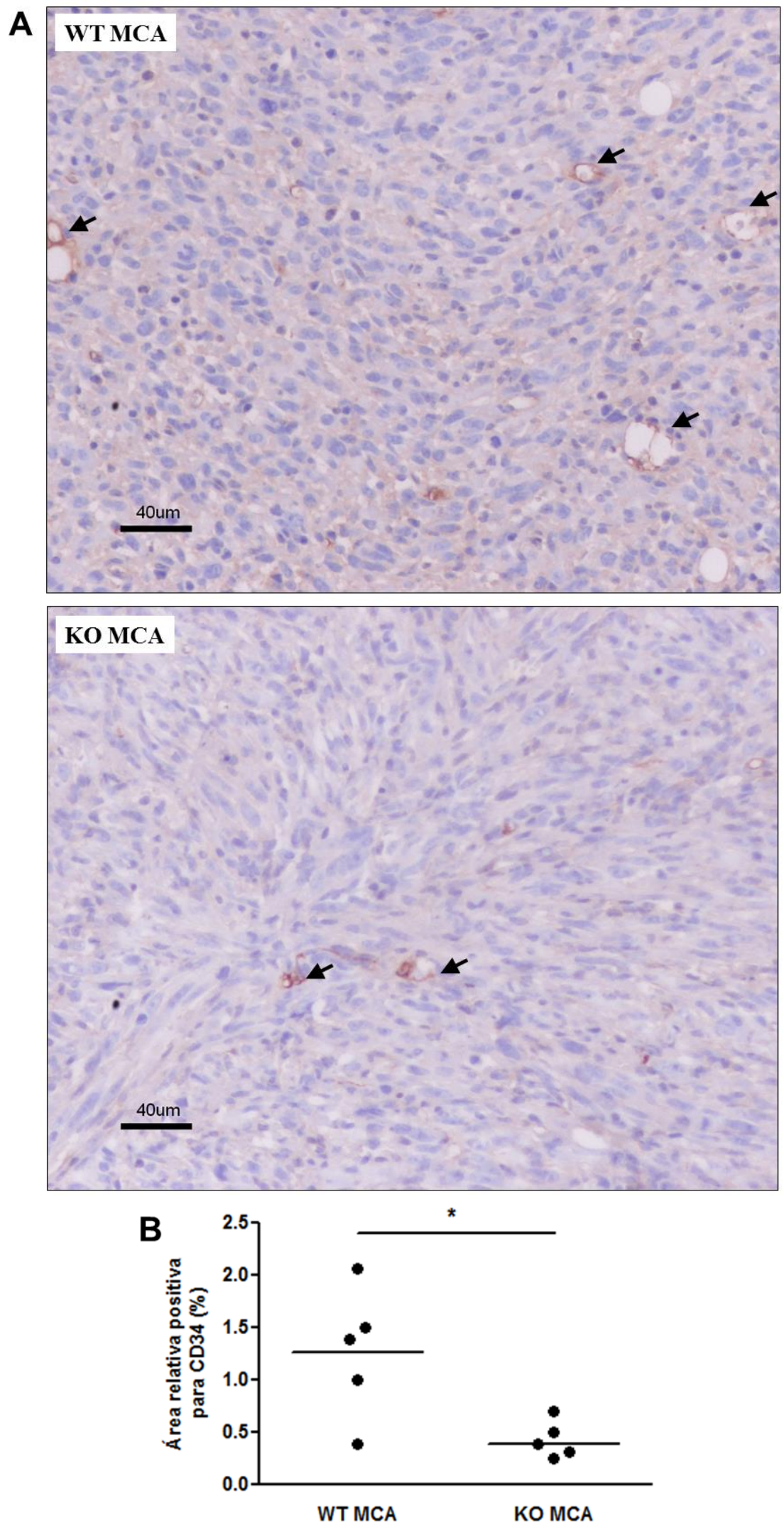

FIGURA 13. Marcação para CD34 em sarcomas induzidos por MCA em camundongos WT (WT MCA) e Gal-3 KO (KO MCA). A) Imunoistoquímica para CD34 em secções de tumor, onde vasos sanguíneos (setas) encontram-se marcados em castanho. B) Área relativa positiva para CD34 em secções de tumor. A linha indica a mediana e os dados foram submetidos ao teste de Mann-Whitney; ${ }^{*} \mathrm{p}<0,05$. 
Apesar da alteração encontrada na densidade vascular, a expressão proteica de VEGF, fator importante na via de sinalização da angiogênese, não indicou diferença significativa entre os tumores que expressam gal-3 e os que não a expressam $(p>0,05)$ (FIGURA 14).

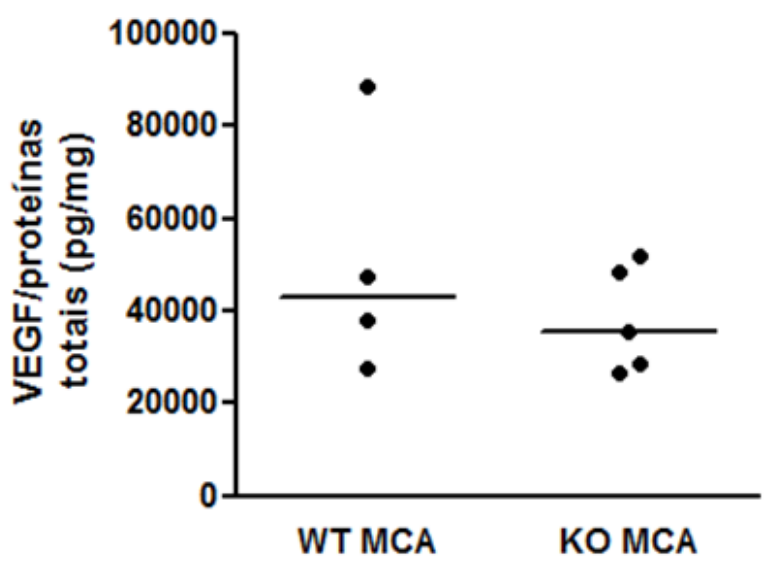

FIGURA 14. Expressão relativa de VEGF em sarcomas induzidos por MCA em camundongos WT (WT MCA) e Gal-3 KO (KO MCA). Relação VEGF/proteínas totais detectada por ELISA "sanduíche" realizada com os extratos proteicos de tumor. Resultado representativo de três experimentos independentes. A linha indica a mediana e os dados foram submetidos ao teste de Mann-Whitney.

A fim de se analisar o caráter funcional da vasculatura intratumoral utilizando metodologias aplicadas ao animal vivo, foram propostas deste trabalho utilizar a US com color Doppler e a PET/CT para avaliação de aspectos que estão relacionados à angiogênese. Alguns dos camundongos que estavam com tumores que atingiram aproximadamente $1 \mathrm{~cm}^{3}$ foram submetidos ao procedimento de US, que possibilita a medição da velocidade de fluxo sanguíneo em vasos de interesse.

A avaliação das velocidades de fluxo comparando todos os vasos examinados não mostrou diferença significativa entre os animais WT e Gal-3 KO (FIGURA 15A). 
Quando comparados vasos peritumorais (representados na FIGURA 16A) e intratumorais (representados na FIGURA 16B) separadamente, camundongos WT e Gal-3 KO não diferem quanto aos vasos peritumorais (FIGURA 15B). Entretanto, camundongos Gal-3 KO apresentaram velocidade média de fluxo sanguíneo significativamente reduzida em vasos intratumorais ( $<<0,05$; FIGURA 15C). Por sua vez, vasos que se localizam no interior do tumor, tanto em camundongos WT quanto Gal-3 KO, tiveram velocidades de fluxo sanguíneo mais elevadas em relação aos vasos peritumorais $(\mathrm{p}<0,01)$. É importante ressaltar que no momento da excisão tumoral, em alguns camundongos Gal-3 KO, foi observada, macroscopicamente, maior quantidade de sangue em áreas adjacentes ao tumor, em relação aos camundongos WT. É provável que o sangue adjacente ao tumor também tenha sido evidenciado pela US de alguns animais Gal-3 KO, como ilustrado na FIGURA 16C. 
A Todos os vasos
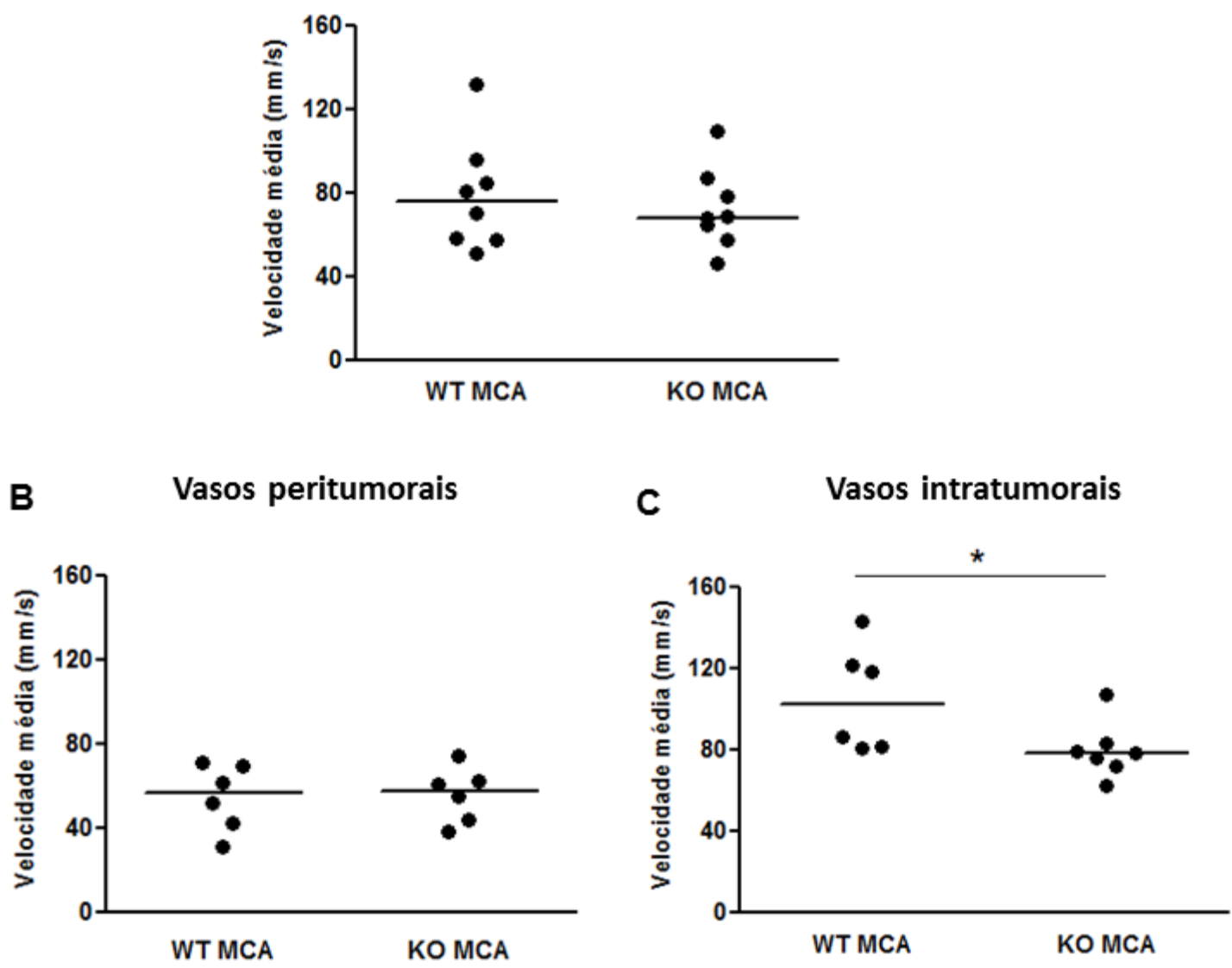

FIGURA 15. Velocidades médias de fluxo sanguíneo em vasos tumorais obtidas por ultrassonografia com color Doppler em sarcomas induzidos por MCA em camundongos WT (WT MCA) ou Gal-3 KO (KO MCA). A) Velocidades médias considerando todos os vasos sanguíneos estudados; B) apenas vasos peritumorais; C) apenas vasos intratumorais. A linha indica a mediana e os dados foram submetidos ao teste de Mann-Whitney; ${ }^{*} \mathrm{p}<0,05$. 
Ultrassonografia com Doppler
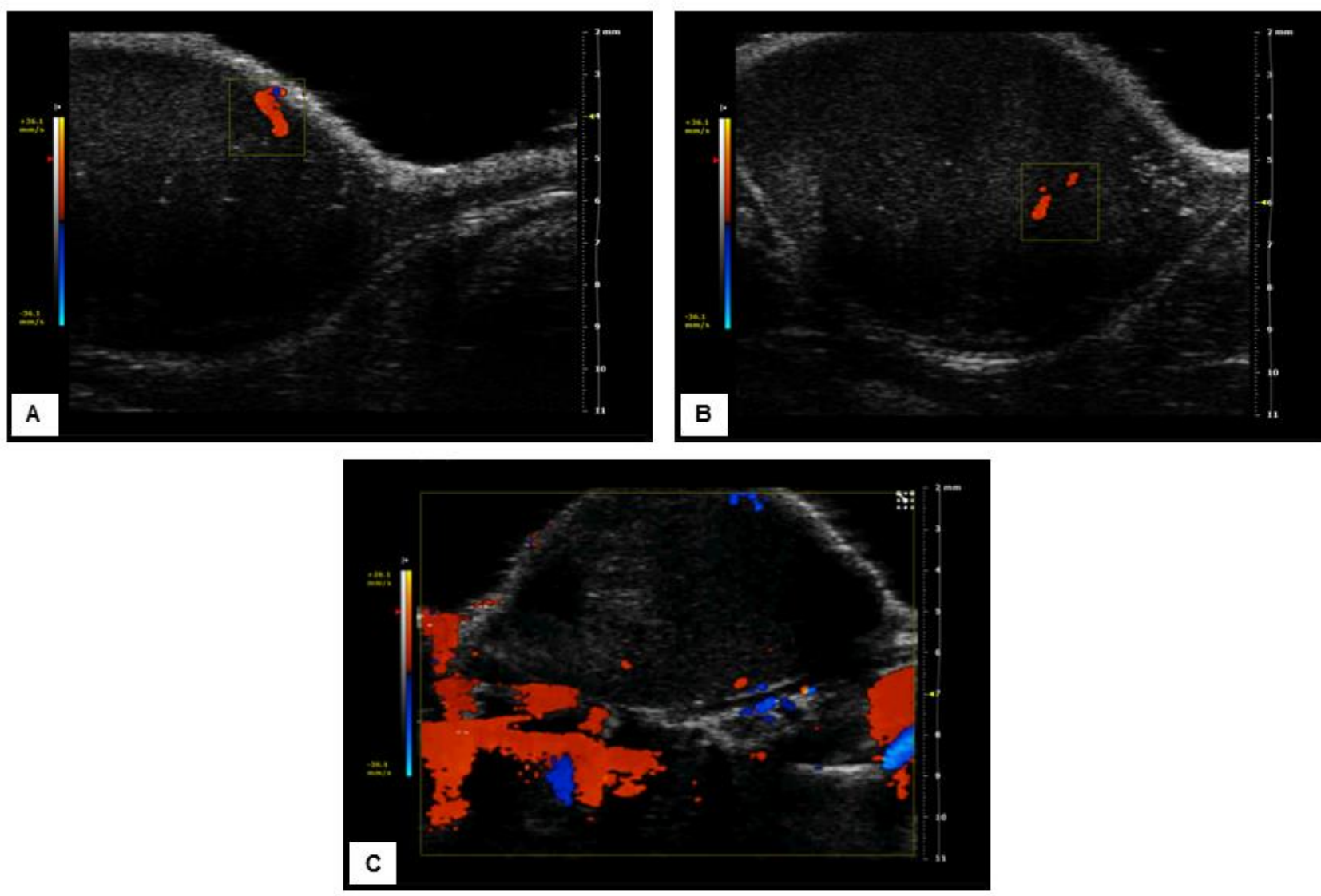

FIGURA 16. Imagens obtidas por ultrassonografia (US) com color Doppler de sarcomas induzidos por MCA em camundongos WT ou Gal-3 KO. Imagens representativas de US de tumor evidenciando, em vermelho, vaso peritumoral (A) ou intratumoral (B). C) Imagem representativa mostrando o fluxo sanguíneo em região adjacente ao tumor em animal Gal-3 KO. As cores vermelho e azul indicam fluxo na direção do transdutor e em direção oposta, respectivamente.

Alguns animais que desenvolveram tumores de aproximadamente $1 \mathrm{~cm}^{3}$ foram submetidos a PET/CT com administração via intravenosa de ${ }^{18}$ F-FDG, um análogo da glicose. Assim, sua captação pelo tecido tumoral, caracterizado por elevada taxa de glicólise, é um reflexo do metabolismo tecidual e também da funcionalidade da vasculatura que irriga o tumor. Imagens representativas da PET/CT dos camundongos WT (FIGURA 17) e Gal-3 KO (FIGURA 18) mostram cortes nos planos coronal, 
transversal e sagital. As imagens de CT possibilitam a localização anatômica do tumor (ROI azul) e as imagens de PET indicam o grau de captação do radiofármaco ${ }^{18}$ F-FDG em cada tecido, representado por uma escala que se inicia na cor preta (sem captação), até a cor vermelha (captação máxima). Em alguns casos, houve captação relativamente alta nos músculos e/ou gordura marrom, devido à atividade física e/ou frio, respectivamente, ou mesmo na cauda, local onde foi realizada a injeção. Nestes casos, foi necessário descartar as imagens dos animais do estudo.

Em geral, tumores de animais WT, como o identificado pela ROI azul na FIGURA 17, apresentaram uma captação de ${ }^{18}$ F-FDG relativamente homogênea, representada pela coloração verde/amarela. Por sua vez, em alguns animais Gal-3 KO (FIGURA 18), a captação não foi tão homogênea, havendo um foco em vermelho no tumor, o que indica maior incorporação do radiofármaco nesta região do tecido. 


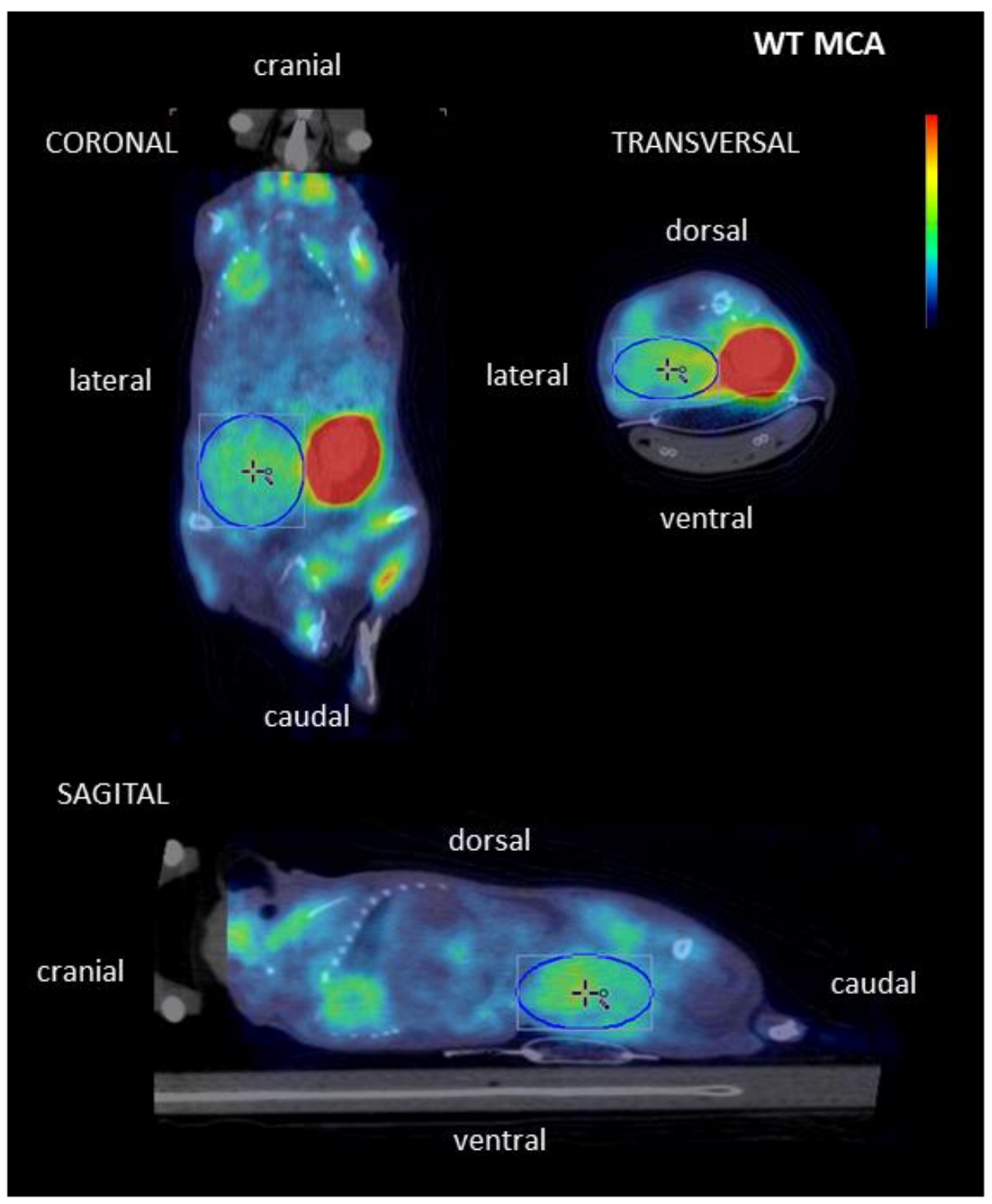

FIGURA 17. Imagens de PET/CT com fluodeoxiglicose $\left({ }^{18}\right.$ F-FDG) de camundongo WT com sarcoma induzido por MCA. Animal em cortes nos planos coronal, transversal e sagital. O tumor está identificado pela ROI azul e o grau de captação de ${ }^{18}$ F-FDG está representado pela escala de cores, onde o vermelho representa as regiões de captação mais elevada (neste caso, a bexiga). 


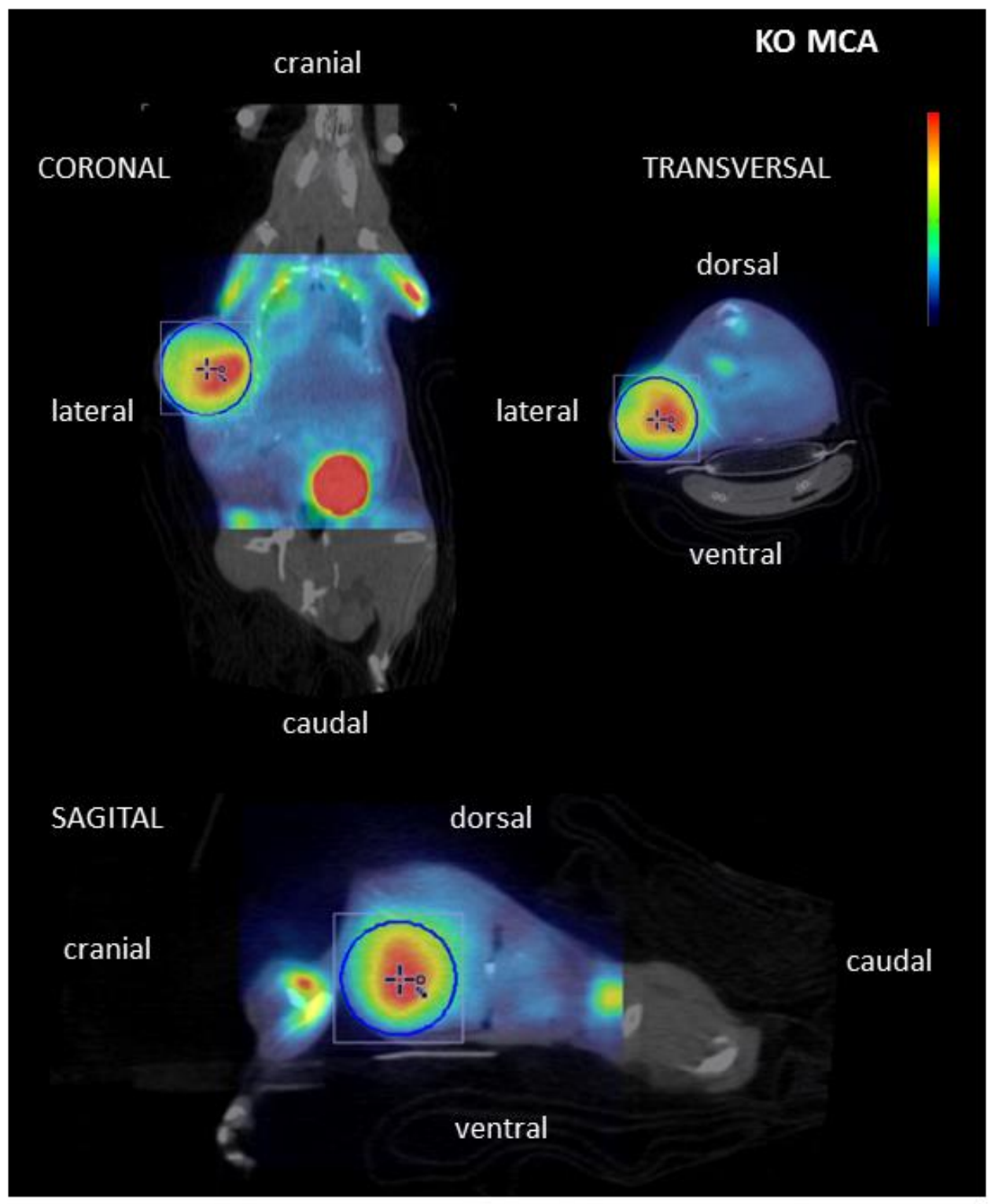

FIGURA 18. Imagens de PET/CT com fluodeoxiglicose $\left({ }^{18}\right.$ F-FDG) de camundongo Gal-3 KO com sarcoma induzido por MCA. Animal em cortes nos planos coronal, transversal e sagital. O tumor está identificado pela ROI azul e o grau de captação de ${ }^{18}$ F-FDG está representado pela escala de cores, onde o vermelho representa as regiões de captação mais elevada (neste caso, a bexiga e a região do tumor em vermelho).

A quantificação da incorporação de ${ }^{18}$ F-FDG pelo tecido tumoral foi realizada de três maneiras: a) atividade total (kBq)/volume (FIGURA 19A); b) atividade máxima (kBq)/volume (FIGURA 19B); c) SUV, que considera a atividade injetada e a massa 
corporal (FIGURA 19C). No caso de a e b, os cálculos foram feitos para a ROI do tumor e para a ROI contralateral de mesmo volume, por fim dividindo-se o valor do tumor pelo valor do contralateral. As quantificações não mostraram diferença significativa na captação de ${ }^{18}$ F-FDG entre os tumores de animais WT e Gal-3 KO.
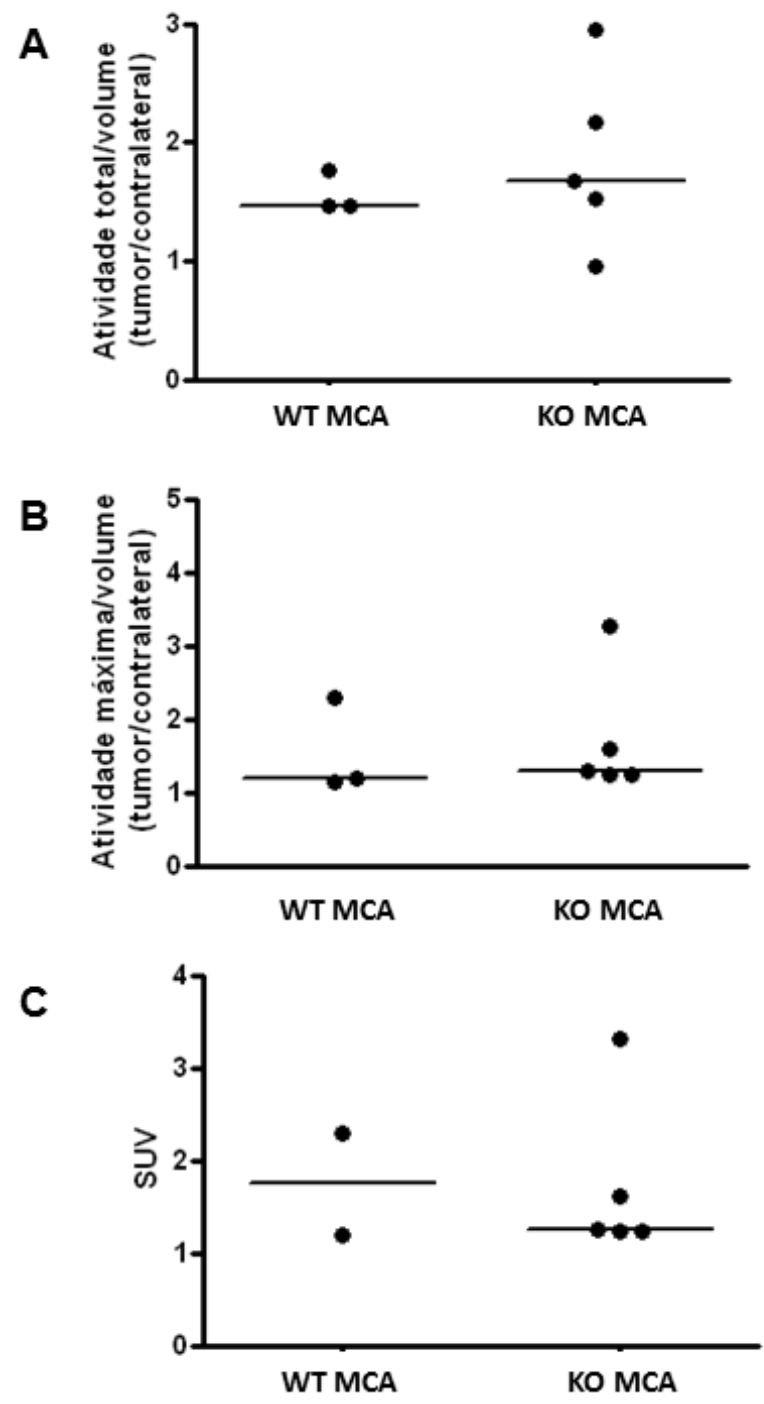

FIGURA 19. Quantificações da incorporação de fluodeoxiglicose $\left({ }^{18}\right.$ F-FDG) em PET/CT pelo tecido tumoral de camundongos WT (WT MCA) e Gal-3 KO (KO MCA). A) atividade total $(\mathrm{kBq}) /$ volume (tumor/contralateral); B) atividade máxima $(\mathrm{kBq}) /$ volume (tumor/contralateral); C) SUV, que considera a atividade injetada e a massa corporal. A linha indica a mediana e os dados foram submetidos ao teste de Mann-Whitney. SUV (standardized uptake value); kBq (quilobecquerel). 
A fim de se avaliar se gal-3 teria um papel importante na densidade de macrófagos na massa tumoral neste modelo, foram quantificadas as células CD68positivas por área em duas regiões do tumor: interior e periferia (FIGURA 20), sendo esta considerada apenas quando havia, nos campos analisados, células estromais ou musculares adjacentes às células tumorais. O número amostral foi muito pequeno, de apenas três animais por grupo e não houve diferença significativa entre os animais WT e Gal-3 KO (FIGURA 21A). O interior dos tumores de animais WT tendeu a apresentar mais macrófagos em comparação ao interior dos tumores de animais Gal-3 KO $(\mathrm{p}=0,07)$. Considerando apenas as células positivas para CD68, observou-se uma tendência dos tumores que expressam gal-3 terem maior porcentagem de macrófagos em seu interior, embora não haja diferença significativa ( $p=0,07$; FIGURA 21B). 




FIGURA 20. Expressão de células positivas para CD68 (macrófagos) na periferia ou interior de sarcomas induzidos por MCA em camundongos WT (WT MCA) e Gal-3 KO (KO MCA). Imunoistoquímica para CD68 em secções de tumor, sendo as células positivas marcadas em castanho (as setas indicam alguns exemplos). 

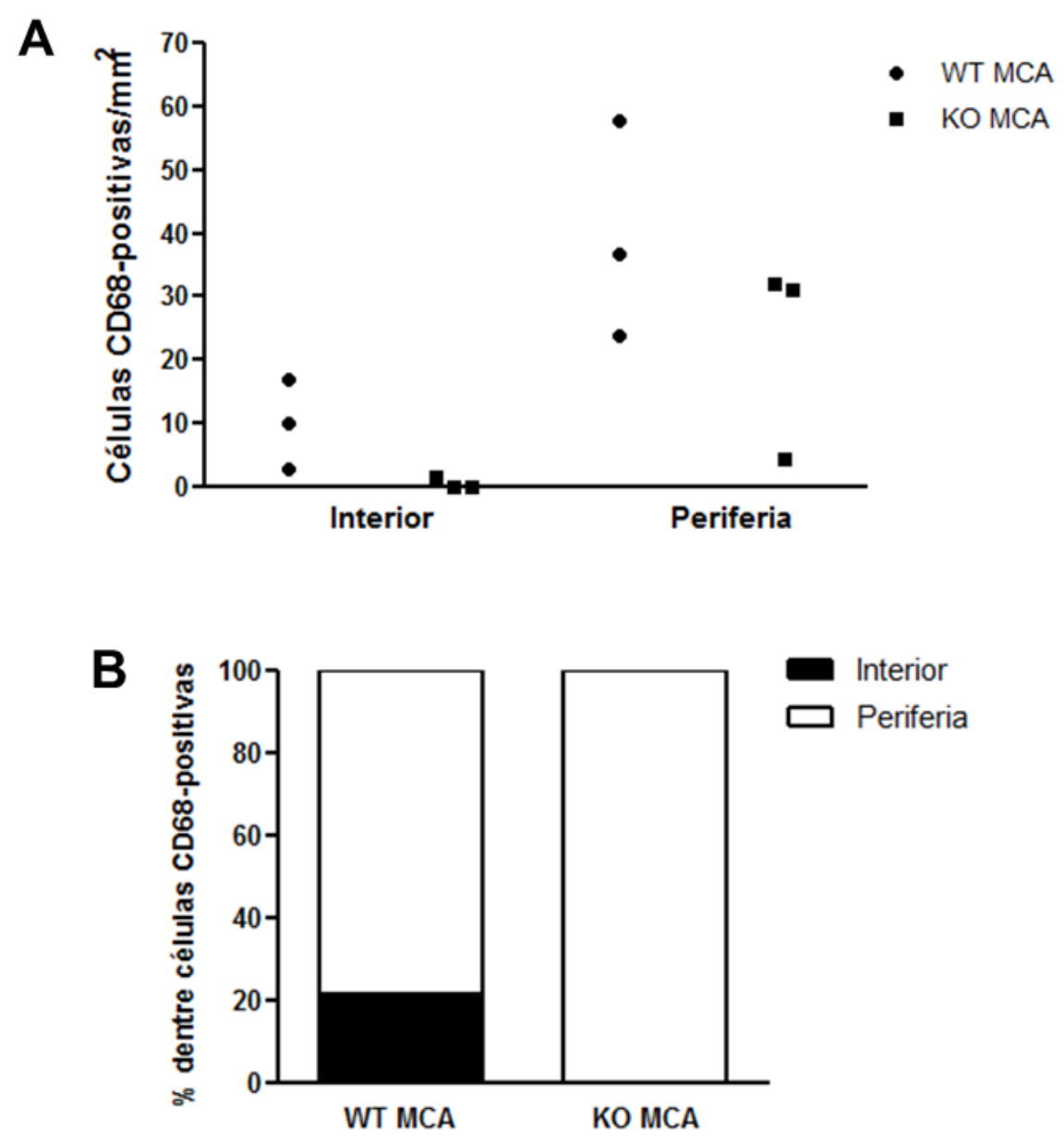

FIGURA 21. Expressão de células positivas para CD68 (macrófagos) na periferia ou interior de sarcomas induzidos por MCA em camundongos WT (WT MCA) e Gal-3 KO (KO MCA). A) Número de células positivas por $\mathrm{mm}^{2}$ na periferia ou interior dos tumores; B) Porcentagem de células na periferia ou interior dos tumores, considerando apenas as células positivas para CD68. Dados submetidos ao teste de Mann-Whitney.

Além disso, foi realizada quantificação da área positiva para CD206, receptor encontrado em macrófagos de fenótipo M2, também na periferia ou interior dos tumores que expressam ou não gal-3 (FIGURA 22A). A área positiva para CD206 foi significativamente maior na periferia do que no interior de tumores de animais WT $(\mathrm{p}<0,05)$ (FIGURA 22B). No interior do tumor, animais Gal-3 KO tenderam a apresentar maior área positiva para CD206 em comparação aos animais WT, sem que houvesse diferença significativa $(\mathrm{p}=0,08)$. 

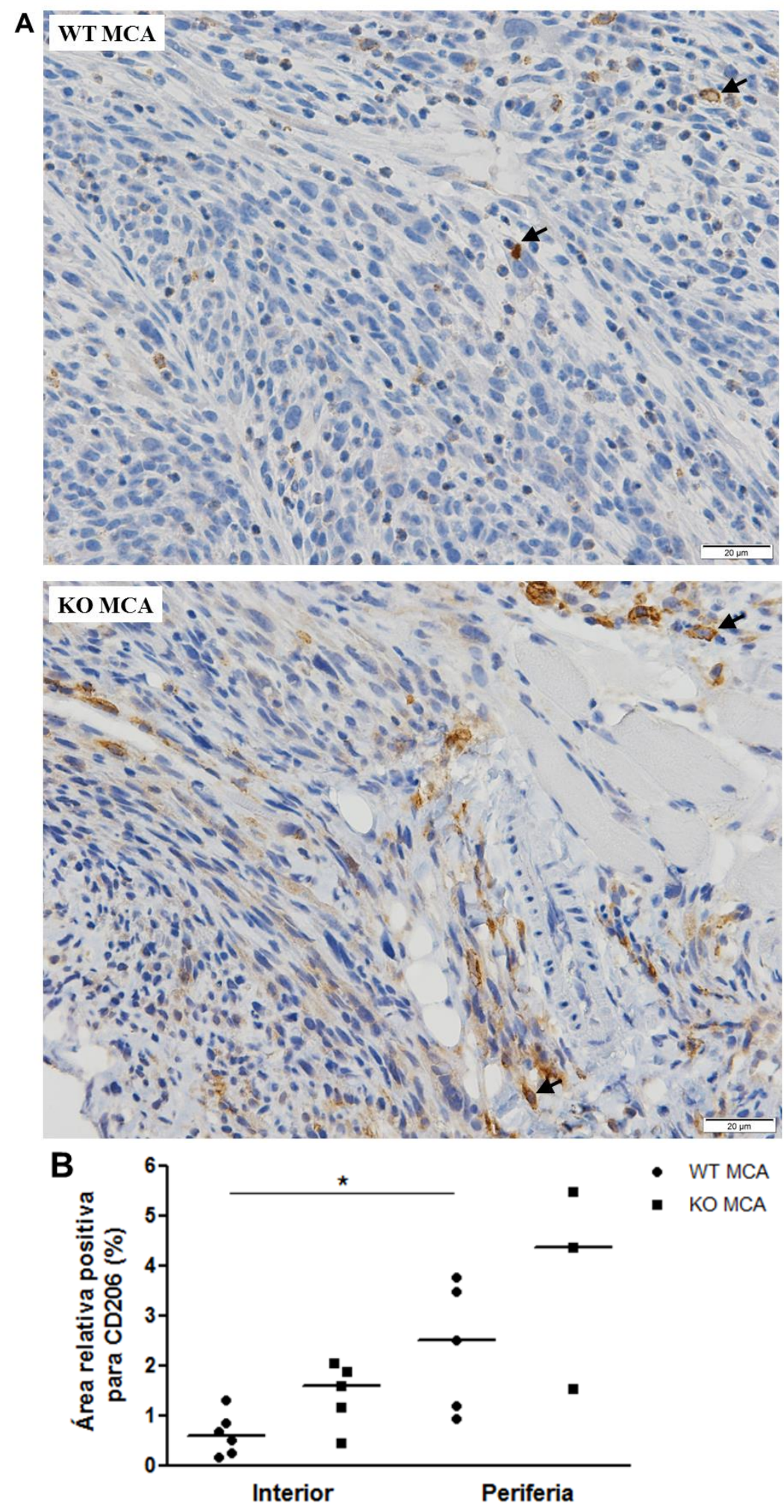

FIGURA 22. Expressão de células positivas para CD206 (macrófagos M2) na periferia ou interior de tumores de camundongos WT (WT MCA) e Gal-3 KO (KO MCA). A) Imunoistoquímica para CD206, sendo a área positiva marcada em castanho (as setas são exemplos de células positivas). Interior do tumor WT MCA e periferia do tumor KO MCA; B) Área relativa marcada por CD206 na periferia ou interior dos tumores. A linha indica a mediana e os dados foram submetidos ao teste de MannWhitney; ${ }^{*} \mathrm{p}<0,05$. 
A avaliação da expressão de genes que codificam para marcadores tipicamente relacionados a macrófagos M1 (iNOS, IL-1 $\beta$ e IFN- $\gamma$ ) e a macrófagos M2 (arginase-1, CD206 e IL-10) também não apontou diferenças significativas. No entanto, a expressão de Nos2 (que codifica para iNOS/NOS2) tendeu a ser menor em tumores de animais Gal-3 KO, com valor de p=0,05 (FIGURA 23; valores de $\Delta \mathrm{C}_{\mathrm{T}}$ em ANEXO).

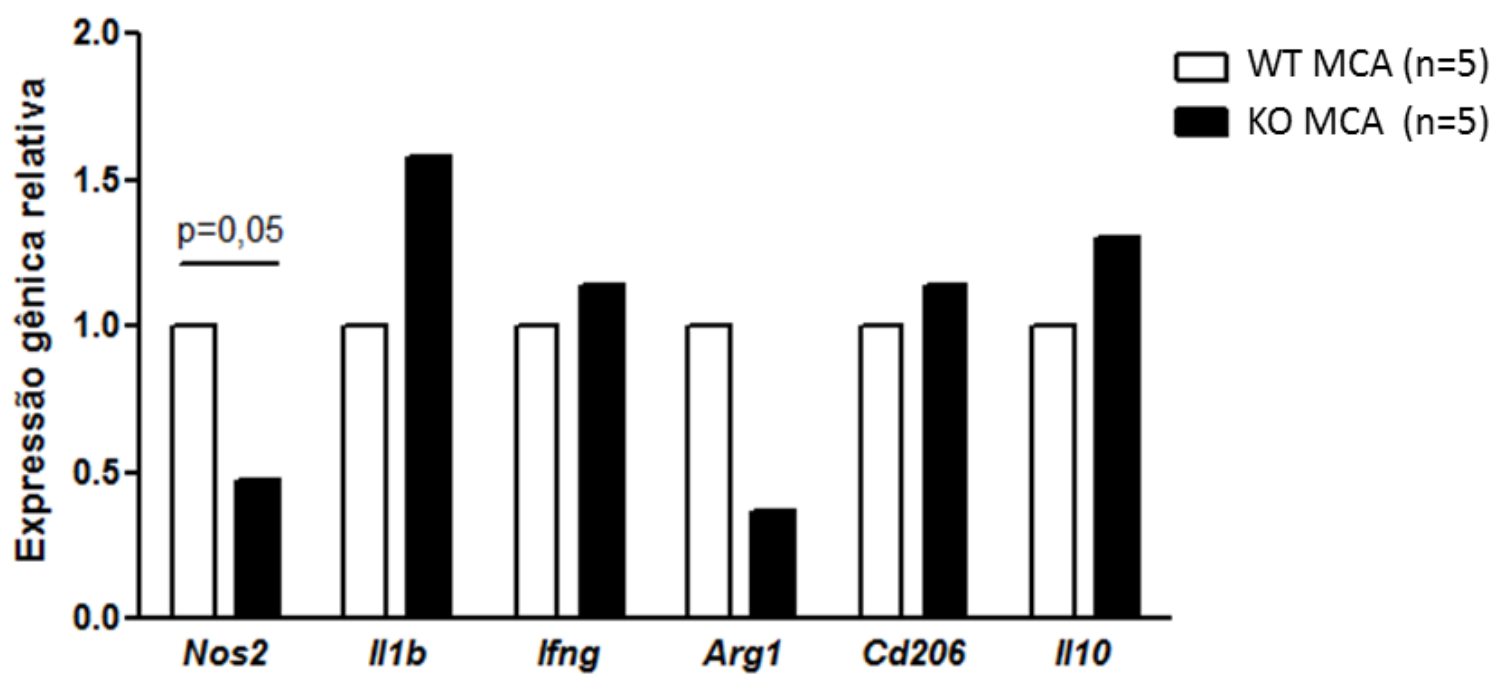

FIGURA 23. Expressão gênica relativa de marcadores relacionados à polarização de macrófagos em sarcomas de camundongos WT (WT MCA) e Gal-3 KO (KO MCA). Os genes Nos2, Il1b e Ifng são associados ao fenótipo M1 e os genes Arg1, Cd206 e Il10, ao fenótipo M2. Quantificação por PCR quantitativa (qPCR), normalizada por Hprt, sendo que não houve expressão relativa diferenciada deste gene entre os dois grupos. A expressão de todos os genes utilizou como referência o grupo de animais WT MCA (quantificação relativa $=1$ ). Resultados representativos de três experimentos independentes, submetidos ao teste de Mann-Whitney.

Como mencionado anteriormente, as células $\mathrm{T}_{\text {reg }}$ contribuem para a imunossupressão e estão relacionadas a macrófagos de fenótipo M2. Com a finalidade de avaliar se a presença de gal-3 influencia no recrutamento das células $T_{\text {reg }}$ para $o$ microambiente neste modelo, realizou-se IHC para a proteína Foxp3, expressa nestas células, também comparando-se a marcação na periferia e no interior dos tumores de 
animais WT e Gal-3 KO (FIGURA 24A). Porém, a quantificação das células positivas para Foxp3 por área não demonstrou diferenças entre os grupos (FIGURA 24B).

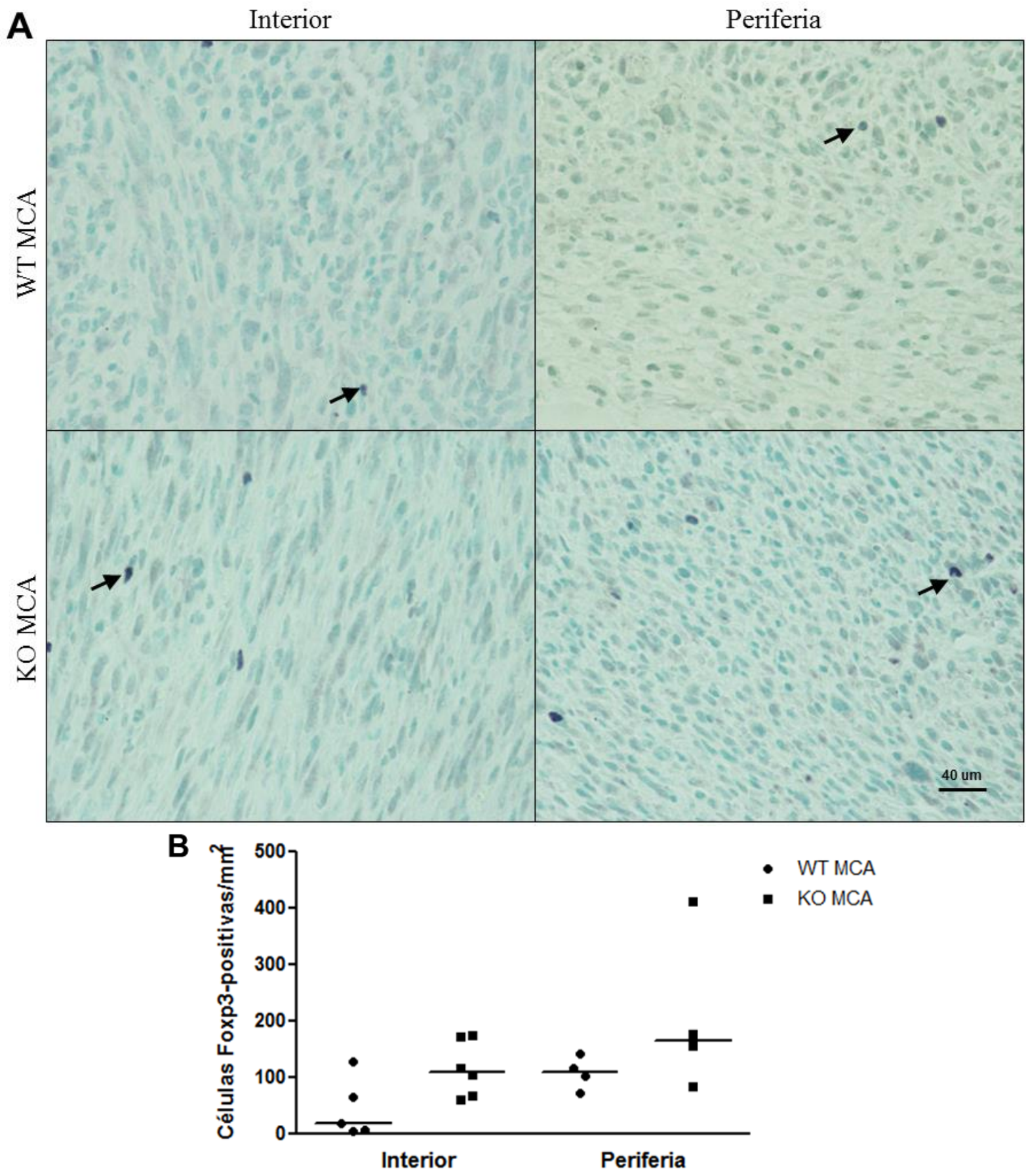

FIGURA 24. Expressão de Foxp3 (células $T_{\text {reg}}$ ) em sarcomas induzidos por MCA em camundongos WT (WT MCA) e Gal-3 KO (KO MCA). A) Imunoistoquímica em secções de tumor, sendo as células positivas marcadas em roxo (as setas indicam alguns exemplos); B) Número de células positivas para Foxp3 por área na periferia ou interior dos tumores. A linha indica a mediana e os dados foram submetidos ao teste de MannWhitney. 


\section{FASES INICIAIS DA TUMORIGÊNESE}

Nos estudos realizados durante as fases iniciais da tumorigênese, avaliou-se a região da pele e tecido subcutâneo de camundongos que receberam injeção de MCA ou apenas o veículo de diluição (via subcutânea), em dois momentos:

- uma semana após a primeira injeção

- uma semana após a segunda injeção

Lembrando que o intervalo entre as duas injeções foi de oito semanas. Primeiramente, a expressão de gal-3 foi avaliada qualitativamente por IHC em tecidos obtidos uma semana após a segunda injeção em animais WT e Gal-3 KO. A expressão de gal-3 foi intensa em animais WT que receberam MCA (WT MCA) ou apenas veículo (WT CTL) (FIGURA 25). Nos animais Gal-3 KO, não foi observada positividade nos tecidos analisados (KO MCA e KO CTL) (FIGURA 26). 

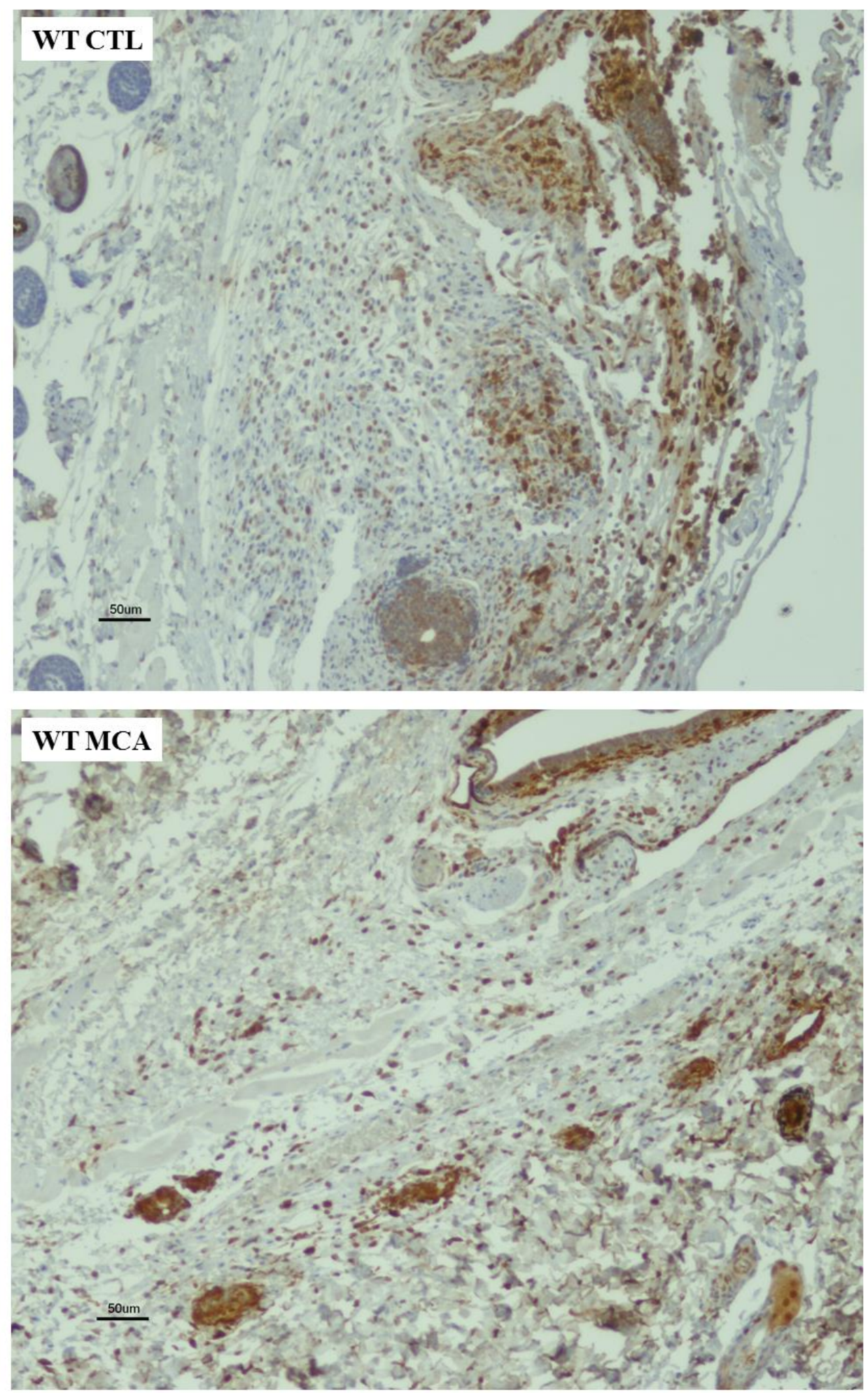

FIGURA 25. Expressão de gal-3 na região de inóculo de MCA ou veículo em camundongo WT uma semana após a segunda injeção. Reação imunoistoquímica revelou expressão de gal-3 no citoplasma e/ou núcleo de células presentes no local da injeção de MCA (WT MCA) ou apenas veículo (WT CTL). Células positivas encontram-se marcadas em castanho. 

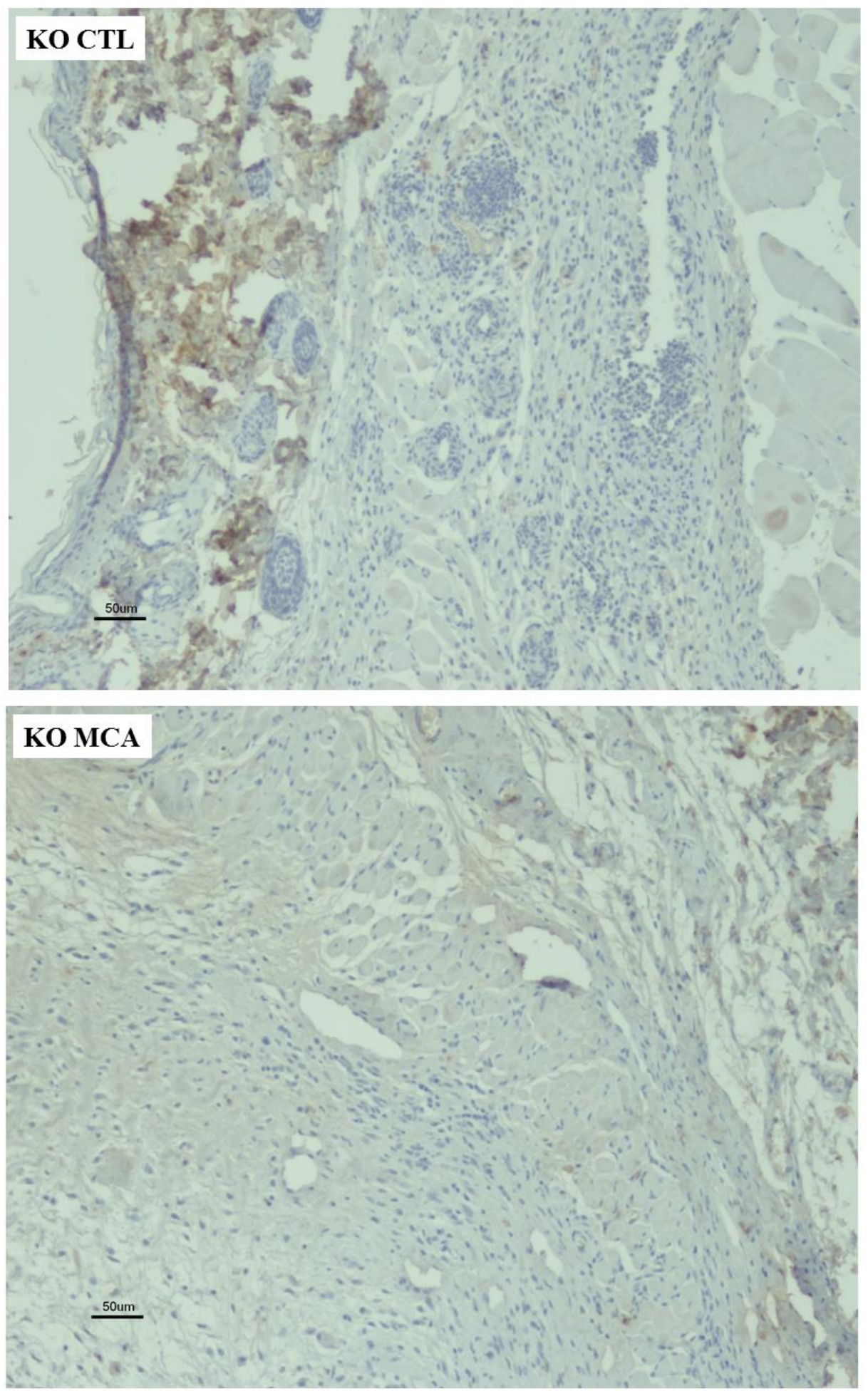

FIGURA 26. Expressão de gal-3 na região de inóculo de MCA ou veículo em camundongo Gal-3 KO uma semana após a segunda injeção. Reação imunoistoquímica para gal-3 não mostrou positividade no local da injeção de MCA (KOMCA) ou apenas veículo (KO CTL). 
A quantificação de macrófagos após marcação IHC para CD68 foi realizada nos tecidos retirados uma semana após a primeira injeção de MCA ou veículo (FIGURA 27) e nos tecidos retirados uma semana após a segunda injeção (FIGURA 28).

Comparando-se os grupos de animais WT ou Gal-3 KO que receberam MCA (WT MCA, KO MCA) ou veículo (WT CTL, KO CTL), não houve diferença significativa na quantificação de macrófagos em geral, em ambos os tempos (FIGURAS 27 e 28B).

\section{Uma semana após primeira injeção de MCA}

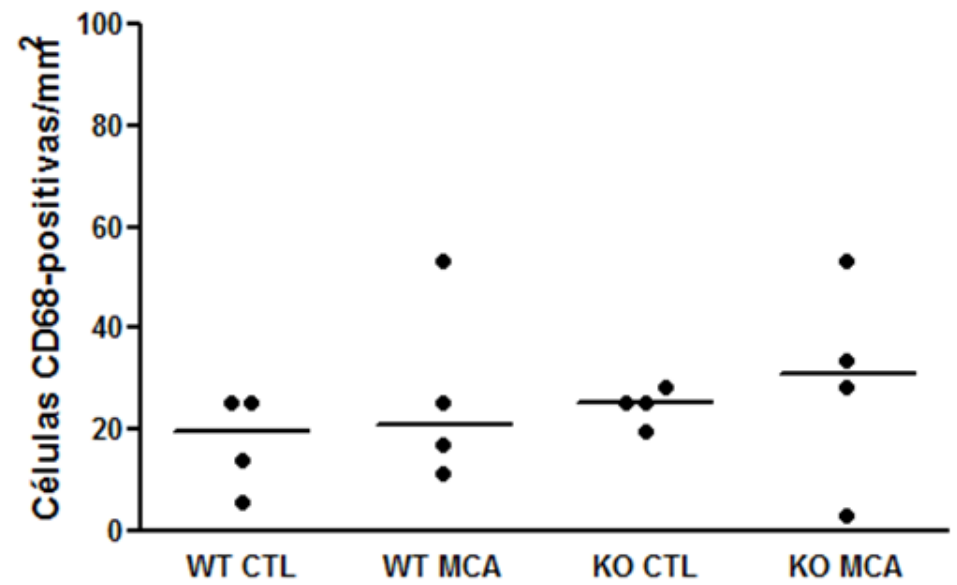

FIGURA 27. Quantificação de células CD68-positivas (macrófagos) em camundongos WT e Gal-3 KO, no local de injeção subcutânea de MCA ou veículo. Os animais receberam MCA (WT MCA ou KO MCA) ou apenas veículo de diluição (WT CTL ou KO CTL) e o tecido do local do inóculo foi retirado uma semana após a primeira injeção. A quantificação foi realizada pela contagem de células positivas por área após reação imunoistoquímica. A linha indica a mediana e os dados foram submetidos ao teste de Mann-Whitney. 


\section{Uma semana após segunda injeção de MCA}

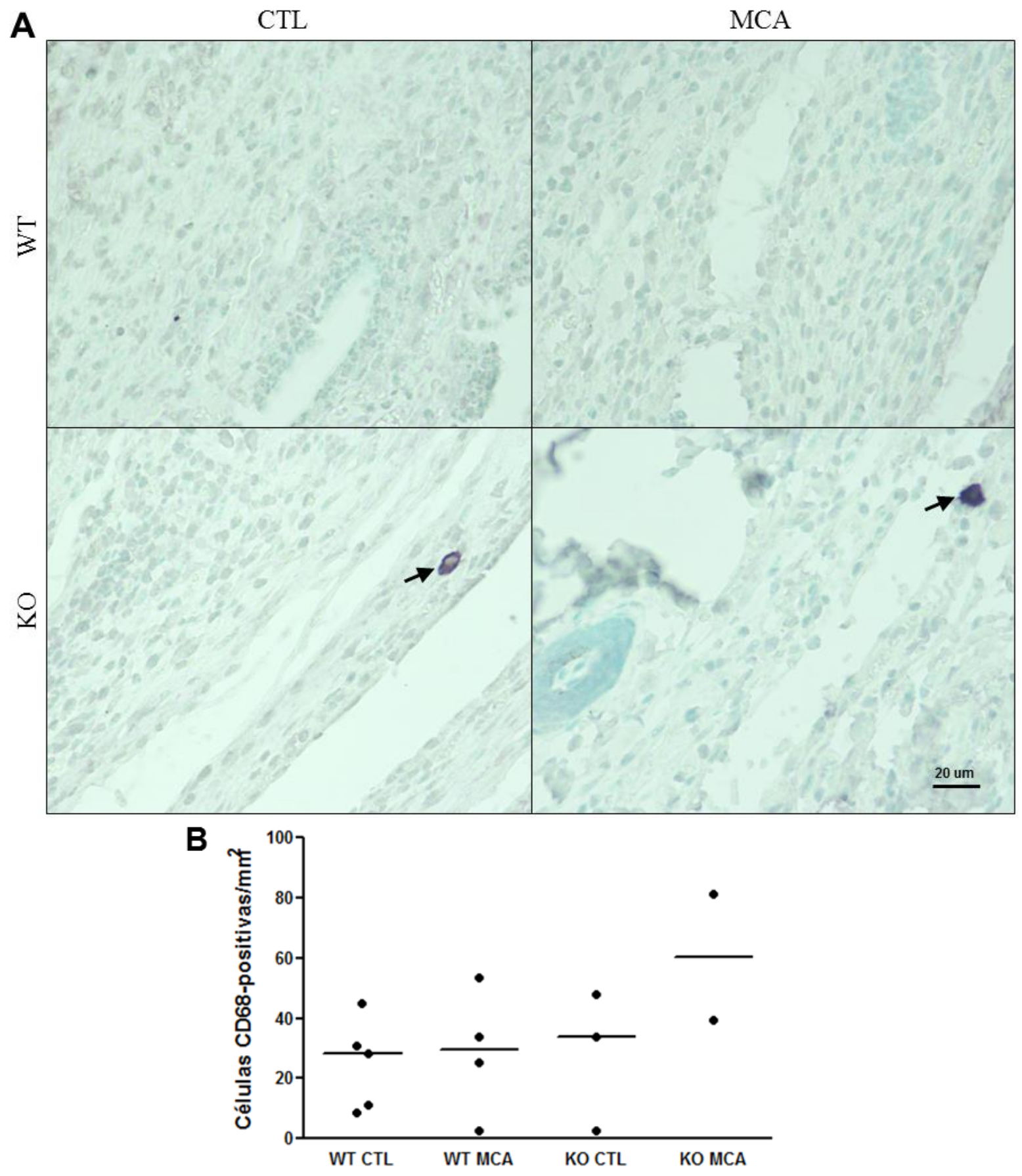

FIGURA 28. Expressão de CD68 (macrófagos) em camundongos WT e Gal-3 KO, no local de injeção subcutânea de MCA ou veículo. Os animais receberam MCA (WT MCA ou KO MCA) ou apenas veículo de diluição (WT CTL ou KO CTL) e o tecido do local do inóculo foi retirado uma semana após a segunda injeção. A) Imunoistoquímica para CD68 em secções de tecido, sendo as células positivas marcadas em roxo (setas); B) Quantificação de células CD68-positivas por área. A linha indica a mediana e os dados foram submetidos ao teste de Mann-Whitney. 
Também foi realizada a quantificação de macrófagos com fenótipo M2 através de reação IHC para CD206 nos tecidos retirados uma semana após a primeira injeção de MCA ou veículo (FIGURA 29) e nos tecidos retirados uma semana após a segunda injeção de MCA ou veículo (FIGURA 30).

Uma semana após a primeira injeção, também não houve diferença na marcação para macrófagos M2, entre os grupos de animais WT e Gal-3 KO (FIGURA 29). Entretanto, uma semana após a segunda injeção de MCA ou veículo, a marcação para CD206 indicou que há mais macrófagos com fenótipo M2 no tecido de animais Gal-3 KO inoculados com veículo (KO CTL) do que no tecido de animais WT (WT CTL) ( $<<0,05 ;$ FIGURA 30B). Além disso, os tecidos de animais Gal-3 KO inoculados com MCA (KO MCA) tenderam a apresentar mais macrófagos M2 do que os tecidos de animais WT inoculados com MCA (WT MCA) (p=0,05; FIGURA 30B).

\section{Uma semana após primeira injeção de MCA}

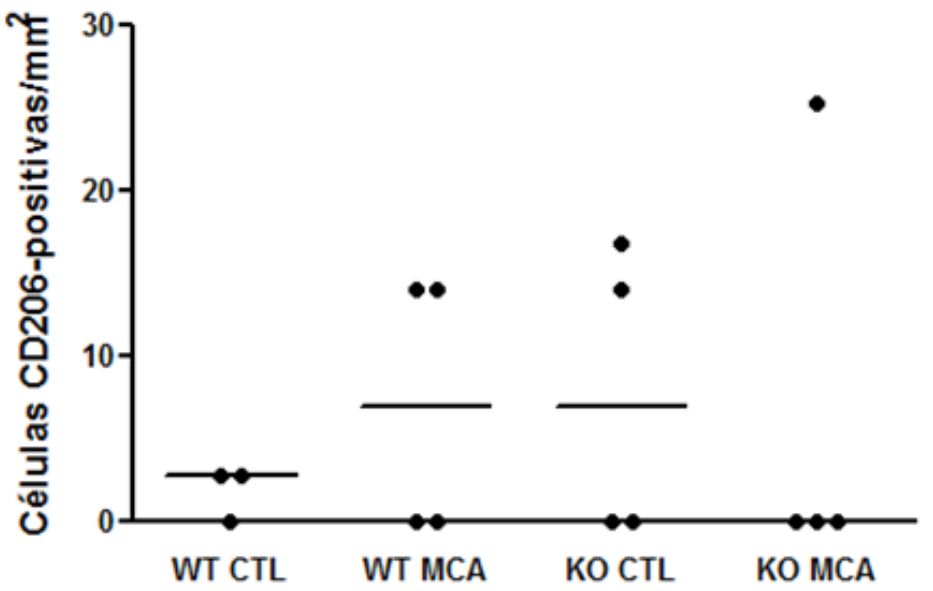

FIGURA 29. Quantificação de células CD206-positivas (macrófagos M2) em camundongos WT e Gal-3 KO, no local de injeção subcutânea de MCA ou veículo. Os animais receberam MCA (WT MCA ou KO MCA) ou apenas veículo de diluição (WT CTL ou KO CTL) e o tecido do local do inóculo foi retirado uma semana após a primeira injeção. A quantificação foi realizada pela contagem de células positivas por área após reação imunoistoquímica. A linha indica a mediana e os dados foram submetidos ao teste de Mann-Whitney. 


\section{Uma semana após segunda injeção de MCA}

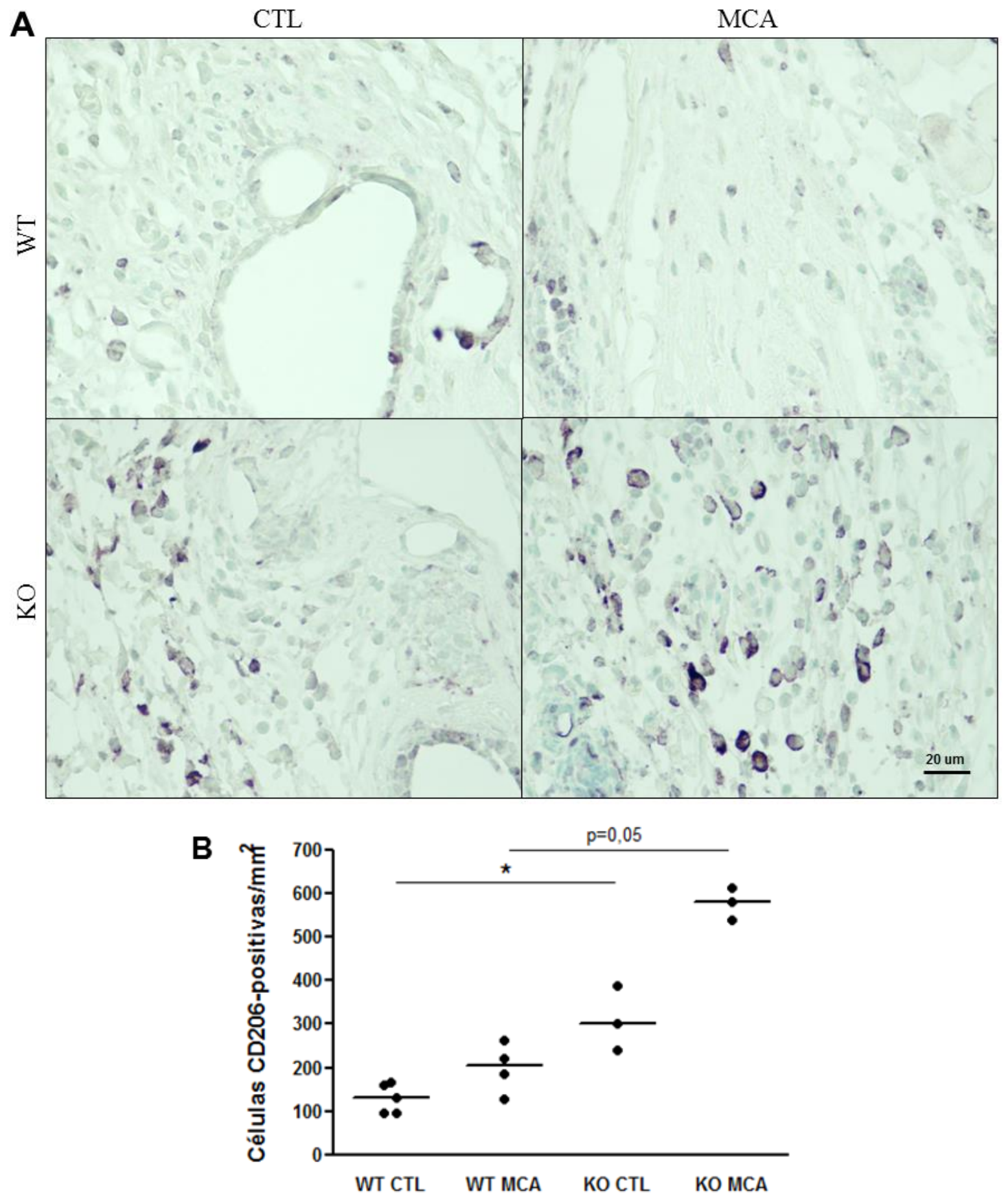

FIGURA 30. Expressão de CD206 (macrófagos M2) em camundongos WT e Gal-3 KO, no local de injeção subcutânea de MCA ou veículo. Os animais receberam MCA (WT MCA ou KO MCA) ou apenas veículo de diluição (WT CTL ou KO CTL) e o tecido do local do inóculo foi retirado uma semana após a segunda injeção. A) Imunoistoquímica para CD206 em secções de tecido, sendo as células positivas marcadas em roxo; B) Quantificação de células CD206-positivas por área. A linha indica a mediana e os dados foram submetidos ao teste de Mann-Whitney; ${ }^{*} \mathrm{p}<0,05$. 


\section{SUMÁRIO DE RESULTADOS}

- A ausência de gal-3 não inibiu o desenvolvimento de sarcomas induzidos por MCA nos camundongos;

- Não houve diferença na área necrótica e na proliferação celular entre sarcomas de camundongos WT e Gal-3 KO;

- Não detectamos diferenças na produção de VEGF, mas tumores de camundongos Gal-3 KO apresentaram menor densidade vascular;

- A velocidade de fluxo sanguíneo em vasos intratumorais foi menor em sarcomas de camundongos Gal-3 KO;

- Não houve diferença quantitativa na incorporação de ${ }^{18}$ F-FDG entre tumores de camundongos WT e Gal-3 KO;

- Sugere-se que ocorra uma maior densidade de macrófagos em tumores de camundongos WT;

- Sugere-se que a população de macrófagos M2 seja maior em sarcomas de camundongos Gal-3 KO;

- $\quad$ Em fases iniciais da tumorigênese, sugere-se que a população de macrófagos M2 seja maior em camundongos Gal-3 KO. 


\section{DISCUSSÃO}

Gal-3 é uma proteína muito estudada devido à ampla variedade de funções que exerce, embora muitas vezes contraditórias, em diferentes tecidos e tipos celulares (Liu e Rabinovich, 2005). Muitos estudos têm evidenciado que gal-3 participa de diferentes etapas relacionadas ao câncer e que seu papel depende muito do tecido e célula onde se encontra, assim como de sua localização nos compartimentos intracelulares. Por exemplo, em tumores de tireóide e estômago gal-3 tem expressão elevada, enquanto que em câncer de pele, mama e ovário, sua expressão está diminuída (Dumic et al., 2006).

A expressão de gal-3 foi observada em linhagens celulares de sarcoma murino (de Melo et al., 2007) e em estudos clínicos de osteosarcoma (Khanna et al., 2001; Zhou et al., 2014), estando relacionada à progressão e invasão tumoral (Melo et al., 2011). No presente estudo, foi utilizado um modelo de indução química de sarcoma tanto em camundongos WT quanto em camundongos Gal-3 KO, visando investigar algumas das possíveis funções de gal-3 na tumorigênese. Os modelos experimentais de carcinogênese são importantes instrumentos de pesquisa, pois geram lesões de maneira similar à que ocorre em humanos (Maronpot et al., 2004). Por isto, auxiliam na construção do conhecimento sobre a biologia e a etiologia do câncer, na descoberta de marcadores para diagnóstico precoce e, finalmente, no desenvolvimento de terapias.

Em um modelo de indução de tumor renal com dietilestilbestrol (DES) em hamster, gal-1 e gal-3 parecem ter um papel nas primeiras fases da transformação neoplásica. A expressão destas proteínas foi observada em tumores pequenos, após um mês de tratamento com DES. Por sua vez, gal-7 e gal-8 foram detectadas apenas em tumores médios e grandes, sete a dez meses após o início do tratamento (Saussez et al., 2005). 
Até o momento, apenas um estudo demonstrou o uso do carcinógeno MCA em camundongos Gal-3 KO (de Melo et al., 2011), sendo realizadas duas injeções de $50 \mu \mathrm{g}$ de MCA por animal, com 12 semanas de intervalo. A sobrevida livre de tumor de camundongos Gal-3 KO só demonstrou ser significativamente maior que a de camundongos WT a partir do sétimo mês após inóculo. Em nosso estudo, utilizamos duas injeções de $200 \mu \mathrm{g}$ de MCA por animal, com oito semanas de intervalo e não observamos diferenças na sobrevida livre de sarcoma entre os grupos de animais WT e Gal-3 KO (FIGURA 05). O período de experimento foi de quatro meses a quatro meses e três semanas, dependendo do grupo.

Em outros modelos experimentais, nos quais foram utilizadas diferentes doses de MCA, a quantidade de carcinógeno influenciou na incidência tumoral. A diferença na formação de tumor entre camundongos WT e knockout mostrou-se mais relevante quando eram utilizados $25 \mu \mathrm{g}$ de MCA por animal. Já em doses maiores, de até $400 \mu \mathrm{g}$ por animal, as diferenças deixavam de existir (Kaplan et al., 1998; Cretney et al., 2002).

Em outro estudo, utilizou-se um potente carcinógeno do tabaco para indução de adenocarcinoma pulmonar em camundongos Gal-3 KO e WT. Observou-se que após um período de 28 semanas, não havia diferença na incidência de tumor entre os dois grupos, mas, ao final de 32 semanas, a incidência foi menor nos camundongos Gal-3 KO (Abdel-Aziz et al., 2008). Em contraste, a ausência de gal-3 não apresentou efeito direto no desenvolvimento de carcinoma de língua quimicamente induzido em camundongos (de Faria et al., 2011). Conclusões similares foram relatadas por Eude-Le Parco et al. (2009) que, utilizando camundongos Gal-3 KO, mostraram que a ausência desta proteína não afetou a progressão de tumores intestinais e de mama, nem o desenvolvimento de metástases pulmonares. 
No presente modelo experimental, a ausência de gal-3 não influenciou diretamente no desenvolvimento de sarcomas (FIGURA 06), resultado que poderia ser diferente caso fosse utilizada uma dose menor de MCA. Entretanto, o foco do estudo estava na investigação de possíveis efeitos que gal-3 possa ter no microambiente que influenciem na dinâmica da angiogênese e, não necessariamente, no desenvolvimento tumoral.

Mesmo no início da tumorigênese (FIGURA 22) ou nos sarcomas nas fases mais tardias (FIGURA 07), nossos resultados mostraram que, de fato, os microambientes estudados em animais WT são positivos para gal-3 e, em animais Gal-3 KO, são negativos. Gal-3 pode promover a proliferação de fibroblastos e a síntese de colágeno, além de estimular a adesão e a migração celular (Li et al., 2014). A produção de colágeno, o componente mais abundante da ECM, é realizada predominantemente por fibroblastos. A deposição elevada desta proteína na ECM, assim como o remodelamento da matriz, estão relacionados à progressão tumoral (Levental et al., 2009; Shields et al., 2012). Por vezes, o sarcoma pode caracterizar-se por uma significativa produção de colágeno, mas este não é um atributo obrigatório. No presente modelo, a quantificação das fibras de colágeno nos tumores de animais WT e Gal-3 KO não apontou diferenças significativas entre os dois grupos (FIGURA 8).

Além de seu papel na adesão celular, gal-3 também promove a proliferação celular in vitro em muitos tipos de câncer, como de próstata (Wang et al., 2009), renal (Xu et al., 2016) e pancreático (Song et al., 2012). No entanto, a análise da expressão de PCNA e a contagem de figuras de mitose não apontaram diferenças no aspecto proliferativo entre tumores de animais WT e Gal-3 KO (FIGURAS 09 e 10). De maneira similar, em um estudo realizado com tumores humanos de tireoide, a 
superexpressão de gal-3 não correlacionou-se à atividade proliferativa, avaliada pela marcação de PCNA (Cvejic et al., 2005).

Células tumorais altamente proliferativas e uma microcirculação com anormalidades estruturais são fatores que contribuem para a formação de áreas de hipóxia, as quais podem resultar em morte celular por necrose (Höckel e Vaupel, 2001). A expressão de gal-3 tem sido relacionada à hipóxia, um fenômeno comum em tumores sólidos (Greijer et al., 2005; Ikemori et al., 2014; de Oliveira et al., 2015). Em concordância com os resultados de proliferação celular e de crescimento tumoral, não houve diferença na quantificação de áreas de necrose entre os tumores que expressam e os que não expressam gal-3 (FIGURA 11). Em estudo anterior de nosso grupo, Machado et al. (2014) demonstraram que células de melanoma murino implantadas em camundongos geram tumores maiores quando há expressão de gal-3. Além disso, estes tumores são mais vascularizados e apresentam menores áreas de necrose, comparados aos tumores onde gal-3 está ausente.

Semelhantemente, mesmo com as diferenças no modelo experimental, nossos resultados mostraram que os sarcomas de camundongos WT possuem uma densidade vascular mais elevada, comparados aos de camundongos Gal-3 KO (FIGURA 12). Jiang et al. (2014) analisaram a expressão do marcador CD34, presente em células endoteliais vasculares, em hepatocarcinoma humano e observaram uma correlação positiva entre a expressão de gal-3 e a densidade vascular, o que indica que esta proteína atuaria estimulando a angiogênese neste modelo.

É interessante que mesmo com uma menor densidade vascular, os tumores de animais Gal-3 KO não tiveram seu crescimento prejudicado. O marcador utilizado, CD34, reconhece principalmente células endoteliais progenitoras (Peichev et al., 2000), características do processo angiogênico (formação de novos vasos sanguíneos a partir 
da vasculatura preexistente). No entanto, tumores como o sarcoma não são totalmente dependentes da angiogênese para progredir (Pezzella et al., 1997). Devido à sua origem mesenquimal, o sarcoma ocorre no estroma intersticial, o qual já é vascularizado. O suprimento sanguíneo pode ocorrer através da cooptação de vasos preexistentes, independentemente da angiogênese (Donnem et al., 2013). Ainda assim, na ausência de gal-3, os sarcomas eram menos vascularizados.

Contrastando com o aumento na densidade vascular observado na presença de gal-3, a quantificação de VEGF, o fator pró-angiogênico mais conhecido, nos sarcomas não revelou diferenças entre os grupos de animais WT e Gal-3 KO (FIGURA 13). Embora o VEGF seja importante nas etapas iniciais da tumorigênese, a progressão é frequentemente acompanhada por alterações na expressão de outros fatores angiogênicos. Por exemplo, tumores de mama em estadiamento avançado expressam, além de VEGF, fatores como FGF-1, FGF-2 (ou bFGF), TGF- $\beta 1$, PDGF e fator de crescimento placentário (PLGF) (Relf et al., 1997). Estudos têm mostrado que gal-3 intratumoral também exerce seu papel pró-angiogênico através de vias independentes de VEGF (Piccolo et al., 2013; Iwai et al., 2016), como a via de sinalização por bFGF (Nangia-Makker et al., 2002; Markowska et al., 2010, 2011). Para complementar o presente estudo, é importante avaliar a expressão de VEGF utilizando-se outra metodologia, assim como a expressão de outros fatores pró-angiogênicos nos sarcomas.

Com o desenvolvimento de novas estratégias de tratamento cujo alvo é a vasculatura tumoral, o monitoramento do crescimento tumoral tornou-se essencial. O processo de angiogênese pode ser estudado através da avaliação de parâmetros fisiológicos como perfusão regional, função e metabolismo. A angiogênese tumoral pode ser estudada por abordagens invasivas ou não invasivas. Técnicas histológicas e moleculares permitem análises subcelulares, mas não são as mais adequadas para 
estudos cinéticos e funcionais, além de serem invasivas (Niu e Chen, 2009). Por sua vez, métodos de imageamento não invasivos ou minimamente invasivos abrangem um volume maior de tumor, comparando-se à histologia, e mostram a dinâmica temporal, sendo possível determinar quantitativamente algumas funções fisiológicas (Fukumura e Jain, 2008).

A US é um método bem estabelecido para medição de velocidade de fluxo sanguíneo, empregando-se o princípio do efeito Doppler e também pelo uso de microbolhas como agente de contraste (Forsberg et al., 2004). O efeito Doppler está relacionado ao movimento das hemácias nos vasos sanguíneos, que reflete a funcionalidade vascular intratumoral. O ultrassom de alta frequência possui a vantagem de fornecer imagens em tempo real e de maneira não invasiva, com alta resolução espacial, de até $30 \mu \mathrm{m}$. Esta metodologia possibilita a detecção de alterações na perfusão tumoral antes mesmo que mudanças estruturais tornem-se histologicamente evidentes (Chen et al., 2011).

Em um modelo murino de implante de células de câncer de próstata, a área relativa de vasos funcionais foi analisada por US em diferentes tempos. Observou-se que conforme o tumor crescia, a área vascular periférica aumentava e, no interior do tumor, diminuía, o que sustenta a hipótese de que a atividade angiogênica é, em geral, maior na periferia tumoral (Oostendorp et al., 2010; Chen et al., 2011). O mecanismo que resulta neste fenômeno ainda não está claro, mas uma possível explicação seria a elevada pressão do fluido intersticial no interior da neoplasia (Fleischer, 2000). Em nossos estudos de US com color Doppler, verificamos que os vasos sanguíneos localizados no interior do tumor apresentam velocidades de fluxo mais elevadas que os periféricos, tanto em animais WT quanto em animais Gal-3 KO (FIGURA 14B e C). Este dado pode ser resultado da pressão intersticial aumentada no interior do tumor. Os 
estudos de Sehgal et al. (2000) demonstraram, através da US, que ocorre uma maior vascularização no interior da massa tumoral em relação à periferia, em carcinoma mamário humano.

Em nosso modelo de sarcoma, a velocidade média de fluxo sanguíneo nos vasos intratumorais foi significativamente menor nos camundongos Gal-3 KO, quando comparados aos WT (FIGURA 14C). Portanto, além de resultar na redução da densidade vascular (alteração estrutural), a ausência de gal-3 teve consequências na funcionalidade da vasculatura. Similarmente, Drevs et al. (2000) demonstraram uma correlação entre alterações no fluxo sanguíneo e a densidade microvascular, sem que houvesse uma correlação com o volume tumoral. Estes pesquisadores também observaram, em modelo murino de carcinoma renal, que tumores com maior volume eram menos vascularizados que os menores. Eles reforçam a hipótese de que a taxa de proliferação das células tumorais murinas, superior à das células endoteliais, resulta em um crescimento tumoral parcialmente independente de angiogênese.

A PET é outra técnica amplamente utilizada para avaliação da perfusão tumoral, sendo a mais sensível e específica para imageamento molecular in vivo em humanos. Radioisótopos podem ser detectados em concentrações picomolares nos tecidos alvo, geralmente tendo pouco ou nenhum efeito fisiológico no paciente ou modelo experimental (Phelps et al, 2000; Niu e Chen, 2009). A resolução espacial da PET permite sua aplicação não apenas no diagnóstico e desenvolvimento de drogas, mas também na pesquisa pré-clínica em animais. Para superar a limitação de sua baixa resolução anatômica (aproximadamente 4 a $8 \mathrm{~mm}^{3}$ em sistemas clínicos e 1 a $2 \mathrm{~mm}^{3}$ em sistemas para pequenos animais), foram desenvolvidos sistemas híbridos de PET/CT (Beyer et al., 2000; Willmann et al., 2008). 
Análises de fluxo sanguíneo ou de perfusão tumoral por PET são comumente realizadas com ${ }^{15} \mathrm{O}-\mathrm{H}_{2} \mathrm{O}$ (água marcada com o isótopo ${ }^{15} \mathrm{O}$ ), biologicamente e metabolicamente inerte (Dimitrakopoulou-Strauss et al., 2001; Komar et al., 2014). Devido à sua curta meia-vida (aproximadamente 2 minutos), há a necessidade de um cíclotron próximo ao equipamento de PET/CT, o que ocorre em poucos centros de medicina nuclear. Mullani et al. (2008) desenvolveram um modelo baseado no metabolismo da glicose, utilizando ${ }^{18}$ F-FDG, para análise in vivo do fluxo sanguíneo em pacientes e demonstraram boa correlação entre este modelo e o uso de ${ }^{15} \mathrm{O}-\mathrm{H}_{2} \mathrm{O}$. Além disso, em glioma humano, a incorporação aumentada de ${ }^{18}$ F-FDG mostrou-se relacionada a uma alta vascularização e elevado volume sanguíneo microvascular (Aronen et al., 2000) e, em câncer colorretal humano, a captação deste composto teve uma correlação positiva com o fluxo sanguíneo tumoral (Tixier et al., 2014). Entretanto, nem sempre esta correlação é observada, como em câncer de pulmão de células não pequenas (van Elmpt et al., 2013).

$\mathrm{O}{ }^{18}$ F-FDG, cuja meia-vida é de aproximadamente 110 minutos, entra na célula através de transportadores de glicose na membrana plasmática e, assim como a glicose, é fosforilado pela hexoquinase. Diferente da glicose-6-fosfato, ${ }^{18}$ F-FDG-6-fosfato não é substrato da fosfoglicose isomerase e não continua sendo metabolizado, ficando retido no interior da célula (Di Chiro et al., 1982; Buck e Reske, 2004). Enquanto tecidos necróticos ou fibrosos reduzem a captação de ${ }^{18} \mathrm{~F}$-FDG, células inflamatórias podem contribuir para a sua captação em tumores (Ichiya et al., 1996; Pio et al., 2003).

A quantificação da incorporação de ${ }^{18}$ F-FDG pelos sarcomas gerados em camundongos WT e Gal-3 KO não apontou diferenças significativas entre os grupos (FIGURA 19). No entanto, imagens de PET/CT de alguns animais Gal-3 KO mostraram tumores com pouca captação e uma região adjacente apresentando alta captação 
(FIGURAS 17 e 18). Similarmente, em alguns animais Gal-3 KO, também foram observadas através da US, áreas adjacentes ao tumor onde havia sangue (FIGURA 15C). Estes achados podem corresponder ao mesmo tipo de estrutura, que resulta no aumento na quantidade de sangue nas proximidades do tumor. Este pode ser um indício de que a ausência de gal-3 causa anomalias estruturais na rede vascular que irriga o tumor, contribuindo para a diminuição da densidade vascular e da velocidade de fluxo sanguíneo. As alterações estruturais na vasculatura, além de ocorrerem no interior da neoplasia, parecem estar presentes também em áreas adjacentes ao tumor, refletindo em uma deficiente funcionalidade vascular neste modelo.

A angiogênese pode ser estimulada pelos macrófagos por vias dependentes e independentes de VEGF, assim como fatores pró-angiogênicos como VEGF e TGF- $\beta$ podem atrair macrófagos para o microambiente tumoral (Ruffell et al., 2012). Evidências in vitro indicam que gal-3 pode promover a migração de monócitos interagindo seletivamente com componentes da ECM (Danella Polli et al., 2013). No estudo de Machado et al. (2014), a quantificação de macrófagos (células CD68positivas) nos tumores dos diferentes grupos experimentais indicou que havia maior presença destas células quando gal-3 era expressa apenas pelas células tumorais, e não pelas estromais. Similarmente, sarcomas de animais WT tenderam a apresentar maior número de macrófagos no interior do tumor, embora não houvesse diferença significativa (FIGURA 21), sendo importante complementar esta análise aumentando a amostragem.

Em neoplasias malignas, muitos estudos evidenciaram que os TAMs exibem predominantemente um fenótipo M2 (Mantovani et al., 2002; Biswas et al., 2006). Entretanto, o fenótipo dos TAMs pode ser dependente do estadiamento da neoplasia (Redente et al., 2010), sendo mais similar a M1 nas etapas iniciais de desenvolvimento 
tumoral, geralmente havendo inflamação crônica, e mais similar a M2 no tumor já estabelecido (Biswas et al., 2008). Um dos reguladores dos sinais que desencadeiam processos inflamatórios é o fator de transcrição $\mathrm{NF \kappa B}$ (fator nuclear $\kappa \mathrm{B}$ ), posterior à ativação de TLR, e a sua ativação resulta na produção de citocinas inflamatórias como IL-12 e TNF- $\alpha$. Evidências indicam que, nas etapas iniciais do desenvolvimento tumoral, NFкB está ativo em macrófagos (Karin e Greten, 2005; Biswas et al., 2008).

Nossos resultados oriundos de tecidos nas fases iniciais da tumorigênese reforçam estes dados da literatura. Nos tecidos analisados uma semana após a segunda injeção de MCA, a marcação para CD206 indicou que a presença de gal-3 está relacionada a uma menor densidade de macrófagos M2 (FIGURA 30B). Outros estudos mostraram que gal-3 atua de maneira autócrina e parácrina para promover, em macrófagos, a liberação de mediadores pró-inflamatórios, como TNF- $\alpha$, IL-12, CCL3 e CCL4, assim como espécies reativas de nitrogênio geradas através de iNOS (Liu et al., 1995; Nishi et al., 2007; Jeon et al., 2010). Pode-se sugerir que a ausência de gal-3 contribua para uma maior participação de macrófagos M2 no sítio de desenvolvimento tumoral em suas fases iniciais. No entanto, ressaltamos a importância de aumentar a amostragem também nos ensaios de início de tumorigênese.

Curiosamente, nos sarcomas em fases mais tardias, a marcação para CD206 sugeriu que tumores que expressam gal-3 apresentam menor quantidade de macrófagos M2, em relação aos tumores gal-3-negativos, mas não houve diferença significativa (FIGURA 22B). Os resultados da expressão de genes associados aos fenótipos M1 e M2 também não evidenciaram diferenças significativas, mas indicam que sarcomas de animais WT possuem maior expressão de iNOS, característica de macrófagos M1, em relação aos animais Gal-3 KO (FIGURA 23). Estes resultados devem ser melhor investigados, mas sugerem que a ausência de gal-3 contribua para uma maior 
participação de macrófagos M2, também em tumores já estabelecidos. Em contraste, alguns estudos tem mostrado a participação de gal-3 na ativação e infiltração de macrófagos M2 no tumor (MacKinnon et al., 2008; Jia et al., 2013).

Uma evidência que sustenta a predominância de macrófagos M2 na massa tumoral em fases tardias está relacionada ao NF-кB. Contrastando com o papel deste fator de transcrição em macrófagos durante as etapas iniciais da tumorigênese, foi demonstrado que NF-кB é inibido em TAMs derivados de fibrossarcoma murino. No decorrer da progressão tumoral, a sinalização por NFאB é inibida pela expressão constitutiva de homodímeros de p50 que, por sua vez, inibe a transcrição de citocinas pró-inflamatórias como IL-12p40 e TNF- $\alpha$. Assim, os TAMs passam a exibir um fenótipo mais similar a M2 (Biswas et al., 2006; Saccani et al., 2006).

É válido ressaltar que, mesmo sugerindo-se uma maior densidade de macrófagos M2 em sarcomas que não expressam gal-3, isto não resultou em produção mais elevada de VEGF, nem estimulou a angiogênese. Corroborando estes dados, Machado et al. (2014) demonstraram in vitro que macrófagos deficientes em gal-3 são menos responsivos ao estímulo de TGF- $\beta 1$ e secretam menos VEGF. Assim, nossos achados sugerem que a ausência de gal-3 resulta em macrófagos disfuncionais, causando um impacto significativo na angiogênese associada a tumores. 


\section{CONCLUSÃO}

Em um modelo in vivo de indução de sarcoma por carcinógeno, demonstramos que galectina-3 contribuiu para a angiogênese tumoral e que sua ausência acarretou em mudanças na estrutura vascular no interior da neoplasia e também em regiões adjacentes. Além disso, observamos que estas alterações estruturais refletiram em aspectos funcionais, como na diminuição do fluxo sanguíneo intratumoral. Estas alterações mostraram-se associadas a diferenças no padrão de infiltração de macrófagos: reduzida no caso de células CD68-positivas, porém aumentada no caso de células CD206-positivas em animais knockout para galectina-3. Este padrão indica aumento relativo da densidade de macrófagos M2 na ausência de galectina-3. Apesar de maior densidade de macrófagos M2, funcionalmente o padrão de angiogênese observado indica atenuação funcional de macrófagos associados a tumores. Portanto, na ausência de galectina-3, estes macrófagos parecem disfuncionais. O aumento da densidade de células CD206+ foi também observado nas fases iniciais da montagem da reação inflamatória em resposta ao 3metilcolantreno na ausência de galectina-3, pois já havia maior densidade de macrófagos comprometidos com o fenótipo M2. 


\section{ANEXO}

Valores de $\mathrm{C}_{\mathrm{T}}$ média e $\Delta \mathrm{C}_{\mathrm{T}}$ de cada amostra de animais WT e Gal-3 KO por PCR quantitativa. Sendo $\Delta \mathrm{C}_{\mathrm{T}}=\mathrm{C}_{\mathrm{T}}$ média do gene alvo $-\mathrm{C}_{\mathrm{T}}$ média do gene endógeno Hprt. $\mathrm{C}_{\mathrm{T}}$, Cycle Threshold.

\begin{tabular}{cccccc}
\hline Amostras & Cт média (Hprt) & CT média (Nos2) & Cт média (Cd206) & $\Delta \mathbf{C T}$ (Nos2) & $\Delta \mathbf{C T}($ Cd206) \\
\hline WT 01 & 19,24 & 26,53 & 19,93 & 7,29 & 0,69 \\
WT 02 & 19,26 & 25,59 & 19,94 & 6,32 & 0,68 \\
WT 03 & 19,42 & 24,46 & 20,60 & 5,04 & 1,18 \\
WT 04 & 19,05 & 25,27 & 19,86 & 6,21 & 0,81 \\
WT 05 & 19,50 & 25,73 & 20,39 & 6,23 & 0,89 \\
\hline Gal-3 KO 01 & 19,32 & 26,75 & 20,02 & 7,43 & 0,70 \\
Gal-3 KO 02 & 19,83 & 26,90 & 21,59 & 7,07 & 1,75 \\
Gal-3 KO 03 & 19,80 & 27,52 & 19,44 & 7,72 & $-0,36$ \\
Gal-3 KO 04 & 19,64 & 26,84 & 20,40 & 7,19 & 0,75 \\
\hline
\end{tabular}

\begin{tabular}{cccccc}
\hline Amostras & Cт média (Hprt) & Cт média (Il1b) & Cт média (Ifng) & $\Delta$ CT (Il1b) & $\Delta$ CT (Ifng) \\
\hline WT 01 & 19,17 & 23,84 & 27,63 & 4,68 & 8,46 \\
WT 02 & 19,13 & 22,11 & 26,35 & 2,98 & 7,22 \\
WT 03 & 19,62 & 20,61 & 25,93 & 0,99 & 6,31 \\
WT 04 & 19,10 & 20,93 & 25,72 & 1,82 & 6,62 \\
WT 05 & 19,55 & 23,00 & 28,80 & 3,45 & 9,25 \\
\hline Gal-3 KO 01 & 19,15 & 21,64 & 26,37 & 2,49 & 7,22 \\
Gal-3 KO 02 & 19,78 & 20,81 & 27,19 & 1,03 & 7,41 \\
Gal-3 KO 03 & 19,86 & 22,63 & 27,97 & 2,77 & 8,11 \\
Gal-3 KO 04 & 19,75 & 21,95 & 26,55 & 2,21 & 6,81 \\
\hline
\end{tabular}




\begin{tabular}{cccc}
\hline Amostras & Cт média (Hprt) & Cт média (Arg1) & $\Delta \mathbf{C T}$ \\
\hline WT 01 & 19,37 & 25,93 & 6,57 \\
WT 02 & 19,17 & 23,00 & 3,83 \\
WT 03 & 19,46 & 23,82 & 4,35 \\
WT 04 & 19,10 & 24,65 & 5,55 \\
WT 05 & 19,53 & 22,81 & 3,28 \\
\hline Gal-3 KO 01 & 19,18 & 26,38 & 7,20 \\
Gal-3 KO 02 & 19,68 & 25,01 & 5,33 \\
Gal-3 KO 03 & 19,74 & 26,19 & 6,45 \\
Gal-3 KO 04 & 19,54 & 25,07 & 5,53 \\
\hline
\end{tabular}

\begin{tabular}{cccc}
\hline Amostras & CT média (Hprt) & CT média (II10) & $\boldsymbol{\Delta C \mathbf { T }}$ \\
\hline WT 01 & 19,17 & 28,36 & 9,19 \\
WT 02 & 19,10 & 27,67 & 8,57 \\
WT 03 & 19,29 & 27,65 & 8,36 \\
WT 04 & 19,00 & 27,64 & 8,64 \\
WT 05 & 19,34 & 29,29 & 9,95 \\
\hline Gal-3 KO 01 & 19,16 & 27,79 & 8,63 \\
Gal-3 KO 02 & 19,81 & 28,33 & 8,52 \\
Gal-3 KO 03 & 19,71 & 28,16 & 8,45 \\
Gal-3 KO 04 & 19,65 & 28,51 & 8,86 \\
\hline
\end{tabular}




\section{REFERÊNCIAS BIBLIOGRÁFICAS}

Abdel-Aziz HO, Murai Y, Takasaki I, et al. (2008). Targeted disruption of the galectin-3 gene results in decreased susceptibility to NNK-induced lung tumorigenesis: an oligonucleotide microarray study. J Cancer Res Clin Oncol; 134(7):777-88.

Almuhaideb A, Papathanasiou N, Bomanji J (2011). ${ }^{18}$ F-FDG PET/CT imaging in oncology. Ann Saudi Med; 31(1):3-13.

Arango Duque G, Descoteaux A (2014). Macrophage cytokines: involvement in immunity and infectious diseases. Front Immunol; 5:491.

Arbiser JL, Moses MA, Fernandez CA, Ghiso N, Cao Y, Klauber N, Frank D, Brownlee M, Flynn E, Parangi S, Byers HR, Folkman J (1997). Oncogenic H-ras stimulates tumor angiogenesis by two distinct pathways. Proc Natl Acad Sci U S A; 94(3):861-6.

Aronen HJ, Pardo FS, Kennedy DN, Belliveau JW, Packard SD, Hsu DW, Hochberg FH, Fischman AJ, Rosen BR (2000). High microvascular blood volume is associated with high glucose uptake and tumor angiogenesis in human gliomas. Clin Cancer Res; 6(6):2189-200.

Aubin JE, Liu F, Malaval L, Gupta AK (1995). Osteoblast and chondroblast differentiation. Bone; 17(2 Suppl):77S-83S.

Bergers G, Brekken R, McMahon G, Vu TH, Itoh T, Tamaki K, Tanzawa K, Thorpe P, Itohara S, Werb Z, Hanahan D (2000). Matrix metalloproteinase-9 triggers the angiogenic switch during carcinogenesis. Nat Cell Biol; 2(10):737-44.

Beyer T, Townsend DW, Brun T, Kinahan PE, Charron M, Roddy R, Jerin J, Young J, Byars L, Nutt R (2000). A combined PET/CT scanner for clinical oncology. J Nucl Med; 41(8):1369-79.

Bingle L, Lewis CE, Corke, KP, Reed MW, Brown, NJ (2006). Macrophages promote angiogenesis in human breast tumour spheroids in vivo. Br.J.Cancer 94, 101-107. 
Biswas SK, Gangi L, Paul S, et al. (2006). A distinct and unique transcriptional program expressed by tumor-associated macrophages (defective NF-kappaB and enhanced IRF-3/STAT1 activation). Blood; 107(5):2112-22.

Biswas SK, Sica A, Lewis CE (2008). Plasticity of macrophage function during tumor progression: regulation by distinct molecular mechanisms. J Immunol.; 180(4):20117.

Boström MM, Irjala H, Mirtti T, Taimen P, Kauko T, Ålgars A, Jalkanen S, Boström PJ (2015). Tumor-Associated Macrophages Provide Significant Prognostic Information in Urothelial Bladder Cancer. PLoS One; 10(7):e0133552.

Buck AK, Reske SN (2004). Cellular origin and molecular mechanisms of 18F-FDG uptake: is there a contribution of the endothelium? J Nucl Med; 45(3):461-3.

Bussolino F, Mantovani A, Persico G (1997). Molecular mechanisms of blood vessel formation. Trends Biochem Sci; 22(7):251-6.

Chalmin F, Mignot G, Bruchard M, Chevriaux A, Végran F, Hichami A, Ladoire S, Derangère V, Vincent J, Masson D, Robson SC, Eberl G, Pallandre JR, Borg C, Ryffel B, Apetoh L, Rébé C, Ghiringhelli F. (2012). Stat3 and Gfi-1 transcription factors control Th17 cell immunosuppressive activity via the regulation of ectonucleotidase expression. Immunity. 36(3):362-73.

Chen HY, Fermin A, Vardhana S, Weng IC, Lo KF, Chang EY, Maverakis E, Yang RY, Hsu DK, Dustin ML, Liu FT (2009). Galectin-3 negatively regulates TCR-mediated CD4+ T-cell activation at the immunological synapse. Proc Natl Acad Sci USA; 106(34):14496-501.

Chen JJ, Chen JJ, Chiang CS, Hong JH, Yeh CK (2011). Assessment of tumor vasculature for diagnostic and therapeutic applications in a mouse model in vivo using 25-MHz power Doppler imaging. Ultrasonics; 51(8):925-31.

Chen P, Bonaldo P (2013). Role of macrophage polarization in tumor angiogenesis and vessel normalization: implications for new anticancer therapies. Int Rev Cell Mol Biol.; 301:1-35. 
Clark MA, Fisher C, Judson I, Thomas JM (2005). Soft-tissue sarcomas in adults. $N$ Engl J Med.; 353(7):701-11.

Coussens LM, Werb Z (2002). Inflammation and cancer. Nature. 420(6917):860-7.

Cretney E, Takeda K, Yagita H, Glaccum M, Peschon JJ, Smyth MJ (2002). Increased susceptibility to tumor initiation and metastasis in TNF-related apoptosis-inducing ligand-deficient mice. J Immunol; 168(3):1356-61.

Cvejic D, Savin S, Petrovic I, Selemetjev S, Paunovic I, Tatic S, Havelka M (2005). Galectin-3 and proliferating cell nuclear antigen (PCNA) expression in papillary thyroid carcinoma. Exp Oncol; 27(3):210-4.

D'Haene N, Sauvage S, Maris C, Adanja I, Le Mercier M, Decaestecker C, Baum L, Salmon I. (2013). VEGFR1 and VEGFR2 involvement in extracellular galectin-1and galectin-3-induced angiogenesis. PLoS One. 17;8(6):e67029.

Danella Polli C, Alves Toledo K, Franco LH, Sammartino Mariano V, de Oliveira LL, Soares Bernardes E, Roque-Barreira MC, Pereira-da-Silva G. Monocyte Migration Driven by Galectin-3 Occurs through Distinct Mechanisms Involving Selective Interactions with the Extracellular Matrix. ISRN Inflamm., 2013:259256.

Dagher SF, Wang JL, Patterson RJ (1995). Identification of galectin-3 as a factor in premRNA splicing. Proc Natl Acad Sci USA; 92(4):1213-7.

Davies LC, Jenkins SJ, Allen JE, Taylor PR (2013). Tissue-resident macrophages. Nat Immunol; 14(10):986-95.

De Bock K, Cauwenberghs S, Carmeliet P (2011). Vessel abnormalization: another hallmark of cancer? Molecular mechanisms and therapeutic implications. Curr Opin Genet Dev., 21(1):73-9.

de Faria PR, Chammas R, de Melo TL, Hsu DK, Liu FT, Nonogaki S, Cardoso SV, Loyola AM (2011). Absence of galectin-3 does not affect the development of experimental tongue carcinomas in mice. Exp Mol Pathol; 90(2):189-93. 
de Melo FH, Butera D, Medeiros RS, Andrade LN, Nonogaki S, Soares FA, Alvarez RA, Moura da Silva AM, Chammas R (2007). Biological applications of a chimeric probe for the assessment of galectin-3 ligands. J Histochem Cytochem.; 55(10):1015-26.

de Oliveira JT, Ribeiro C, Barros R, Gomes C, de Matos AJ, Reis CA, Rutteman GR, Gärtner F (2015). Hypoxia Up-Regulates Galectin-3 in Mammary Tumor Progression and Metastasis. PLoS One; 10(7):e0134458.

de Visser KE, Korets LV, Coussens LM. (2005). De novo carcinogenesis promoted by chronic inflammation is B lymphocyte dependent. Cancer Cell. 7(5):411-23.

Delacour D, Koch A, Jacob R (2009). The role of galectins in protein trafficking. Traffic; 10(10):1405-13.

Demotte N, Stroobant V, Courtoy PJ, et al. (2008). Restoring the association of the T cell receptor with CD8 reverses anergy in human tumor-infiltrating lymphocytes. Immunity; 28(3):414-24.

DeNardo DG, Andreu P and Coussens LM (2010). Interactions between lymphocytes and myeloid cells regulate pro- versus anti-tumor immunity. Cancer Metastasis Rev.; 29, 309-316.

Di Chiro G, DeLaPaz RL, Brooks RA, et al. (1982). Glucose utilization of cerebral gliomas measured by [18F] fluorodeoxyglucose and positron emission tomography. Neurology; 32(12):1323-9.

Dieu-Nosjean MC, Antoine M, Danel C, Heudes D, Wislez M, Poulot V, Rabbe N, Laurans L, Tartour E, de Chaisemartin L, Lebecque S, Fridman WH, Cadranel J (2008). Long-term survival for patients with non-small-cell lung cancer with intratumoral lymphoid structures. J Clin Oncol.; 26(27):4410-7.

Dimitrakopoulou-Strauss A, Strauss LG, Burger C (2001). Quantitative PET studies in pretreated melanoma patients: a comparison of 6-[18F]fluoro-L-dopa with 18F-FDG and (15)O-water using compartment and noncompartment analysis. J Nucl Med; 42(2):248-56. 
Dineen SP, Lynn KD, Holloway SE, et al. (2008). Vascular endothelial growth factor receptor 2 mediates macrophage infiltration into orthotopic pancreatic tumors in mice. Cancer Res. 68, 4340-4346.

Donnem T, Hu J, Ferguson M, Adighibe O, Snell C, Harris AL, Gatter KC, Pezzella F (2013). Vessel co-option in primary human tumors and metastases: an obstacle to effective anti-angiogenic treatment? Cancer Med; 2(4):427-36.

Drevs J, Hofmann I, Hugenschmidt H, et al. (2000). Effects of PTK787/ZK 222584, a specific inhibitor of vascular endothelial growth factor receptor tyrosine kinases, on primary tumor, metastasis, vessel density, and blood flow in a murine renal cell carcinoma model. Cancer Res; 60(17):4819-24.

Dumic J, Dabelic S, Flögel M (2006). Galectin-3: An open-ended story. Biochimica et Biophysica Acta., 1760:616-635.

Ebenstein P, Kinder B, Bankole DO, Richards FF, Armstrong MY (1979). Expression of endogenous xenotropic retrovirus by methylcholanthrene-induced squamous cell carcinoma of the mouse respiratory tract. J Exp Med.; 150(6):1567-70.

Elad-Sfadia G, Haklai R, Balan E, Kloog Y (2004). Galectin-3 augments K-Ras activation and triggers a Ras signal that attenuates ERK but not phosphoinositide 3-kinase activity. J Biol Chem; 279(33):34922-30.

Elola MT, Wolfenstein-Todel C, Troncoso MF, Vasta GR, Rabinovich GA (2007). Galectins: matricellular glycan-binding proteins linking cell adhesion, migration, and survival. Cell Mol Life Sci; 64(13):1679-700.

Eude-Le Parco I, Gendronneau G, Dang T, Delacour D, Thijssen VL, Edelmann W, Peuchmaur M, Poirier F (2009). Genetic assessment of the importance of galectin-3 in cancer initiation, progression, and dissemination in mice. Glycobiology; 19(1):68-75.

Facciabene A, Peng X, Hagemann IS, Balint K, Barchetti A, Wang LP, Gimotty PA, Gilks CB, Lal P, Zhang L, Coukos G (2011). Tumour hypoxia promotes tolerance and angiogenesis via CCL28 and T(reg) cells. Nature; 475(7355):226-30. 
Fang W, Ye L, Shen L, Cai J, Huang F, Wei Q, Fei X, Chen X, Guan H, Wang W, Li X, Ning G (2014). Tumor-associated macrophages promote the metastatic potential of thyroid papillary cancer by releasing CXCL8. Carcinogenesis; 35(8):1780-7.

Ferrara N (2009). Vascular endothelial growth factor. Arterioscler Thromb Vasc Biol; 29(6):789-91.

Fleischer AC (2000). Sonographic depiction of tumor vascularity and flow: from in vivo models to clinical applications. J Ultrasound Med; 19(1):55-61.

Flesher JW, Horn J, Lehner AF (1998). Carcinogenicity of 1-hydroxy-3methylcholanthrene and its electrophilic sulfate ester 1-sulfooxy-3methylcholanthrene in Sprague-Dawley rats. Biochem Biophys Res Commun. 243(1):30-5.

Forsberg F, Ro RJ, Potoczek M, Liu JB, Merritt CR, James KM, Dicker AP, Nazarian LN (2004). Assessment of angiogenesis: implications for ultrasound imaging. Ultrasonics; 42(1-9):325-30.

Fridman WH, Mlecnik B, Bindea G, Pagès F, Galon J (2011). Immunosurveillance in human non-viral cancers. Curr Opin Immunol; 23:272-278.

Fridman WH, Pagès F, Sautès-Fridman C, Galon J (2012). The immune contexture in human tumours: impact on clinical outcome. Nat Rev Cancer; 12(4):298-306.

Fukumura D, Jain RK (2008). Imaging angiogenesis and the microenvironment. APMIS; 116(7-8):695-715.

Fukushi J, Makagiansar IT, Stallcup WB. (2004). NG2 Proteoglycan Promotes Endothelial Cell Motility and Angiogenesis via Engagement of Galectin-3 and $\alpha 3 \beta 1$ Integrin. Mol Biol Cell 15:3580-3590.

Gabrilovich DI, Ostrand-Rosenberg S, Bronte V (2012). Coordinated regulation of myeloid cells by tumours. Nat. Rev.Immunol. 12, 253-268.

Gerhardt H, Betsholtz C (2003). Endothelial-pericyte interactions in angiogenesis. Cell Tissue Res. 314(1):15-23. 
Gollapudi K, Galet C, Grogan T, Zhang H, Said JW, Huang J, Elashoff D, Freedland SJ, Rettig M, Aronson WJ (2013). Association between tumor-associated macrophage infiltration, high grade prostate cancer, and biochemical recurrence after radical prostatectomy. Am J Cancer Res; 3(5):523-9.

Greijer AE, van der Groep P, Kemming D, et al. (2005). Up-regulation of gene expression by hypoxia is mediated predominantly by hypoxia-inducible factor 1 (HIF-1). $J$ Pathol; 206(3):291-304.

Grivennikov SI, Greten FR and Karin M (2010). Immunity, inflammation, and cancer. Cell; 140, 883-899.

Hanada T, Nakagawa M, Emoto A, Nomura,T, Nasu N, Nomura Y (2000). Prognostic value of tumor-associated macrophage count in human bladder cancer. Int. J. Urol. 7, 263-269.

Hanahan D, Folkman J (1996). Patterns and emerging mechanisms of the angiogenic switch during tumorigenesis. Cell; 86(3):353-64.

Hanahan D, Weinberg RA (2011). Hallmarks of cancer: the next generation. Cell; 144:646-674

Happel C, Steele AD, Finley MJ, Kutzler MA, Rogers TJ (2008). DAMGO-induced expression of chemokines and chemokine receptors: the role of TGF-beta1. J.Leukoc Biol. 83(4):956-63.

Harmey JH, Dimitriadis E, Kay E, Redmond HP, Bouchier-Hayes D (1998). Regulation of macrophage production of vascular endothelial growth factor (VEGF) by hypoxia and transforming growth factor beta-1. Ann Surg Oncol.; 5(3):271-8.

He H, Xu J, Warren CM, et al. (2012). Endothelial cells provide na instructive niche for the differentiation and functional polarization of M2-like macrophages. Blood 120, 3152-3162.

Hicklin DJ (2007). Promoting angiogenesis to a fault. Nat Biotechnol.; 25(3):300-2. 
Hirabayashi J, Kasai K (1993). The family of metazoan metal-independent betagalactoside-binding lectins: structure, function and molecular evolution. Glycobiology; 3(4):297-304.

Hlatky L, Hahnfeldt P, Folkman J (2002). Clinical application of antiangiogenic therapy: microvessel density, what it does and doesn't tell us. J Natl Cancer Inst; 94(12):88393.

Ho VW and Sly LM (2009). Derivation and characterization of murine alternatively activated (M2) macrophages. Methods Mol.Biol. 531, 173-185.

Höckel M, Vaupel P (2001). Tumor hypoxia: definitions and current clinical, biologic, and molecular aspects. J Natl Cancer Inst; 93(4):266-76.

Hsu DK, Yang RY, Pan Z, Yu L, Salomon DR, Fung-Leung WP, Liu FT (2000). Targeted disruption of the galectin-3 gene results in attenuated peritoneal inflammatory responses. Am J Pathol; 156(3):1073-83.

Huang B, Lei Z, Zhao J, Gong W, Liu J, Chen Z, Liu Y, Li D, Yuan Y, Zhang GM, Feng ZH (2007). CCL2/CCR2 pathway mediates recruitment of myeloid suppressor cells to cancers. Cancer Lett; 252(1):86-92.

Hughes RC (1997). The galectin family of mammalian carbohydrate-binding molecules. Biochem Soc Trans; 25(4):1194-8

Hunt TK, Knighton DR, Thakral KK, Goodson WH 3rd, Andrews WS (1984). Studies on inflammation and wound healing: angiogenesis and collagen synthesis stimulated in vivo by resident and activated wound macrophages. Surgery; 96(1):48-54.

Ichiya Y, Kuwabara Y, Sasaki M, Yoshida T, Akashi Y, Murayama S, Nakamura K, Fukumura T, Masuda K (1996). FDG-PET in infectious lesions: The detection and assessment of lesion activity. Ann Nucl Med., 10(2):185-91.

Ikemori RY, Machado CM, Furuzawa KM, Nonogaki S, Osinaga E, Umezawa K, de Carvalho MA, Verinaud L, Chammas R (2014). Galectin-3 up-regulation in hypoxic and nutrient deprived microenvironments promotes cell survival. PLoS One; 9(11):e111592. 
Italiani P, Boraschi D (2014). From Monocytes to M1/M2 Macrophages: Phenotypical vs. Functional Differentiation. Front Immunol; 5:514.

Iwai T, Sugimoto M, Harada S, Yorozu K, Kurasawa M, Yamamoto K (2016). Continuous administration of bevacizumab plus capecitabine, even after acquired resistance to bevacizumab, restored anti-angiogenic and antitumor effect in a human colorectal cancer xenograft model. Oncol Rep; 36(2):626-32.

Jain RK, Duda DG, Clark JW, Loeffler JS (2006). Lessons from phase III clinical trials on anti-VEGF therapy for cancer. Nat Clin Pract Oncol; 3(1):24-40.

Jeon SB, Yoon HJ, Chang CY, Koh HS, Jeon SH, Park EJ (2010). Galectin-3 exerts cytokine-like regulatory actions through the JAK-STAT pathway. J Immunol; 185(11):7037-46.

Jia W, Kidoya H, Yamakawa D, Naito H, Takakura N (2013). Galectin-3 accelerates M2 macrophage infiltration and angiogenesis in tumors. Am J Pathol. 182(5):1821-31.

Jiang SS, Weng DS, Wang QJ, Pan K, Zhang YJ, Li YQ, Li JJ, Zhao JJ, He J, Lv L, Pan QZ, Xia JC (2014). Galectin-3 is associated with a poor prognosis in primary hepatocellular carcinoma. J Transl Med., 12(1):273.

Kamper P, Bendix K, Hamilton-Dutoit S, Honore B, Nyengaard JR, d'Amore F (2011). Tumor infiltrating macrophages correlate with adverse prognosis and Epstein-Barr virus status in classical Hodgkin's lymphoma. Haematologica. 96(2):269-76.

Kaplan DH, Shankaran V, Dighe AS, Stockert E, Aguet M, Old LJ, Schreiber RD (1998). Demonstration of an interferon gamma-dependent tumor surveillance system in immunocompetent mice. Proc Natl Acad Sci USA; 95(13):7556-61.

Karin M, Greten FR (2005). NF-kappaB: linking inflammation and immunity to cancer development and progression. Nat Rev Immunol; 5(10):749-59.

Karlsson A, Christenson K, Matlak M, Björstad A, Brown KL, Telemo E, Salomonsson E, Leffler H, Bylund J (2009). Galectin-3 functions as an opsonin and enhances the macrophage clearance of apoptotic neutrophils. Glycobiology; 19(1):16-20. 
Khaldoyanidi SK, Glinsky VV, Sikora L, Glinskii AB, Mossine VV, Quinn TP, Glinsky GV, Sriramarao P (2003). MDA-MB-435 human breast carcinoma cell homo- and heterotypic adhesion under flow conditions is mediated in part by ThomsenFriedenreich antigen-galectin-3 interactions. J Biol Chem.; 278(6):4127-34.

Khanna C, Khan J, Nguyen P, Prehn J, Caylor J, Yeung C, Trepel J, Meltzer P, Helman L (2001). Metastasis-associated differences in gene expression in a murine model of osteosarcoma. Cancer Res; 61(9):3750-9.

Kim R, Emi M and Tanabe K (2007). Cancer immunoediting from immune surveillance to immune escape. Immunology; 121, 1-14.

Koebel CM, Vermi W, Swann JB, Zerafa N, Rodig SJ, Old LJ, Smyth MJ, Schreiber RD (2007). Adaptive immunity maintains occult cancer in an equilibrium state. Nature; 450(7171):903-7.

Koh YW, Park CS, Yoon DH, Suh C, Huh J (2014). CD163 expression was associated with angiogenesis and shortened survival in patients with uniformly treated classical Hodgkin lymphoma. PLoS One; 9(1):e87066.

Koide N, Nishio A, Sato T, Sugiyama A, Miyagawa S (2004). Significance of macrophage chemoattractant protein-1 expression and macrophage infiltration in squamous cell carcinoma of the esophagus. Am.J. Gastroenterol. 99, 1667-1674.

Komar G, Lehtiö K, Seppänen M, et al. (2014). Prognostic value of tumour blood flow, $\left[{ }^{8} \mathrm{~F}\right] \mathrm{EF} 5$ and $\left[{ }^{8} \mathrm{~F}\right] \mathrm{FDG}$ PET/CT imaging in patients with head and neck cancer treated with radiochemotherapy. Eur J Nucl Med Mol Imaging; 41(11):2042-50.

Kushner EJ, Bautch VL (2013). Building blood vessels in development and disease. Curr Opin Hematol., 20(3):231-6.

Lakshmi Narendra B, Eshvendar Reddy K, Shantikumar S, Ramakrishna S (2013). Immune system: a double-edged sword in cancer. Inflamm Res. 62(9):823-34.

Laughner E, Taghavi P, Chiles K, Mahon PC, Semenza GL (2001). HER2 (neu) signaling increases the rate of hypoxia-inducible factor 1alpha (HIF-1alpha) synthesis: novel mechanism for HIF-1-mediated vascular endothelial growth factor expression. $\mathrm{Mol}$ Cell Biol; 21(12):3995-4004. 
Lee YJ, Song YK, Song JJ, Siervo-Sassi RR, Kim HR, Li L, Spitz DR, Lokshin A, Kim JH (2003). Reconstitution of galectin-3 alters glutathione content and potentiates TRAIL-induced cytotoxicity by dephosphorylation of Akt. Exp Cell Res; 288(1):2134.

Leek RD, Lewis CE, Whitehouse R, Greenal M, Clarke J, Harris AL (1996). Association of macrophage infiltration with angiogenesis and prognosis in invasive breast carcinoma. Cancer Res. 56, 4625-4629.

Levental KR, Yu H, Kass L, et al. (2009). Matrix crosslinking forces tumor progression by enhancing integrin signaling. Cell; 139(5):891-906.

Lewis CE, Pollard JW (2006). Distinct role of macrophages in different tumor microenvironments. Cancer Res; 66(2):605-12.

Lewis JS, Landers RJ, Underwood JC, Harris AL, Lewis CE (2000). Expression of vascular endothelial growth factor by macrophages is upregulated in poorly vascularized areas of breast carcinomas. J. Pathol. 192, 150-158.

Li JL, Sainson RC, Shi W, Leek R, Harrington LS, Preusser M, Biswas S, Turley H, Heikamp E, Hainfellner JA, Harris AL (2007). Delta-like 4 Notch ligand regulates tumor angiogenesis, improves tumor vascular function, and promotes tumor growth in vivo. Cancer Res.; 67(23):11244-53.

Li LC, Li J, Gao J (2014). Functions of galectin-3 and its role in fibrotic diseases. $J$ Pharmacol Exp Ther; 351(2):336-43.

Li Y, Komai-Koma M, Gilchrist DS, Hsu DK, Liu FT, Springall T, Xu D (2008). Galectin-3 is a negative regulator of lipopolysaccharide-mediated inflammation. $J$ Immunol., 181(4):2781-9.

Liu FT, Hsu DK, Zuberi RI, Kuwabara I, Chi EY, Henderson WR Jr (1995). Expression and function of galectin-3, a beta-galactoside-binding lectin, in human monocytes and macrophages. Am J Pathol; 147(4):1016-28.

Liu FT, Patterson RJ, Wang JL (2002). Intracellular functions of galectins. Biochim Biophys Acta.; 1572(2-3):263-73. 
Liu FT and Rabinovich GA (2005). Galectins as modulators of tumour progression. Nat Ver Cancer. 5(1):29-41.

Liu L, Sakai T, Sano N, Fukui K (2004). Nucling mediates apoptosis by inhibiting expression of galectin-3 through interference with nuclear factor kappaB signalling. Biochem J.; 380(Pt 1):31-41.

Livak KJ, Schmittgen TD (2001). Analysis of relative gene expression data using realtime quantitative PCR and the 2(-Delta Delta C(T)) Method. Methods; 25(4):402-8.

Loening AM, Gambhir SS (2003). AMIDE: a free software tool for multimodality medical image analysis. Mol Imaging. 2(3):131-7.

Lu T, Ramakrishnan R, Altiok S, et al. (2011). Tumor-infiltrating myeloid cells induce tumor cell resistance to cytotoxic T cells in mice. J. Clin.Invest. 121, 4015-4029.

Lumeng CN, Bodzin JL, Saltiel AR (2007). Obesity induces a phenotypic switch in adipose tissue macrophage polarization. J Clin Invest; 117(1):175-84.

Machado CM, Andrade LN, Teixeira VR, Costa FF, Melo CM, dos Santos SN, Nonogaki S, Liu FT, Bernardes ES, Camargo AA, Chammas R (2014). Galectin-3 disruption impaired tumoral angiogenesis by reducing VEGF secretion from TGF $\beta 1$-induced macrophages. Cancer Med., 3(2):201-14.

MacKinnon AC, Farnworth SL, Hodkinson PS, Henderson NC, Atkinson KM, Leffler H, Nilsson UJ, Haslett C, Forbes SJ, Sethi T (2008). Regulation of alternative macrophage activation by galectin-3. J Immunol. 15;180(4):2650-8.

Maniotis AJ, Folberg R, Hess A, Seftor EA, Gardner LM, Pe'er J, Trent JM, Meltzer PS, Hendrix MJ (1999). Vascular channel formation by human melanoma cells in vivo and in vitro: vasculogenic mimicry. Am J Pathol.; 155(3):739-52.

Mantovani A, Allavena P, Sica A, Balkwill F (2008). Cancer-related inflammation. Nature; 454(7203):436-44.

Mantovani A, Sica A, Allavena P, Garlanda C, Locati M (2009). Tumor-associated macrophages and the related myeloid-derived suppressor cells as a paradigm of the diversity of macrophage activation. Hum.Immunol. 70, 325-330. 
Mantovani A, Sica A, Sozzani S, Allavena P, Vecchi A, Locati M. (2004). The chemokine system in diverse forms of macrophage activation and polarization. Trends Immunol.; 25(12):677-86.

Mantovani A, Sozzani S, Locati M, Allavena P, Sica A (2002). Macrophage polarization: tumor-associated macrophages as a paradigm for polarized M2 mononuclear phagocytes. Trends in Immunology. 23(11):549-555.

Markowska AI, Liu FT, Panjwani N (2010). Galectin-3 is an important mediator of VEGF- and bFGF-mediated angiogenic response. J Exp Med. 207(9):1981-93.

Markowska AI, Jefferies KC, Panjwani N (2011). Galectin-3 protein modulates cell surface expression and activation of vascular endothelial growth factor receptor 2 in human endothelial cells. J Biol Chem. 286(34):29913-21.

Maronpot RR, Flake G, Huff J (2004). Relevance of animal carcinogenesis findings to human cancer predictions and prevention. Toxicol Pathol; 32 Suppl 1:40-8.

Martin F, Apetoh L, Ghiringhelli F (2012). Controversies on the role of Th17 in cancer: a TGF- $\beta$-dependent immunosuppressive activity? Trends Mol Med. 18(12):742-9.

Martinez FO, Helming L, Gordon S (2009). Alternative activation of macrophages: na immunologic functional perspective. Annu.Rev.Immunol. 27, 451-483.

Matarrese P, Tinari N, Semeraro ML, Natoli C, Iacobelli S, Malorni W (2000). Galectin-3 overexpression protects from cell damage and death by influencing mitochondrial homeostasis. FEBS Lett.; 473(3):311-5.

Matsushita H, Vesely MD, Koboldt DC, et al. (2012). Cancer exome analysis reveals a Tcell-dependent mechanism of cancer immunoediting. Nature; 482(7385):400-4.

Meira LB, Bugni JM, Green SL, Lee CW, Pang B, Borenshtein D, Rickman BH, Rogers AB, Moroski-Erkul CA, McFaline JL, Schauer DB, Dedon PC, Fox JG, Samson LD (2008). DNA damage induced by chronic inflammation contributes to colon carcinogenesis in mice. J Clin Invest; 118(7):2516-25. 
Melo FH, Butera D, Junqueira Mde S, Hsu DK, da Silva AM, Liu FT, Santos MF, Chammas R (2011). The promigratory activity of the matricellular protein galectin-3 depends on the activation of PI-3 kinase. PLoS One; 6(12):e29313.

Mills CD. (2001) Macrophage arginine metabolism to ornithine/urea or nitric oxide/citrulline: a life or death issue. Crit Rev Immunol. 21(5):399-425.

Mirza R, DiPietro LA, Koh TJ (2009). Selective and specific macrophage ablation is detrimental to wound healing in mice. Am J Pathol; 175(6):2454-62.

Mithoefer AB, Supran S, Freeman RB (2002). Risk factors associated with the development of skin cancer after liver transplantation. Liver Transpl; 8(10):939-44.

Modolell M, Corraliza IM, Link F, Soler G, Eichmann K (1995). Reciprocal regulation of the nitric oxide synthase/arginase balance in mouse bone marrow-derived macrophages by TH1 and TH2 cytokines. Eur.J. Immunol. 25, 1101-1104.

Mosser DM, Edwards JP (2008). Exploring the full spectrum of macrophage activation. Nat Rev Immunol. 8(12):958-69.

Mourad-Zeidan AA, Melnikova VO, Wang H, Raz A, Bar-Eli M (2008). Expression profiling of Galectin-3-depleted melanoma cells reveals its major role in melanoma cell plasticity and vasculogenic mimicry. Am J Pathol.; 173(6):1839-52.

Moutsatsos IK, Wade M, Schindler M, Wang JL (1987). Endogenous lectins from cultured cells: nuclear localization of carbohydrate binding protein 35 in proliferating 3T3 fibroblasts. Proc Natl Acad Sci USA. 84:6452-6.

Mullani NA, Herbst RS, O'Neil RG, Gould KL, Barron BJ, Abbruzzese JL (2008). Tumor blood flow measured by PET dynamic imaging of first-pass 18F-FDG uptake: a comparison with 15O-labeled water-measured blood flow. J Nucl Med; 49(4):517-23.

Murdoch C, Giannoudis A, Lewis CE (2004). Mechanisms regulating the recruitment of macrophages into hypoxic areas of tumors and other ischemic tissues. Blood; 104(8):2224-34.

Murdoch C, Muthana M, Coffelt SB, Lewis CE (2008). The role of myeloid cells in the promotion of tumour angiogenesis. Nat.Rev.Cancer 8, 618-631. 
Nagy JA, Chang SH, Shih SC, Dvorak AM, Dvorak HF (2010). Heterogeneity of the tumor vasculature. Semin Thromb Hemost; 36(3):321-31.

Nakahara S, Oka N, Raz A (2005). On the role of galectin-3 in cancer apoptosis. Apoptosis; 10(2):267-75.

Nakahara S, Oka N, Wang Y, Hogan V, Inohara H, Raz A (2006). Characterization of the nuclear import pathways of galectin-3. Cancer Res; 66(20):9995-10006.

Nangia-Makker P, Balan V, Raz A (2008). Regulation of tumor progression by extracellular galectin-3. Cancer Microenviron; 1(1):43-51.

Nangia-Makker P, Hogan V, Honjo Y, Baccarini S, Tait L, Bresalier R, Raz A (2002). Inhibition of human cancer cell growth and metastasis in nude mice by oral intake of modified citrus pectin. J Natl Cancer Inst.; 94(24):1854-62.

Nangia-Makker P, Honjo Y, Sarvis R, Akahani S, Hogan V, Pienta KJ, Raz A (2000). Galectin-3 induces endothelial cell morphogenesis and angiogenesis. Am J Pathol. 156(3):899-909.

Nangia-Makker P, Raz T, Tait L, Hogan V, Fridman R, Raz A (2007). Galectin-3 cleavage: a novel surrogate marker for matrix metalloproteinase activity in growing breast cancers. Cancer Res.; 67(24):11760-8.

Nangia-Makker P, Wang Y, Raz T, Tait L, Balan V, Hogan V, Raz A (2010). Cleavage of galectin-3 by matrix metalloproteases induces angiogenesis in breast cancer. Int $J$ Cancer.; 127(11):2530-41.

Newlaczyl AU, Yu LG (2011). Galectin-3--a jack-of-all-trades in cancer. Cancer Lett; 313(2):123-8.

Nishi Y, Sano H, Kawashima T, et al. (2007). Role of galectin-3 in human pulmonary fibrosis. Allergol Int; 56(1):57-65.

Nishie A, Ono M, Shono T, et al. (1999). Macrophage infiltration and hemeoxygenase-1 expression correlate with angiogenesis in human gliomas. Clin. Cancer Res. 5, 11071113.

Niu G, Chen X (2009). PET Imaging of Angiogenesis. PET Clin; 4(1):17-38. 
Noguera-Troise I, Daly C, Papadopoulos NJ, Coetzee S, Boland P, Gale NW, Lin HC, Yancopoulos GD, Thurston G (2006). Blockade of Dll4 inhibits tumour growth by promoting non-productive angiogenesis. Nature; 444(7122):1032-7.

Noman MZ, Messai Y, Carré T, Akalay I, Méron M, Janji B, Hasmim M, Chouaib S (2011) Microenvironmental hypoxia orchestrating the cell stroma cross talk, tumor progression and antitumor response. Crit Rev Immunol; 31(5):357-377.

O'Sullivan T, Saddawi-Konefka R, Vermi W, et al. (2012). Cancer immunoediting by the innate immune system in the absence of adaptive immunity. $J$ Exp Med; 209(10):1869-82.

Ochieng J, Fridman R, Nangia-Makker P, Kleiner DE, Liotta LA, Stetler-Stevenson WG, Raz A (1994). Galectin-3 is a novel substrate for human matrix metalloproteinases-2 and -9. Biochemistry.; 33(47):14109-14.

Ochieng J, Furtak V, Lukyanov P (2004). Extracellular functions of galectin-3. Glycoconj J., 19(7-9):527-35.

Ochieng J, Leite-Browning ML, Warfield P (1998). Regulation of cellular adhesion to extracellular matrix proteins by galectin-3. Biochem Biophys Res Commun; 246(3):788-91.

Oka N, Nakahara S, Takenaka Y, Fukumori T, Hogan V, Kanayama HO, Yanagawa T, Raz A (2005). Galectin-3 inhibits tumor necrosis factor-related apoptosis-inducing ligand-induced apoptosis by activating Akt in human bladder carcinoma cells. Cancer Res; 65(17):7546-53.

Oostendorp M, Douma K, Hackeng TM, van Zandvoort MA, Post MJ, Backes WH (2010). Pharmacokinetics of contrast agents targeted to the tumor vasculature in molecular magnetic resonance imaging. Contrast Media Mol Imaging; 5(1):9-17.

Paik S, Shak S, Tang G, Kim C, Baker J, Cronin M, Baehner FL, Walker MG, Watson D, Park T, Hiller W, Fisher ER, Wickerham DL, Bryant J, Wolmark N (2004). A multigene assay to predict recurrence of tamoxifen-treated, node-negative breast cancer. N Engl J Med. 351(27):2817-26. 
Park JY, Shigenaga MK, Ames BN (1996). Induction of cytochrome P4501A1 by 2,3,7,8tetrachlorodibenzo-p-dioxin or indolo(3,2-b)carbazole is associated with oxidative DNA damage. Proc Natl Acad Sci USA; 93(6):2322-7.

Paron I, Scaloni A, Pines A, Bachi A, Liu FT, Puppin C, Pandolfi M, Ledda L, Di Loreto C, Damante G, Tell G (2003). Nuclear localization of Galectin-3 in transformed thyroid cells: a role in transcriptional regulation. Biochem Biophys Res Commun; 302(3):545-53.

Peichev M, Naiyer AJ, Pereira D, et al. (2000). Expression of VEGFR-2 and AC133 by circulating human CD34(+) cells identifies a population of functional endothelial precursors. Blood; 95(3):952-8.

Perillo NL, Marcus ME, Baum LG (1998). Galectins: versatile modulators of cell adhesion, cell proliferation, and cell death. J Mol Med. 76:402-12.

Pezzella F, Pastorino U, Tagliabue E, et al. (1997). Non-small-cell lung carcinoma tumor growth without morphological evidence of neo-angiogenesis. Am J Pathol; 151(5):1417-23.

Phelps ME (2000). PET: the merging of biology and imaging into molecular imaging. $J$ Nucl Med; 41(4):661-81.

Piccolo E, Tinari N, Semeraro D, et al. (2013). LGALS3BP, lectin galactoside-binding soluble 3 binding protein, induces vascular endothelial growth factor in human breast cancer cells and promotes angiogenesis. J Mol Med (Berl); 91(1):83-94.

Pio BS, Byrne FR, Aranda R, Boulay G, Spicher K, Song MH, Birnbaumer L, Phelps ME, Czernin J, Silverman DH (2003). Noninvasive quantification of bowel inflammation through positron emission tomography imaging of 2-deoxy-2-[18F]fluoro-D-glucoselabeled white blood cells. Mol Imaging Biol., 5(4):271-7.

Pollard JW (2009). Trophic macrophages in development and disease. Nat Rev Immunol; 9(4):259-70.

Prosniak M, Harshyne LA, Andrews DW, Kenyon LC, Bedelbaeva K, Apanasovich TV, Heber-Katz E, Curtis MT, Cotzia P, Hooper DC (2013). Glioma grade is associated 
with the accumulation and activity of cells bearing M2 monocyte markers. Clin Cancer Res., 19(14):3776-86.

Qian BZ and Pollard JW (2010). Macrophage diversity enhances tumor progression and metastasis. Cell; 141, 39-51.

Qin Z, Kim HJ, Hemme J, Blankenstein T (2002). Inhibition of methylcholanthreneinduced carcinogenesis by an interferon gamma receptor-dependent foreign body reaction. J Exp Med; 195(11):1479-90.

Quattrochi LC, Vu T, Tukey RH (1994). The human CYP1A2 gene and induction by 3methylcholanthrene. A region of DNA that supports AH-receptor binding and promoter-specific induction. J Biol Chem. 269(9):6949-54.

Quintana FJ, Basso AS, Iglesias AH, Korn T, Farez MF, Bettelli E, Caccamo M, Oukka M, Weiner HL (2008). Control of T(reg) and T(H)17 cell differentiation by the aryl hydrocarbon receptor. Nature. 453(7191):65-71.

Rabinovich GA, Croci DO (2012). Regulatory circuits mediated by lectin-glycan interactions in autoimmunity and cancer. Immunity; 36(3):322-35.

Rabinovich GA, Toscano MA, Jackson SS, Vasta GR (2007). Functions of cell surface galectin-glycoprotein lattices. Curr Opin Struct Biol; 17(5):513-20.

Raica M, Cimpean AM, Ribatti D (2009). Angiogenesis in pre-malignant conditions. Eur J Cancer; 45(11):1924-34.

Redente EF, Dwyer-Nield LD, Merrick DT, Raina K, Agarwal R, Pao W, Rice PL, Shroyer KR, Malkinson AM (2010). Tumor progression stage and anatomical site regulate tumor-associated macrophage and bone marrow-derived monocyte polarization. Am J Pathol; 176(6):2972-85.

Relf M, LeJeune S, Scott PA, et al. (1997). Expression of the angiogenic factors vascular endothelial cell growth factor, acidic and basic fibroblast growth factor, tumor growth factor beta-1, platelet-derived endothelial cell growth factor, placenta growth factor, and pleiotrophin in human primary breast cancer and its relation to angiogenesis. Cancer Res; 57(5):963-9. 
Rice JM, Kovatch RM, Anderson LM (1989). Intraperitoneal mesotheliomas induced in mice by a polycyclic aromatic hydrocarbon. J Toxicol Environ Health; 27(1):153-60.

Ruffell B, Affara NI, Coussens LM (2012). Differential macrophage programming in the tumor microenvironment. Trends Immunol. 33, 119-126.

Saccani A, Schioppa T, Porta C, Biswas SK, Nebuloni M, Vago L, Bottazzi B, Colombo MP, Mantovani A, Sica A (2006). p50 nuclear factor-kappaB overexpression in tumor-associated macrophages inhibits M1 inflammatory responses and antitumor resistance. Cancer Res; 66(23):11432-40.

Sano H, Hsu DK, Apgar JR, Yu L, Sharma BB, Kuwabara I, Izui S, Liu FT (2003). Critical role of galectin-3 in phagocytosis by macrophages. J Clin Invest; 112(3):38997.

Sato S, Hughes RC (1992). Binding specificity of a baby hamster kidney lectin for H type I and II chains, polylactosamine glycans, and appropriately glycosylated forms of laminin and fibronectin. J Biol Chem.; 267(10):6983-90.

Sato S and Hughes RCJ (1994). Regulation of secretion and surface expression of Mac-2, a galactoside-binding protein of macrophages. J Biol Chem. 269:4424-30.

Saussez S, Nonclercq D, Laurent G, Wattiez R, André S, Kaltner H, Gabius HJ, Kiss R, Toubeau G (2005). Toward functional glycomics by localization of tissue lectins: immunohistochemical galectin fingerprinting during diethylstilbestrol-induced kidney tumorigenesis in male Syrian hamster. Histochem Cell Biol; 123(1):29-41.

Savage ND, de Boer T, Walburg KV, Joosten SA, van Meijgaarden K, Geluk A, Ottenhoff TH (2008). Human anti-inflammatory macrophages induce Foxp3+ GITR+ CD25+ regulatory $\mathrm{T}$ cells, which suppress via membrane-bound TGFbeta-1. J Immunol; 181(3):2220-6.

Sehgal CM, Arger PH, Rowling SE, Conant EF, Reynolds C, Patton JA (2000). Quantitative vascularity of breast masses by Doppler imaging: regional variations and diagnostic implications. J Ultrasound Med; 19(7):427-40.

Shekhar MP, Nangia-Makker P, Tait L, Miller F, Raz A (2004). Alterations in galectin-3 expression and distribution correlate with breast cancer progression: functional 
analysis of galectin-3 in breast epithelial-endothelial interactions. Am J Pathol.; 165(6):1931-41.

Shields MA, Dangi-Garimella S, Redig AJ, Munshi HG (2012). Biochemical role of the collagen-rich tumour microenvironment in pancreatic cancer progression. Biochem J; 441(2):541-52.

Sica A, Allavena P, Mantovani A (2008). Cancer related inflammation: the macrophage connection. Cancer Lett.; 267(2):204-15.

Sica A, Saccani A, Bottazzi B, Polentarutti N, Vecchi A, van Damme J, Mantovani A (2000). Autocrine production of IL-10 mediates defective IL-12 production and NFkappa B activation in tumor-associated macrophages. J Immunol. 164(2):762-7.

Solinas G, Germano G, Mantovani A, Allavena P (2009). Tumor-associated macrophages (TAM) as major players of the cancer-related inflammation. $J$ Leukoc Biol. 86(5):1065-73.

Song S, Ji B, Ramachandran V, Wang H, Hafley M, Logsdon C, Bresalier RS (2012). Overexpressed galectin-3 in pancreatic cancer induces cell proliferation and invasion by binding Ras and activating Ras signaling. PLoS One; 7(8):e42699.

Stillman BN, Hsu DK, Pang M, Brewer CF, Johnson P, Liu FT, Baum LG (2006). Galectin-3 and galectin-1 bind distinct cell surface glycoprotein receptors to induce $\mathrm{T}$ cell death. J Immunol.; 176(2):778-89.

Stockmann C, Doedens A, Weidemann A, Zhang N, Takeda N, Greenberg JI, Cheresh DA, Johnson RS (2008). Deletion of vascular endothelial growth factor in myeloid cells accelerates tumorigenesis. Nature; 456(7223):814-8.

Stockmann C, Schadendorf D, Klose R, Helfrich I (2014). The impact of the immune system on tumor: angiogenesis and vascular remodeling. Front Oncol., 4:69.

Sun T, Yang Y, Luo X, Cheng Y, Zhang M, Wang K, Ge C (2014). Inhibition of tumor angiogenesis by interferon- $\gamma$ by suppression of tumor-associated macrophage differentiation. Oncol Res; 21(5):227-35. 
Teng MWL, Swann JB, Koebel CM, Schreiber RD and Smyth MJ (2008). Immunemediated dormancy: an equilibrium with cancer. J. Leukoc. Biol.; 84, 988-993.

Théry C, Boussac M, Véron P, Ricciardi-Castagnoli P, Raposo G, Garin J, Amigorena S (2001). Proteomic analysis of dendritic cell-derived exosomes: a secreted subcellular compartment distinct from apoptotic vesicles. J Immunol; 166(12):7309-18.

Tiemessen MM, Jagger AL, Evans HG, van Herwijnen MJ, John S, Taams LS (2007). CD4+CD25+Foxp3+ regulatory $\mathrm{T}$ cells induce alternative activation of human monocytes/macrophages. Proc Natl Acad Sci USA; 104(49):19446-51.

Tixier F, Groves AM, Goh V, Hatt M, Ingrand P, Le Rest CC, Visvikis D (2014). Correlation of intra-tumor 18F-FDG uptake heterogeneity indices with perfusion CT derived parameters in colorectal cancer. PLoS One; 9(6):e99567.

Torroella-Kouri M, Rodríguez D, Caso R (2013). Alterations in macrophages and monocytes from tumor-bearing mice: evidence of local and systemic immune impairment. Immunol Res.; 57(1-3):86-98.

Tsuboi S, Sutoh M, Hatakeyama S, et al. (2011). A novel strategy for evasion of NK cell immunity by tumours expressing core2 O-glycans. EMBO J.; 30(15):3173-85.

van den Brûle F, Califice S, Castronovo V (2004). Expression of galectins in cancer: a critical review. Glycoconj J.; 19(7-9):537-42.

van Elmpt W, Das M, Hüllner M, et al. (2013). Characterization of tumor heterogeneity using dynamic contrast enhanced CT and FDG-PET in non-small cell lung cancer. Radiother Oncol; 109(1):65-70.

Veldhoen M, Hirota K, Westendorf AM, Buer J, Dumoutier L, Renauld JC, Stockinger B (2008). The aryl hydrocarbon receptor links TH17-cell-mediated autoimmunity to environmental toxins. Nature. 453(7191):106-9.

Wang R, Zhang J, Chen S, Lu M, Luo X, Yao S, Liu S, Qin Y, Chen H (2011). Tumorassociated macrophages provide a suitable microenvironment for non-small lung cancer invasion and progression. Lung Cancer; 74(2):188-96. 
Wang W, Guo H, Geng J, Zheng X, Wei H, Sun R, Tian Z (2014). Tumor-released Galectin-3, a soluble inhibitory ligand of human NKp30, plays an important role in tumor escape from NK cell attack. J Biol Chem.; 289(48):33311-9.

Wang Y, Nangia-Makker P, Tait L, Balan V, Hogan V, Pienta KJ, Raz A (2009). Regulation of prostate cancer progression by galectin-3. Am J Pathol; 174(4):151523.

Watnick RS (2012). The role of the tumor microenvironment in regulating angiogenesis. Cold Spring Harb Perspect Med. 2(12).

Wen Y, Makagiansar IT, Fukushi J, Liu FT, Fukuda MN, Stallcup WB (2006). Molecular basis of interaction between NG2 proteoglycan and galectin-3. J Cell Biochem. 1;98(1):115-27.

Wesley UV, Vemuganti R, Ayvaci ER, Dempsey RJ (2013). Galectin-3 enhances angiogenic and migratory potential of microglial cells via modulation of integrin linked kinase signaling. Brain Res., 1496:1-9.

Willmann JK, van Bruggen N, Dinkelborg LM, Gambhir SS (2008). Molecular imaging in drug development. Nat Rev Drug Discov; 7(7):591-607.

Wiseman DM, Polverini PJ, Kamp DW, Leibovich SJ (1988). Transforming growth factor-beta (TGF beta) is chemotactic for human monocytes and induces their expression of angiogenic activity. Biochem Biophys Res Commun. 157(2):793-800.

Xu Y, Li C, Sun J, Li J, Gu X, Xu W (2016). Antitumor effects of galectin-3 inhibition in human renal carcinoma cells. Exp Biol Med (Maywood); 241(13):1365-73.

Yang E, Shim JS, Woo HJ, Kim KW, Kwon HJ (2007). Aminopeptidase N/CD13 induces angiogenesis through interaction with a pro-angiogenic protein, galectin-3. Biochem Biophys Res Commun.; 363(2):336-41.

Yang RY, Hsu DK, Liu FT (1996). Expression of galectin-3 modulates T-cell growth and apoptosis. Proc Natl Acad Sci USA; 93(13):6737-42.

Yang RY, Rabinovich GA, Liu FT (2008). Galectins: structure, function and therapeutic potential. Expert Rev Mol Med., 10:e17. 
Yu F, Finley RL Jr, Raz A, Kim HR (2002). Galectin-3 translocates to the perinuclear membranes and inhibits cytochrome c release from the mitochondria. A role for synexin in galectin-3 translocation. J Biol Chem; 277(18):15819-27.

Zamarron BF, Chen W. (2011). Dual roles of immune cells and their factors in cancer development and progression. Int J Biol Sci.; 7(5):651-8.

Zhang W, Ran S, Sambade M, Huang X, Thorpe PE (2002). A monoclonal antibody that blocks VEGF binding to VEGFR2 (KDR/Flk-1) inhibits vascular expression of Flk-1 and tumor growth in an orthotopic human breast cancer model. Angiogenesis; 5(12):35-44.

Zheng X, Yu CL, Sha W, Radu C, Huang SC, Feng D (2011). Study of an image-derived SUV and a modified SUV using mouse FDG-PET. Nucl Med Biol. 38(3):353-62.

Zhou X, Jing J, Peng J, Mao W, Zheng Y, Wang D, Wang X, Liu Z, Zhang X (2014). Expression and clinical significance of galectin-3 in osteosarcoma. Gene; 546(2):4037. 


\section{APÊNDICE}

Carta de aprovação do Comitê de Ética no Uso de Animais

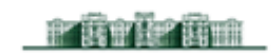 \\ MEDICINA \\ TSP \\ COMISSÃO|DE ÉTICA NO USO DE ANIMAIS}

A CEUA do Comitê de Ética em Pesquisa da Faculdade de Medicina da Universidade de São Paulo, em sessão de 03/o4/2014, APROVOU o Protocolo de Pesquisa $n^{\circ}$ 020/14 intitulado: "Avaliação do papel de galectina-3 no recrutamento de macrófagos e sua participação na angiogênese em modelo de fibrossarcoma" que utilizará 60 animais da espécie CAMUNDONGOS, apresentado pelo Departamento de Radiologia e Oncologia

Cabe ao pesquisador elaborar e apresentar ao CEP-FMUSP, o relatório final sobre a pesquisa, (Lei Procedimentos para o Uso Científico de Animais - Lei ${ }^{\circ}{ }^{11.794-8 ~ d e ~ o u t u b r o ~ d e ~ 2008) . ~}$

Pesquisador (a) Responsável: Roger Chammas

Pesquisador (a) Executante: Karina Mie Furuzawa

CEP-FMUSP, 04 de abril de 2014.

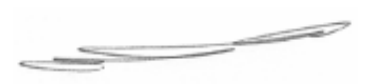

Dr. Eduardo Pompeu

Coordenador

Comissão de Ética no Uso de Animais

$$
\text { Zlheminn. }
$$

Prof. Dr. Roger Chammas

$$
\text { Coordenador }
$$

Comitê de Ética em Pesquisa 